Portland State University

PDXScholar

1992

\title{
Modeling Techniques for Water Supply Forecasting in the Western United States
}

David Charles Garen

Portland State University

Follow this and additional works at: https://pdxscholar.library.pdx.edu/open_access_etds Let us know how access to this document benefits you.

\section{Recommended Citation}

Garen, David Charles, "Modeling Techniques for Water Supply Forecasting in the Western United States" (1992). Dissertations and Theses. Paper 1323.

https://doi.org/10.15760/etd.1322

This Dissertation is brought to you for free and open access. It has been accepted for inclusion in Dissertations and Theses by an authorized administrator of PDXScholar. Please contact us if we can make this document more accessible: pdxscholar@pdx.edu. 


\title{
MODELING TECHNIQUES FOR WATER SUPPLY FORECASTING \\ IN THE WESTERN UNITED STATES
}

\author{
by \\ DAVID CHARLES GAREN
}

A dissertation submitted in partial fulfillment of the requirements for the degree of

\author{
DOCTOR OF PHILOSOPHY \\ in \\ SYSTEMS SCIENCE: \\ CIVIL ENGINEERING
}

Portland State University

1992 
TO THE OFFICE OF GRADUATE STUDIES:

The members of the Committee approve the dissertation of David Charles Garen presented May 7, 1992.
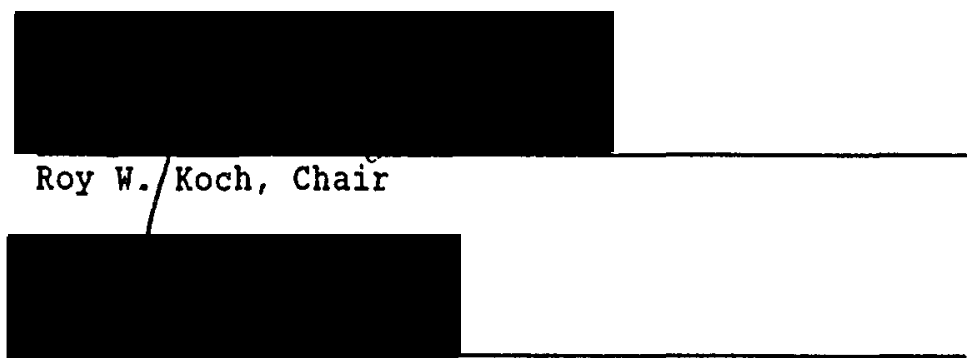
Martin Zwick

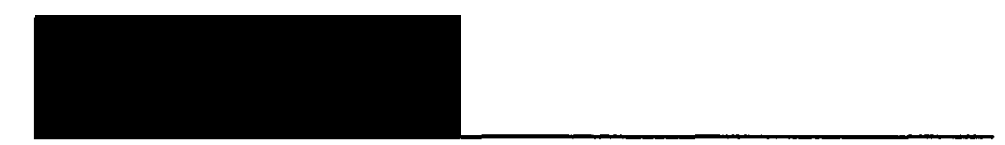
Bradford Crain

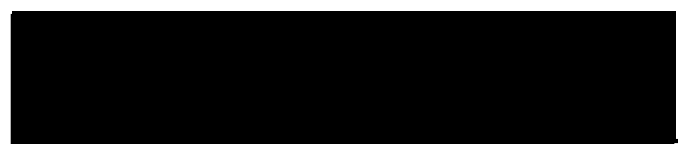

Scott Wélls

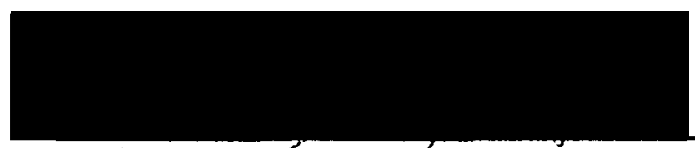

Daniel Johnson

APPROVED :

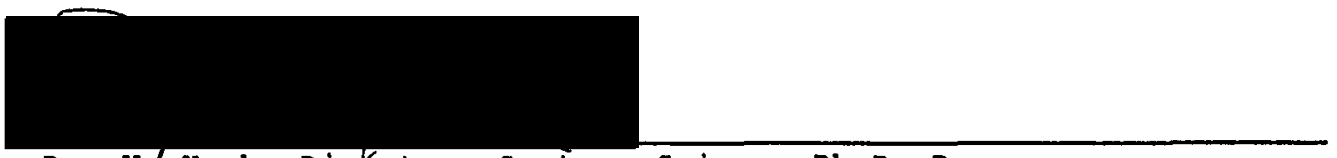

Roy W/ Kach, Diréctor, Systems Science Ph.D. Program

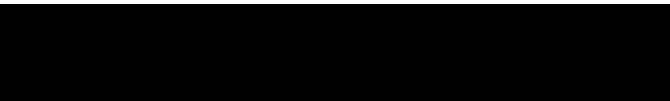

c. William Savery, Vice Provost for Graduate studies and Research 
AN ABSTRACT OF THE DISSERTATION OF David Charles Garen for the Doctor of Philosophy in Systems Science: Civil Engineering presented May 7, 1992.

Title: Modeling Techniques for Hater Supply Forecasting in the Hestern United States

APPROVED BY THE MEMBERS OF THE DISSERTATION COMMITTEE:

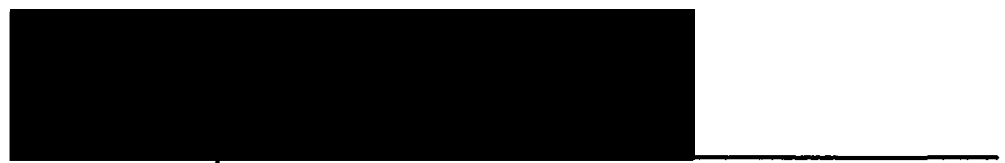

Roy W. Koch, Chair

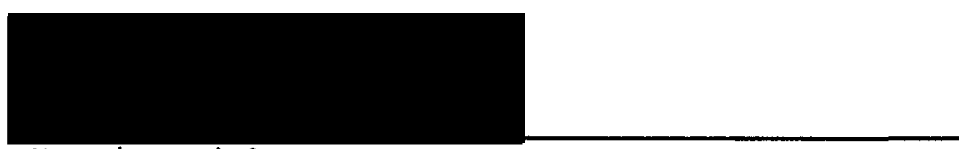

Martin Zwick

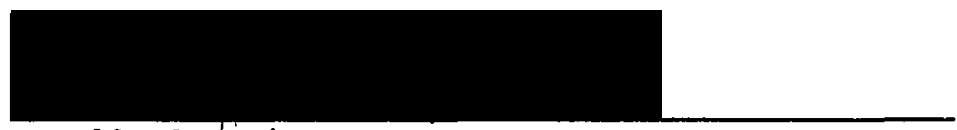
Bradford drain

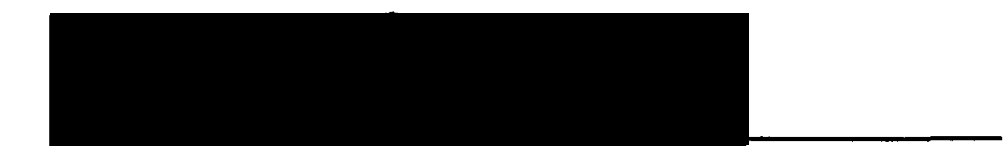

Scott Hells

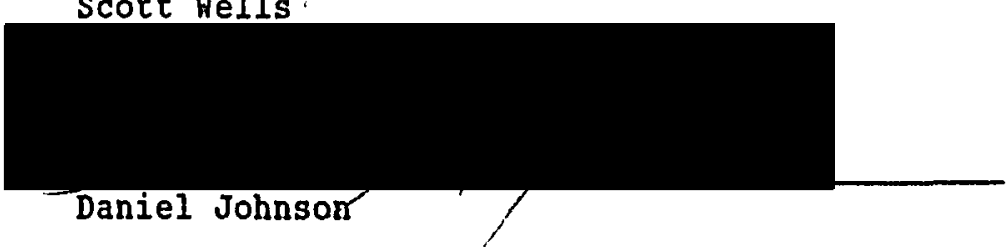

Water supply forecasting in the western United States is the prediction of the volume of water passing a given point on a stream during the primary snowmelt runoff season. Most water supply forecasts are produced from multiple linear regression models using snowpack, 
precipitation, and streamflow measurements as independent variables. In recent years, conceptual watershed simulation models, typically using a time step of one day, have also been used to produce these forecasts. This study examines model usage for water supply forecasting in the West and has three specific purposes. The first is to examine the traditional usage of multiple linear regression and develop improved regression techniques to overcome several recognized weaknesses in traditional practice. Four techniques have been used in this study to improve water supply forecasts based on regression. They are: (1) basing the regression model only on data known at forecast time (no future data); (2) principal components regression; (3) cross-validation; and (4) systematic searching for optimal or near-optimal combinations of variables.

The second purpose of the study is to develop a monthly streamflow simulation model suitable for use in water supply forecasting. Such a model has not previously been used in this application, and it provides a forecasting tool midway in complexity between regression procedures and conceptual watershed simulation models.

The third purpose of the study is to compare the accuracy of forecasts from regression, the monthly model developed here, and two conceptual watershed simulation models. It has generally been assumed, but not tested, that complex simulation models will give more accurate forecasts than simpler models. This study attempts to begin determining if this is true. Conceptual modeling results from previous studies on three basins in Idaho and Montana vere obtained to represent current practice in the usage of this type of model. 
The results of the study led to the following conclusions: (1) significant improvements in forecast accuracy over past practice with regression can be obtained by the use of the four techniques developed here; (2) the monthly model performed better than the conceptual watershed models most of the time, for both seasonal volumes and monthly flows; (3) for the three test watersheds, regression provided the best forecast accuracy among the three modeling techniques most of the time, for both seasonal volumes and monthly flows; (4) optimal use of conceptual watershed models requires automated calibration schemes; and (5) in basins of complex orography, denser data networks will be required to calculate meaningful values of mean areal precipitation. This study has contributed to the practice of water supply forecasting by providing improvements to regression techniques, providing a new monthly model, developing a mean areal precipitation and temperature procedure based on kriging, and giving some initial direction for further investigations in the use of conceptual watershed models. The inability of the two simulation approaches to surpass regression in forecast accuracy brings up several issues with respect to modeling. These issues are in the areas of model calibration, model conceptualization, spatial and temporal aggregation, and areal averaging of input data. Further investigation is required to elucidate these issues before clear conclusions can be made about the relative forecasting abilities of simple and complex models. Further investigation is also required to study water management decision making and the kinds and accuracies of forecast information required to optimize these decisions. 


\section{ACKNOHLEDGEMENTS}

This dissertation was begun as I saw the need for research into water supply forecasting techniques while I was with the National Weather Service's Northwest River Forecast Center in Portland. I am indebted to Charles Orwig, Hydrologist-in-Charge, for freeing me from my duties there to attend Portland State University full time for an academic year to complete my coursework for the Ph.D. degree. Part way through this research, I moved to the Water Supply Forecasting staff of the Soil Conservation Service in Portland, whose support and encouragement for this work has been greatly appreciated. I am grateful for the freedom given me by my supervisor, Ken Jones, to pursue this work. I owe a great deal to my colleague, Robert Hartman, now with the National Weather Service in Salt Lake City, who was of tremendous help in developing the regression methods of Chapter II. I have benefitted greatly from many lengthy discussions about statistics with Randal Wortman of the U. S. Army Corps of Engineers in Portland. James Doty of the U. S. Bureau of Reclamation in Boise was kind enough to give me their forecasting equation for the South Fork Boise River. I am deeply grateful for the encouragement and guidance given me by my advisor, Roy Koch. Roy has made me feel more of a colleague than a student. As this dissertation has taken over four years to produce, his patience has been most appreciated. I also am grateful for the support and patience of my family, especially my wife, Betty Burkholder Garen. And ultimately, I 
must acknowledge my Father in heaven, the source of all life, who sustained me, as always, through several major obstacles during the course of this work. 
TABLE OF CONTENTS

PAGE

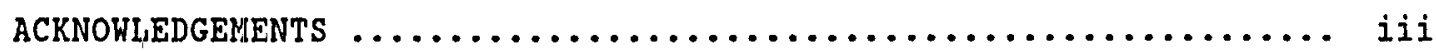

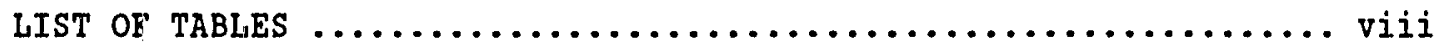

LIST OF FIGURES $\ldots \ldots \ldots \ldots \ldots \ldots \ldots \ldots \ldots \ldots \ldots \ldots \ldots \ldots \ldots \ldots \ldots \ldots \ldots \ldots \ldots \ldots$

CHAPTER

I INTRODUCTION $\ldots \ldots \ldots \ldots \ldots \ldots \ldots \ldots \ldots \ldots \ldots \ldots \ldots \ldots \ldots \ldots \ldots$

The Practice of Water Supply F'orecasting $\ldots \ldots \ldots \ldots .1$

Philosophical Background for Hydrologic Modeling ... 3

Stochastic vs. Deterministic Models

Time Aggregation

Spatial Variability

Model Selection -- Simple vs. Complex

Current Model Usage in Water Supply Forecasting .... 11

Purposes of study $\ldots \ldots \ldots \ldots \ldots \ldots \ldots \ldots \ldots \ldots \ldots \ldots$

II REGRESSION-BASED FORECASTING OF

SEASONAL STREAMFLOW VOLUMES $\ldots \ldots \ldots \ldots \ldots \ldots \ldots \ldots \ldots \ldots, 16$

Iritroduction $\ldots \ldots \ldots \ldots \ldots \ldots \ldots \ldots \ldots \ldots \ldots \ldots \ldots \ldots \ldots \ldots \ldots$

Future variables $\ldots \ldots \ldots \ldots \ldots \ldots \ldots \ldots \ldots \ldots \ldots \ldots, 17$

Usage of Future Variables and Forecast Accuracy Monthly Equations and Forecast Consistency

Usage of Future Variables and Scenario Forecasts

Principal Components Regression $\ldots \ldots \ldots \ldots \ldots \ldots \ldots .23$

Intercorrelation and Past Practice

Principal Components Regression

Selection of Principal Components to Retain 
Cross-Validation $\ldots \ldots \ldots \ldots \ldots \ldots \ldots \ldots \ldots \ldots \ldots \ldots \ldots \ldots$

Systematic Search for Optimal Variable Combinations 31

Example of Results $\ldots \ldots \ldots \ldots \ldots \ldots \ldots \ldots \ldots \ldots \ldots . \ldots \ldots$

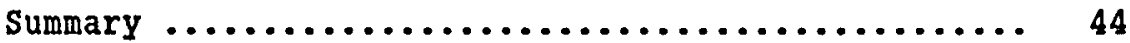

III MONTHLY STREAMFLOH MODELING $\ldots \ldots \ldots \ldots \ldots \ldots \ldots \ldots \ldots \ldots .47$

Introduction $\ldots \ldots \ldots \ldots \ldots \ldots \ldots \ldots \ldots \ldots \ldots \ldots \ldots \ldots \ldots$

Monthly Streamflow Simulation Model ........... 49

Previous Models

Proposed Model

Mean Areal Precipitation $\ldots \ldots \ldots \ldots \ldots \ldots \ldots \ldots \ldots, 67$

MAP Procedure

Mean Areal Temperature $\ldots \ldots \ldots \ldots \ldots \ldots \ldots \ldots \ldots \ldots, 71$

Potential Evapotranspiration $\ldots \ldots \ldots \ldots \ldots \ldots \ldots \ldots, 71$

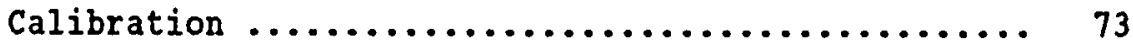

Extended Streamflow Prediction Procedure ........ 77

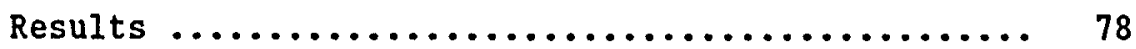

IV CONCEPTUAL WATERSHED MODELING $\ldots \ldots \ldots \ldots \ldots \ldots \ldots \ldots \ldots . . . . . . .63$

Introduction $\ldots \ldots \ldots \ldots \ldots \ldots \ldots \ldots \ldots \ldots \ldots \ldots \ldots$

St. Joe River $\ldots \ldots \ldots \ldots \ldots \ldots \ldots \ldots \ldots \ldots \ldots \ldots \ldots, 84$

Ruby River $\ldots \ldots \ldots \ldots \ldots \ldots \ldots \ldots \ldots \ldots \ldots \ldots \ldots \ldots \ldots \ldots \ldots$

Lower Willow Creek $\ldots \ldots \ldots \ldots \ldots \ldots \ldots \ldots \ldots \ldots, 90 \ldots$

$\checkmark$ MODELING AND FORECASTING RESULTS $\ldots \ldots \ldots \ldots \ldots \ldots \ldots \ldots . . \ldots 2$

Introduction $\ldots \ldots \ldots \ldots \ldots \ldots \ldots \ldots \ldots \ldots \ldots \ldots, 92$

St. Joe River $\ldots \ldots \ldots \ldots \ldots \ldots \ldots \ldots \ldots \ldots \ldots \ldots, 92$

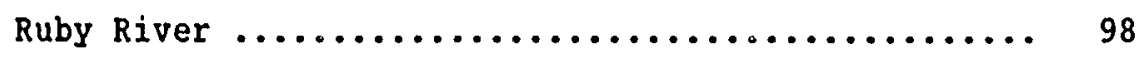

Lower Willow Creek $\ldots \ldots \ldots \ldots \ldots \ldots \ldots \ldots \ldots \ldots, 103$ 
vI SUMMARY AND CONCLUSTONS $\ldots \ldots \ldots \ldots \ldots \ldots \ldots \ldots \ldots \ldots \ldots \ldots$

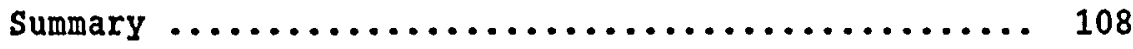

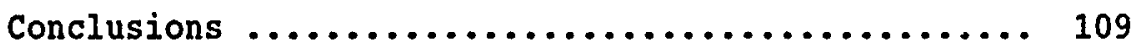

Contributions of This Study to the Practice of Hater Supply Forecasting ............... 110

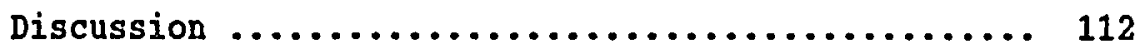

Recommendations for Future Vork $\ldots \ldots \ldots \ldots \ldots \ldots \ldots, 114$

REFERENCES $\ldots \ldots \ldots \ldots \ldots \ldots \ldots \ldots \ldots \ldots \ldots \ldots \ldots \ldots \ldots \ldots \ldots \ldots \ldots \ldots, 116$

APPENDICES

A PRINCIPAL COMPONENTS REGRESSION CALCULATIONS $\ldots \ldots \ldots \ldots .126$

B KRIGING CALCULATIONS $\ldots \ldots \ldots \ldots \ldots \ldots \ldots \ldots \ldots \ldots \ldots \ldots \ldots \ldots$ 
LIST OF TABLES

TABLE

PAGE

I Bureau of Reclamation Forecasting Equation, South Fork Boise River at Anderson Ranch Dam .......

Previous Soil Conservation Service Forecasting Equations, South Fork Boise River at Anderson Ranch Dam .......

III Regression Coefficients for New Forecasting Equations, South Fork Boise River at Anderson Ranch Dam .......

IV Cross-Validation Standard Error Comparison, South Fork Boise River at Anderson Ranch Dam ...... 42

V Forecast Consistency Comparison -- USBR and New Equations, South Fork Boise River at Anderson Ranch Dam .......

VI Forecast Consistency Comparison -- Previous SCS and New Equations, South Fork Boise River at Anderson Ranch

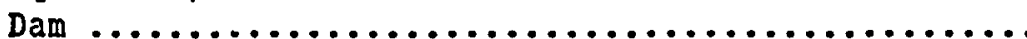

VII Basins Modeled $\ldots \ldots \ldots \ldots \ldots \ldots \ldots \ldots \ldots \ldots \ldots \ldots \ldots \ldots \ldots \ldots$

VIII Monthly Streamflow Simulation Model -- Parameters, State Variables, Input Data, and Output .......... 56

IX Parameter Values for Monthly Model ................. 79

X Precipitation and Temperature Data Sites Used in Monthly Modeling .......................... 80

XI Mean Absolute Errors from Calibration of SSARR and Monthly Model, St. Joe River, 1983-1990

XII Mean Absclute Errors for ESP and Regression Forecasts, St. Joe River, 1983-1990 -- Seasonal Volumes .......

XIII Monthly Fractions for Disaggregating Seasonal Volumes into Monthly Flows, st. Joe River ........ 96

XIV Mean Absolute Errors for ESP and Regression Forecasts, St. Joe River, 1983-1990 -- Monthly Flows ..........

XV Mean Absolute Errors from Calibration of SSARR and

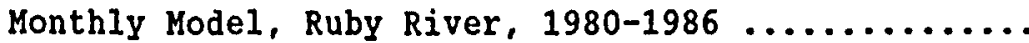


XVI Mean Absolute Errors for Monthly Model ESP and Regression Forecasts, Ruby River, 1973-1989

-- Seasonal Volumes ........................ 100

XVII Monthly Fractions for Disaggregating Seasonal Volumes into Monthly Flows, Ruby River .......... 100

XVIII Mean Absolute Errors for Monthly Model ESP and Disaggregated Regression Forecasts, Ruby River,

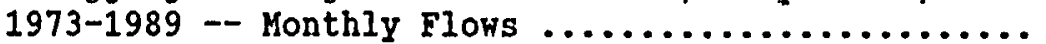

XIX Mean Absolute Errors for April Monthly Model ESP and Regression Forecasts, Ruby River, 1982-1990 Test Period ....................... 102

XX Mean Absolute Errors for NHSRFS and Monthly Hodel, Lower Willow Creek ........................ 104

XXI Mean Absolute Errors for Monthly Model ESP and Regression Forecasts, Lower Willow Creek, 1969-1989

-- Seasonal Volumes ........................ 105

XXII Monthly Fractions for Disaggregating Seasonal Volumes into Monthly Flows, Lower Willow Creek ..... 105

XXIII Mean Absolute Errors for Monthly Model ESP and Disaggregated Regression Forecasts, Lower Hillow Creek, 1969-1989 -- Monthly Flows ..... 106

XXIV Mean Absolute Errors for Monthly Model and Regression, Lower Hillow Creek, 1981-1989 Test Period 
LIST OF FIGURES

FIGURE

PAGE

1. Hydrologic Models and Complexity $\ldots \ldots \ldots \ldots \ldots \ldots \ldots \ldots$

2. South Fork Boise River at Anderson Ranch Dam Watershed Location and Locations of Data Sites ..... 36

3. Vicinity Map for Basins Modeled ................. 50

4. Monthly Streamflow Simulation Model ............... 55

5. Melt Fraction vs. Concurrent Month's Temperature $\left({ }^{\circ} \mathrm{C}\right)$, St. Joe River ......................... 59

6. Monthly Streamflow Simulation Model Soil MoistureEvapotranspiration Relationship ............. 63

7. Thornthwaite vs. Pan (times 0.7) Evapotranspiration, Sandpoint, Idaho, $1990 \ldots \ldots \ldots \ldots \ldots \ldots \ldots \ldots \ldots . \ldots \ldots$

8. Thornthwaite vs. Pan (times 0.7) Evapotranspiration, Moscow, Idaho, 1983-1990 .................. 74

9. Thornthwaite vs. Pan (times 0.7) Evapotranspiration, Arrowrock Dain, Idaho, 1983-1990 .............. 75

10. Thornthwaite vs. Pan (times 0.7) Evapotranspiration, Hungry Horse Dam, Montana, 1983-1990 .......... 75

11. Thornthwaite vs. Pan (times 0.7) Evapotranspiration, Dillon, Montana, 1983-1986 .................. 76

12. Observed and Computed Flows from Monthly Streamflow Model, st. Joe River ..................... 80

13. Observed and Computed Flows from Monthly Streamflow Model, Ruby River ........................ 81

14. Observed and Computed Flows from Monthly streamflow Model, Lower Willow Creek ................... 82

15. SSARR Model Flow Chart $\ldots \ldots \ldots \ldots \ldots \ldots \ldots \ldots \ldots \ldots \ldots . \ldots \ldots$

16. NWSRFS Snow Accumulation and Melt Model (HYDRO-17)

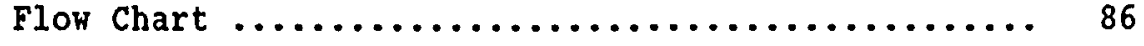


17. NWSRFS Soil Moisture Accounting (Sacramento) Model

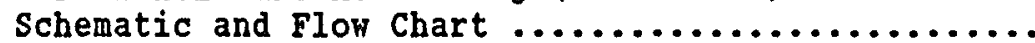

18. Observed and Computed Monthly Flows from SSARR Model Calibration, st. Joe River .................... 88

19. Observed and Computed Monthly Flows from SSARR Hodel Calibration, Ruby River .................... 91

20. Observed and Computed Monthly Flows from NHSRFS Model Calibration and Test, Lower Hillow Creek ........... 91

21. Typical Shape of a Semivariogram and its Characteristic values $. . . \ldots \ldots \ldots \ldots \ldots \ldots \ldots \ldots \ldots \ldots \ldots \ldots \ldots \ldots . . \ldots 131$ 
CHAPTER. I

\section{INTRODUCTION}

THE PRACTICE OF' WATER SUPPLY FORECASTING

In the western United States, most of the water flowing in rivers and creeks originates as snow accumulated during the winter. When this snow melts in the spring and summer, the water finds a number of uses, such as irrigation, hydropower production, and recreation. Management of this vital resource is greatly enhanced by foreknowledge of the amount of water that will be available during the primary snowmelt season. For example, if a large amount of streamflow is anticipated, reservoir managers can evacuate storage space during the winter to be able to catch the runoff and thereby help reduce potential flooding. If only a small amount of streamflow is anticipate $\dot{A}$, reservoir managers can minimize the amount of water released from storage during the winter to make as much water as possible available during the growing season.

Snow is a natural storage system. Measurements of the snow during the winter accumulation season make it possible to forecast the amount of streamflow that will occur when the snow melts during the spring and summer. This type of forecasting, usually called water supply forecasting, has been practiced for decades in the western United States. Water supply forecasting is the prediction of the volume of water passing a given point on a stream for a specified season of the 
year. The seasons are a period of months during which the bulk of the streamflow usually occurs. This period varies throughout the West; common forecast periods are March-June, April-July, and April-September. Forecasts are typically produced once per month from January through May or June. Forecasts made after the beginning of the normal snowmelt season are for the remaining months in the season.

Water supply forecasting in the western United states is done by a number of federal and state agencies, including the following: USDA -Soil Conservation Service (SCS), National Weather Service (NWS), Bureau of Reclamation, U. S. Army Corps of Engineers, Bonneville Power Administration, California Department of Water Resources, and British Columbia Power and Hydro Authority (BC Hydro). (BC Hydro is involved because the upper part of the Columbia River is in Canada.) The forecasts produced by the SCS, NWS, and California Department of Water Resources are for public distribution; forecasts produced by other agencies are for their own internal operations. In addition to the forecasting agencies, users of water supply forecasts include fish and wildlife agencies, forestry agencies, irrigation districts, financial and investment institutions, individual farmers, recreationists, schools -- a whole host of interests having anything to do with water availability for numerous uses.

Forecasts are published in various bulletins. For example, each western state office of the SCS publishes "Basin Outlook Reports" (previously called "Water Supply Outlooks") for the major river basins within their jurisdictions, and the SCS and NWS jointly publish "Water Supply Outlook for the Western United States." These publications cover 
approximately 600 forecast points. Other agencies produce publications for their particular geographic area of interest and clientele, and in recent years, forecasts are available electronically via computer. Streamflow forecasts are a key ingredient in the management of western water resources, and their importance continues to increase. Forecasts have a high economic value in planning hydropower production, irrigation water allocations, and flood control reservoir operations, among other management objectives (McCuen et al. 1979; Gordon and Lamb 1980; Mishalani and Palmer 1988). In addition, competing uses for water in the West are great and growing; for example, increasing demand for hydropower production conflicts with the use of water for irrigation, and new management objectives, such as fisheries protection, are receiving high priorities (High Country News 1987; Long 1990; Northwest Power Planning Council 1991a,b; Palmer 1991). It is clear that continued work to improve forecasting techniques is well worth the effort.

PHILOSOPHICAL BACKGROUND FOR HYDROLOGIC MODELING

Before proceeding into the study, some discussion about the theoretical and practical basis of hydrologic modeling would be helpful in understanding current model usage in water supply forecasting, the motivation of the study, and the interpretation of its results.

Stochastic vs. Deterministic Models

Several authors have offered helpful categorizations of models (e.g., Clarke 1973; Klemes 1978). The first major categories are 
stochastic and deterministic models. Stochastic models attempt to characterize and mimic the statistical properties of stroamflow time series, usually on an annual or monthly basis. These models are used to generate numerous equally-likely random streamflow sequences that can either be analyzed for selected characteristics, such as floods or low flows, or be used as input to reservoir and system simulation models. Stochastic modeling is a major sub-field of hydrology with a large body of literature. As streamflow forecasting is not the primary purpose of these models, they are not used in this study and will not be discussed further. Deterministic models can be thought of as transfer functions providing a one-to-one mapping of input to output. That is, a given input produces a unique output. All of the models considered in this study are of this type.

Within the deterministic model category, there is a range from simple models based on standard statistical prediction methods to complex, spatially-distributed, physically-based models. This is illustrated in Figure 1. At the low end of the scale are the statistical models, such as multiple linear regression. These are relatively simple in structure, have low data requirements, and are easy to use. They are empirical models based purely on statistical associations between the dependent (streamflow) and independent variables and hence have no explicit physical basis. The parameters of these models (regression coefficients) are calculated in a straightforward, objective manner.

At the high end of the scale are models such as PRMS (Leavesley et al. 1983) and SHE (Abbott et al. 1986a,b), which attempt to simulate the 


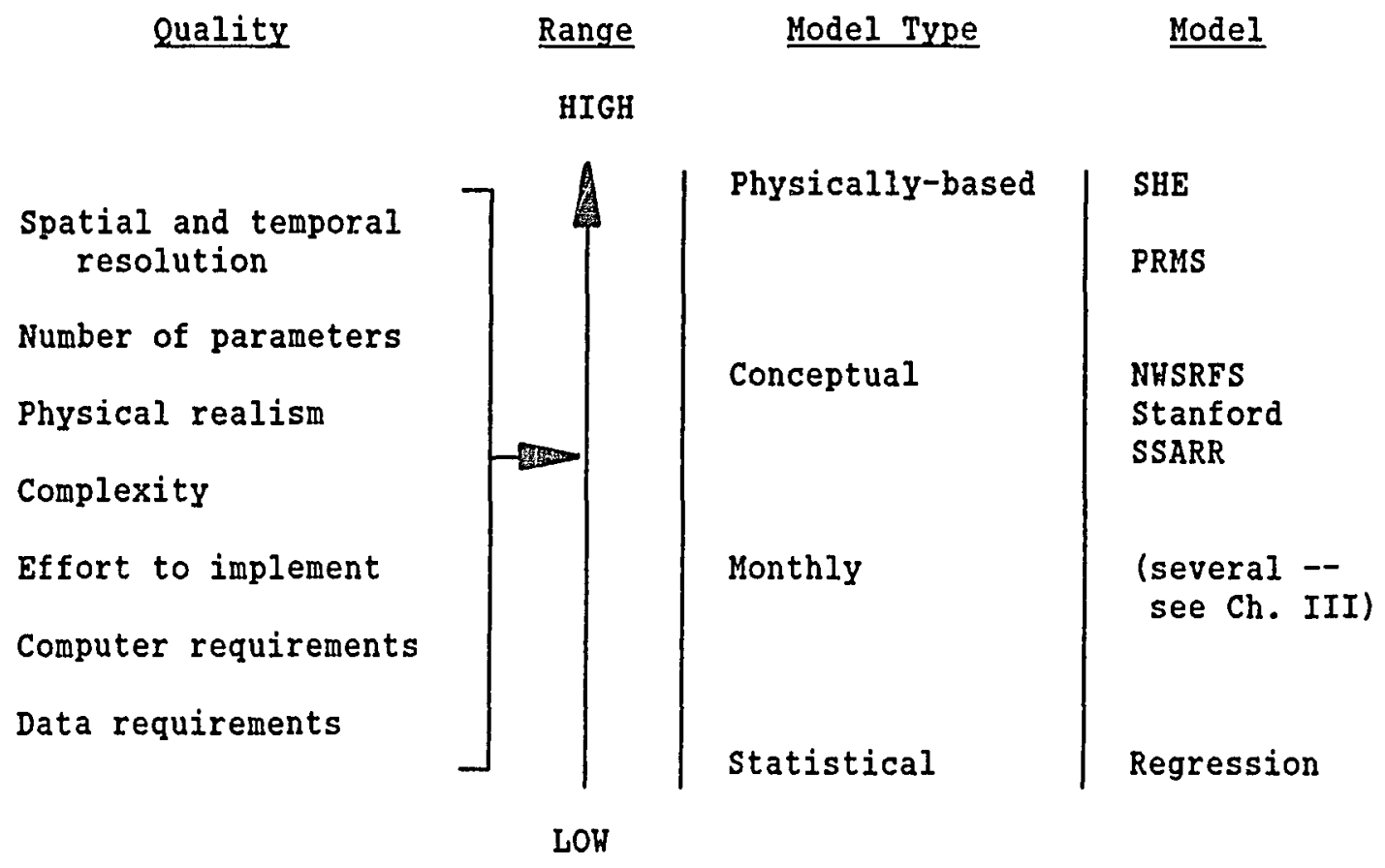

Figure 1. Hydrologic models and complexity.

physical processes of snow accumulation and melt and of water movement occurring in the watershed. The conceptualizations and equations describe the actual physical processes, and many of the parameters of the equations are determined directly from physical information about the watershed (slopes, soil type, vegetation, etc.). The computational time step for these models ranges from fractions of an hour to one day. In between are conceptual watershed models, which also attempt to simulate physical processes in the watershed, but many of the mathematical functions used are simplifications to a degree. They are not all directly derived from the physical equations but rather represent convenient conceptualizations that are inspired by knowledge of the physical zystem but are simplified to be more computationally tractable. The parameters of these equations do not represent 
measurable physical characteristics of the watershed but are more akin to indexes. Their values are usually established by calibration, that is, an iterative process of adjusting parameter values until an acceptable match between computed and observed streamflow is obtained. (Calibration will be explained more fully in Chapter III.) Computationa? time steps used with these models are often longer than with physically-based models; common time steps used are six hours and one day. Examples of conceptual vatershed models are the Stanford Watershed Model (Crawford and Linsley 1966), the streamflow Synthesis and Reservoir Regulation (SSARR) model (U. S. Army Corps of Engineers 1987), and the National Weather Service River Forecast System (NWSRFS) HYDRO-17 snow accumulation and melt model (Anderson 1968, 1973) and Sacramento soil moisture accounting model (Burnash et al. 1973).

Models with a computational time step of one month are highly simplified versions of conceptual models, both in terms of mathematical structure and input data used. Because of this high degree of simplification, they are considered to be in a separate model category. As with conceptual models, their parameter values are determined by calibration.

\section{Time Aggregation}

As mentioned above, the more complex models usually have finer time resolutions than the simpler ones. The statistical models used in traditional water supply forecasting produce highly time-aggregated output, that is, seasonal volumes. Next come models with a time step of one month, then come the conceptual and physically-based models, which 
use time steps of one day or less. Predicting time-aggregated output is the least demanding modeling problem because the continuously occurring physical processes of the watershed are averaged over a large time step, which permits many simplifications in model structure. Simple models are often completely adequate in this situation. Greater model complexity is required for short time steps because it becomes important to have detailed accounting of watershed dynamics at this time scale.

\section{Spatial Variability}

Also as models move up the scale from simple to complex, they usually have finer spatial resolutions. An important distinction to be made here is between spatially lumped and distributed models. Early modeling practice treated the watershed as a single, homogeneous unit. One set of parameter values characterized the spatially integrated behavior of the watershed, and precipitation and temperature inputs were averaged over the watershed area. In recent years, it has come to be recognized that such spatial lumping is inadequate to describe wacershed behavior fully. That is, because a watershed is a nonlinear system, the behavior of a single unit with spatially-averaged characteristics is not the same as a unit whose characteristics are spatially variable and follow some sort of distribution. Finding ways to incorporate spatial variability explicitly into models is an area of active research.

One of the ways spatial variability has been included in models is to divide the watershed into elevation bands. This technique is commonly used in conceptual watershed models, such as the SSARR model (U. S. Army Corps of Engineers 1987). The main motivation for elevation 
bands is to model the spatial variability of snow accumulation and melt, which varies primarily with elevation. It is assumed that the area within a band is homogeneous, and it is treated in a lumped fashion. Separate water accounting is done for each band. Typically, the same parameter values are used for each band (although this is not a necessity), but the precipitation and temperature inputs are different.

Another technique for dealing with spatial variability is to divide the watershed into hydrologic units. This is the technique used in the PRMS model (Leavesley et al. 1983). These units can be delineated according to several criteria, including elevation, slope, aspect, soil type, and vegetation. Each unit is considered homogeneous, and like elevation bands, separate accounting is done for each unit. Unlike elevation bands, however, the parameter values are, in general, different for each unit and can often be derived from physical data and watershed characteristics.

A third way spatial variability has been handled is to consider one or more model parameters to be a random variable and to vary throughout the watershed according to some probability distribution. The works of Smith and Hebbert (1979), Freeze (1980), and Moore and Clarke (1981) are of this type. One difficulty with this approach is the dimensionality of the problem if one considers all model parameters to be jointly distributed random variables. Another difficulty is that little information exists to indicate which probability distributions are most appropriate. A third difficulty is that massive numerical schemes would be required to solve such problems. Thus far, no practical working model of this type has been developed. 
Model Selection -- Simple vs. Complex

Given the multiplicity of available models, one must be able to decide intelligently which is most appropriate for the purpose in mind. To decide this, one must have a clear idea of the goals of the modeling project.

In water supply forecasting, the goal of modeling is to produce accurate and timely streamflow forecasts to facilitate good water management decisions. As the decisions to be made differ for each stream and reservoir, so the information needs differ. The interplay among time aggregation, forecast accuracy, and the decisions that need to be made determines the type of model that should be used for a given stream or reservoir. For example, consider a reservoir whose primary purpose is to supply irrigation water, and suppose it is large with respect to the annual volume of water flowing into it. In this case, seasonal or monthly volume forecasts are probably all that are required; the reservoir can hold virtually all the water coming in, and all that needs to be known is the quantity so that water allocation decisions can be made. Alternatively, management of a multi-purpose reservoir, which must balance competing water uses, might require monthly or daily flow forecasts to assist, for example, in avoiding downstream flooding or in maintaining a desired pool level for recreation or hydropower production during a specific period of time. The information needs at each location, then, are the first determinant of whether a simple or complex model is appropriate. 
Another consideration in model selection is whether complex nodels can provide better forecasts than regression or simple monthly models. It has generally been assumed, but not tested, that they can. The broad question of whether, in general, more complex models give better results is an important topic that has been discussed in the literature; the results that have been presented give sufficient reasons to have doubts (Naef 1981; Loague and Freeze 1985; Beven 1989; Hilcox et al. 1990). The comments of Klemes $(1983,1986,1988)$ also cause one to pause and think: is greater model complexity a true advancement of the science or is it just a more elegant curve-fitting exercise? Klemes $(1978,1983)$ also points out that the conceptualization of a model is a function of its spatial and temporal scales. There is no a priori reason, therefore, why a complex model would be required to produce spatiallyand temporally-aggregated output (such as monthly or seasonal volumes for a watershed); a simpler model may be entirely adequate or even superior. This is so because complex models have many more parameters requiring estimation than do simple models; if these parameters cannot be estimated well, the model cannot be expected to perform well. It may be that for time-aggregated streamflow forecasts, the more complex models can do no better than the simpler ones.

Wilcox et al. (1990) considered it a success if the complex model performed as well as the simple model. If this could be achieved, nothing would be lost by using a complex model, and complex models offer advantages over simple ones. In the context of water supply forecasting, it would be considered a success, then, if the complex models could forecast seasonal volumes at least as well as regression 
models. The advantage is that the complex models provide more detailed hydrologic information, are more amenable to physical interpretations, and can be updated more conveniently.

Before unequivocally using complex models for water supply forecasting, then, one should first determine whether the complex model gives greater forecast accuracy than regression or a monthly model for seasonal and monthly volumes. If so, it is probably worth the effort to use the complex model. If not, one must then assess the trade-offs between making decisions with the more accurate time-aggregated flows or the less accurate daily flows.

CURRENT MODEL USAGE IN WATER SUPPLY FORECASTING

At present, virtually all water supply forecasts in the West are produced using multiple linear regression models. They are successful because of the repeatibility of patterns of hydroclimatic events in the Hest. Input variables to these models are generally snow water equivalent at one or more snowcourses or SCS SNOTEL (SNOW TELemetry) sites (Barton and Burke 1977; Rallison 1981; Crook 1984), monthly precipitation at one or more sites, and streamflow for previous months at the forecast point. Typical practice has relied on standard multiple regression either using data for individual sites and individual months or, more often, using indexes as independent variables. These indexes combine data for sites and/or months into weighted sums. Construction of indexes and selection of sites to use are based on data quality, correlation analyses, conceptual appropriateness, professional judgment, and trial and error. Several references exist describing the 
conventional use of regression techniques in water supply forecasting, including Water Management Subcommittee of the Columbia Basin Interagency Committee (1964), Schermerhorn and Barton (1968), Soil Conservation Service (1972a), Zuzel and $\operatorname{Cox}$ (1978), McCuen et al. (1979), and stedinger et al. (1988).

With the increasing demands on western water has come the desire for more detailed hydrologic information than just seasonal streamflow volume forecasts. Monthly or daily flow values can be used to improve reservoir operations and water management decisions. This, then, is a logical extension of the traditional realm of water supply forecasting, and with this extension, the practice would be more properly termed long-range streamflow forecasting. The NWS has been the pioneer in this new area, with their Extended Streamflow Prediction (ESP) procedure (Day 1985), described below. Other agencies are also beginning to use these techniques.

The ESP procedure was developed to be used with a conceptual watershed model generally operating with a time step of one day. The procedure assumes (1) that skill in long-range weather forecasts is currently too low to develop meaningful future precipitation and temperature estimates, and (2) that observed precipitation and temperature sequences in the historical record are possible representations of the future. An ESP forecast is made in the following steps: 
1) Run the hydrologic model up to the forecast date using observed precipitation and temperature input data and save the values of the state variables on that date.

2) Using the saved values of the state variables as initial conditions, run the model from the forecast date through the end of the desired forecast period for each historical precipitation and temperature sequence available. Save each streamflow sequence so produced.

3) Perform a statistical analysis on the streamflow sequences. Means, standard deviations, probability distributions, and any other desired statistics can be computed for the streamflow quantities of interest. Common quantities analyzed include seasonal volume, monthly flows, and (for daily models) peak and low flows.

The use of conceptual models and the ESP procedure for water supply forecasting has been suggested and tried by a number of authors (Pearson 1974; Twedt et 21. 1977; Kuehl 1979; Speers and Versteeg 1982; Druce 1984; Day 1985). These techniques have found limited, but increasing, use in the West both as a replacement for regression and as an alternate procedure to be compared with regression forecasts.

\section{PURPOSES OF STUDY}

With these modeling concepts and considerations as a general framework, and with current model usage in mind, there are three specific purposes of this study. The first is to examine the 
traditional practice of water supply forecasting with respect to the statistical procedures used. Advances in statistical techniques and the greater availability of computer hardware and software in recent years have not generally found their way into routine practice. Chapter II describes several techniques for statistical volume forecasting that can give substantial improvements in forecast accuracy over typical past practice. These improvements will afford the greatest forecast accuracy possible from this simple modeling technique.

The second purpose of this study is to develop a monthly streamflow simulation model suitable for use in water supply forecasting. Several monthly models have appeared in the literature, but they have never been used in this particular application, and none of them is entirely adequate for it. A monthly model would provide a forecasting tool midway in complexity between statistical procedures and conceptual watershed models. Their data requirements are only moderately greater than for statistical procedures, and they have a greater physical basis, which may give greater accuracy. They provide a monthly distribution of streamflow, which is an improvement over a seasonal volume, but not as detailed as a daily hydrograph. Being simpler than conceptual watershed models, they require much less effort to implement. Monthly models are discussed in Chapter III.

The third purpose of this study is to compare the accuracy of forecasts from regression, a monthly model, and two conceptual watershed models. The use of the latter is discussed in Chapter IV. As already mentioned, it has generally been assumed, but never tested, that conceptual models will give more accurate forecasts than regression. 
Before expending large amounts of resources in the use of conceptual models, it would be prudent to have a better understanding of the conditions under which such models are advantageous and the conditions under which the simpler models (regression and monthly model) are preferable. The conceptual watershed model results used here represent current practice in the application of such models. Consequently, these results do not necessarily achieve the maximum accuracy obtainable. It was not the intent in this study to examine conceptual models in detail to ensure their optimal use. Rather, the intent was to compare the new regression procedures and the new monthly model with standard practice conceptual modeling results to begin to understand the relative accuracies of the three methods. Optimal usage of conceptual watershed models is an area of ongoing investigation. 
CHAPTER II

REGRESSION-BASED FORECASTING OF SEASONAL STREAMFLOH VOLUMES

INTRODUCTION

Although multiple linear regression has been used for many years to predict seasonal streamflow volumes, the results of the present study indicate that typical past practice has not realized the maximum accuracy obtainable from regression. Several techniques can help provide superior forecast accuracy using regression models: (1) basing the regression model only on data known at forecast time (no future data); (2) principal components regression; (3) cross-validation; and (4) systematic searching for optimal or near-optimal combinations of variables.

Seeking maximum accuracy in regression-based forecasts is useful for several reasons. First, it is, and will remain for some time to come, the mainstay of seasonal streamflow volume forecasting. Conceptual watershed models may hold promise as an improved forecasting technique, but they are used now only on a limited basis, and their widespread use is still many years away. Second, in some cases, regression may remain the forecast method of choice if adequate water management decisions can be made without more detailed hydrologic information or if more complex methods (such as conceptual models) are not sufficiently accurate. Finally, regression forecasts provide a 
baseline level of accuracy against which to test conceptual models. of course, it would be an unfair test to compare conceptual model forecasts against non-optimal regression forecasts.

The regression techniques listed above will be discussed in turn, then some example results will be given.

\section{FUTURE VARIABLES}

\section{Usage of Future Variables and Forecast Accuracy}

Past practice in water supply forecasting has often included variables in multiple regression equations that describe future snow accumulation or precipitation and hence are unknown at the time the forecast is made (Water Management Subcommittee of the Columbia Basin Interagency Committee 1964; Schermerhorn and Barton 1968; Stedinger et al. 1988). The practice has been to calibrate a single equation for a given forecast period using all data through the end of the forecast period. For example, an April-July equation would be calibrated using data through July, which of ten included precipitation through June or July, and snow water equivalent for the maximum accumulation of the year (typically between March and May). This single equation was used in all months that forecasts were made. If a precipitation or streamflow variable was in the future at forecast time, long-term averages were used. If a snow water equivalent variable was in the future, the observed value at forecast time was extrapolated to the target month by adding to it the average accumulation in the intervening months. 
Several reasons have been put forth for this practice, some of which were listed by stedinger et al. (1988). Those and others are briefly described below:

1) It was felt that an equation containing all relevant variables was the most hydrologically sound. An equation containing only data known at the time of the forecast was viewed to be incomplete and therefore an inferior predictor.

2) Such an equation provided stability in the forecasts as the season progressed because the same variables and the same coefficients were always used. Later forecasts were simply updates to previous ones by substituting observed data for the averages previously used. Such updates tended not to vary greatly from month to month, and the variation that did occur was in a conceptually appropriate manner; for example, if the month was wet, the forecast increased, and if the month was dry, the forecast decreased.

3) It allowed the generation of scenario forecasts to answer questions like, "What would the forecast be if we received $x x x \%$ of average precipitation from now on?" It also allowed for the analysis of forecast uncertainty based on the use of a number of historical sequences of future precipitation.

4) When these techniques were developed, computing facilities were much less powerful and not as readily available as they are now. Single equations with data lumped into indexes were the only 
feasible way to get the regression analyses done in a reasonable amount of time.

As shown by stedinger et al. (1988), some work by Koch (1990), and the results of the present study, the use of future variables and the substitution of averages at forecast time can degrade forecast accuracy. An equation calibrated with all input data known is optimal only when those data are known; it is, in general, no longer an optimal forecaster when some of the input data are unknown. Improvements in forecast accuracy by not including future variables can be substantial, especially early in the forecasting season. The results from one example basin will be given in a subsequent section.

\section{Monthly Equations and Forecast Consistency}

If we reject the use of a single equation to avoid using future variables, then we must use a different equation, containing only variables known at forecast time, whenever a forecast must be made. For routine monthly water supply forecasting, this means each forecast point and period must have a separate equation for each month that forecasting is done.

A concern often raised about the use of separate monthly equations is whether the forecasts will show unexplainable jumps up and down from month to month due solely to the different variables and coefficients in the regression models. One expects forecasts to change for hydrologic reasons, but it is undesirable to have changes due to statistical "noise." Such instability in forecasts causes consternation among water managers. Forecasters can use judgment to adjust the equation 
predictions to smooth out undesirable month-to-month fluctuations, but it is preferable to have equations that give forecasts requiring little adjustment.

Although forecast consistency is difficult to define precisely, it is possible to make some, perhaps crude, measures of it. One possible measure of forecast consistency is the average absolute value of monthly forecast changes. This is computed by taking the average of the absolute values of the differences between the January and February, February and March, March and April, and April and May forecasts of the same seasonal volume for all calibration years. If the forecast period changes during the forecasting season, observed flows need to be added to the forecast so that all forecasts are for the same period. For example, if April-July volume is forecast in January through April, and May-July volume is forecast in May, then observed April flow needs to be added to the May-July forecast to obtain an April-July volume to compare with previous forecasts. It is desirable that this measure be minimized, as water managers prefer to have forecasts that change as little as possible from month to month as long as hydrologic validity is maintained.

Another possible measure of forecast consistency is the average number of forecast direction changes. A forecast direction change occurs when

$$
F_{m-2}>F_{m-1} \text { and } F_{m-1}<F_{m}
$$

or then 


$$
F_{m-2}\left(F_{m-1} \text { and } F_{m-1}\right) F_{m}
$$

where $F_{m}$ is the forecast in month $m$. In the first case, the forecasts for months $m-2$ and $m-1$ established a downward trend, but the forecast for month $m$ is up from month $m-1$. In the second case, the forecasts for months $m-2$ and $m-1$ established an upward trend, but the forecast for month $m$ is down from month $m-1$. After determining the total number of direction changes for each year, an average can be computed. Water managers prefer that forecast seesawing up and down be minimized, again as long as hydrologic validity is maintained.

Forecast consistency can be accomplished with monthly equations by selecting variables to maintain a high degree of similarity from month to month without undue loss of forecast accuracy. There is a trade-off between these two goals because the best variables may differ among months. It is a matter of judgment on the part of the forecast developer to strike a compromise between them. Forecast accuracy is the primary goal, but if a significant amount of month-to-month consistency can be obtained by only a small loss in accuracy, then this would be a desirable compromise. A comparison of the two measures of forecast consistency for two single equation procedures and for two sets of monthly equations will be presented in a subsequent section.

\section{Usage of Future Variables and Scenario Forecasts}

Many forecast users ask the question, "What would the forecast be if we received $x \times x \%$ of average precipitation for the rest of the season?" Users ask this to obtain an idea of what may happen assuming some future weather scenario, such as current trends persisting or a 
major change in precipitation patterns. This question presumably gives users an ideal of the forecast uncertainty that might be expected. The question has hydrologic validity and is understandable to the lay person.

Such a scenario forecast can be easily calculated if the regression equation contains future precipitation variables. Instead of using average, one uses the desired percent of average precipitation in the calculation. This, however, cannot be done with equations containing no future variables. To some, this is perceived as a limitation of using monthly equations with no future variables. In fact, it is no limitation, because the generation of scenario forecasts is not the best way to quantify forecast uncertainty. First of all, not all forecast error is due to unknown future weather. Even if the future were known perfectly, there would still be errors in the predictions. A scenario, then, only accounts for part of the forecast uncertainty. Second, the source of forecast error does not matter in decision making as long as the error can be quantified and described probabilistically. Finally, scenario forecasts do not have exceedance probabilities attached to them, so one does not know how likely they are to occur.

The standard process of constructing confidence bands about a prediction provides the means to calculate alternate forecasts with different exceedance probabilities and hence provide the information needed for decision making. For example, the 808 confidence band about a prediction provides forecasts with a $90 \%$ and $10 \%$ exceedance probability, assuming that the errors are normally distributed. These forecasts are what need to be used in decision making rather than 
scenario forecasts. To this end, the Soil Conservation Service now publishes five forecasts with the following exceedance probabilities for each point: $90 \%$ ("reasonable minimum"), 70\%, 50\% ("most probable"), 30\%, and $10 \%$ ("reasonable maximum"). No assumptions about future weather are made in these forecasts; they simply represent different quantiles of the probability distribution of the seasonal runoff volume conditioned on the current hydrologic state. This information fully expresses the forecast uncertainty and is the proper information necessary for optimal decision making. Krzysztofowicz $(1986 a, b)$ gives a detailed analysis of this kind of decision making.

PRINCIPAL COMPONENTS REGRESSION

\section{Intercorrelation and Past Practice}

The predictor variables used in water supply forecasting are usually correlated with each other, particularly data for different stations of the same data type at the same time (e.g., snow water equivalent on a given date at several snowcourses). If attention is paid to the significance of the regression coefficients, standard multiple regression will keep only a very few such variables in the equation. If all of these variables are retained anyway, the coefficients will not be accurately estimated, and they may not make physical sense (e.g., negative coefficients for variables having a positive correlation with streamflow). Such an equation may not give consistently accurate predictions over time and is not conceptually acceptable (McCuen 1985; Kleinbaum et al. 1988). If only the few significant variables are retained in the equation, too heavy a reliance 
is placed on a few data sites to represent spatially-variable snowpack and precipitation consistently, and again one might expect erratic performance over time. A more robust, accurate, and consistent forecasting equation can be obtained by having several sites for the same data type and time in the equation.

In water supply forecasting, the past practice of constructing composite indexes that were used as independent variables had the effect of at least partially circumventing the intercorrelation problem. These composite indexes were typically weighted sums of data from stations of the same data type to produce snow, fall precipitation, winter precipitation, and spring precipitation terms. By combining data from several highly correlated data sites into a single variable before entering the regression, the major source of intercorrelation was removed. The drawback with this technique, however, is that the weights used in constructing the index were determined outside of the regression (based on correlation analyses, judgment, etc.) and were not, in general, statistically optimal for forecasting. Examples of these indexes are given in a subsequent section.

\section{Principal Components Regression}

The most satisfactory and statistically rigorous way to deal with intercorrelation is the use of principal components regression. Previous examples of the use of principal components regression in water supply forecasting are Marsden and Davis (1968), McCuen et al. (1979), and Wortman (1989). Other examples of principal components regression appear in Haan and Allen (1972), Haan (1977), and McCuen (1985). McCuen 
and Snyder (1986) give a thorough discussion of the computations involved and some additional examples.

Principal components analysis is a statistical technique that restructures a set of intercorrelated variables into an equal number of uncorrelated variables. Each new variable (principal component) is a different linear combination of all the original variables. The weights used in the linear combinations are from the eigenvectors of the correlation matrix of the original variables. Each component explains a certain percentage of the total variance in the set of variables; the amount is represented by the eigenvalue. Principal components are usually arranged in order of decreasing amount of explained variance. Typically, most of the variance is explained in the first few components.

Principal components analysis is sometimes used to describe modes of variability in a set of data. For example, Lins (1985) described major modes of streamflow variability in the United States using the first 5 of 106 principal components in his data set. This work was purely descriptive, not predictive, in nature.

For prediction, the principal components, calculated from the set of available predictor variables, can themselves be used as independent variables in a regression equation. The number of components retained in the equation depends on how many of them have statistically significant regression coefficients. This is a different selection technique than in descriptive work, where the magnitude of the eigenvalue and the percentage of variance explained are the main criteria. If there was a high degree of intercorrelation in the 
original data set, the number of components retained in the regression will be much smaller than the number of original variables. This

reduces the Ioss of degrees of freedom because fewer regression coefficents are being estimated. If all components are retained, it is the same as a standard multiple regression, and there is no advantage in using principal components. After the regression coefficients for the components have been computed, the linear transformation can be inverted so that coefficients are expressed in terms of the original predictor variables. A concise description of these calculations is given in Appendix A.

\section{Selection of Principal Components to Retain}

For a given combination of variables, one must determine which of the principal components to retain in the regression. This problem is very similar to a standard regression, that is, determining which of the variables (components) are worth keeping. An additional consideration in principal components regression, however, is whether to require the components to be used in sequence (from large to small eigenvalues) or whether any components can be kept regardless of whether any of its predecessors in the sequence are in the equation.

Determining which components ought to be retained in a regression equation is most straightforwardly evaluated by a standard t-test (or partial F-test) to determine the significance of the regression coefficient for a variable (component). McCuen (1985) discusses examining the magnitude of the eigenvalues as a preliminary screen for selecting significant components, but this is unnecessary. It only 
determines which components explain most of the variance in the original variables and says nothing about their ability to explain the dependent variable. The t-test is completely adequate to determine which components to keep.

When using the t-test, however, it sometimes happens that some components in the sequence will be skipped. For example, the t-test may indicate that only components one, two, and five should be retained. The question is, what does it mean that components three and four were skipped, and should component five be allowed to stay? The answer to this question first requires an explanation of the purpose and philosophy of using principal components.

One of the purposes of principal components regression is to remove the effects of intercorrelation among the original predictor variables. If one has been successful in doing so, one would expect that the regression coefficients would have the same algebraic sign as the correlation coefficient of the predictor variables with the dependent variable (McCuen 1985). In water supply forecasting, then, most regression coefficients should be positive because most predictor variables are positively correlated with streamflow. If a positively correlated variable ends up with a negative regression coefficient, this would suggest that there is intercorrelation among the independent variables; the negative coefficient indicates that this variable is trying to compensate for some of the effect of another independent variable with which it is highly correlated. (If one computes a standard regression with highly correlated independent variables, negative coefficients for some of the variables are frequently obtained, 
even though they are positively correlated with the dependent variable. The correlated variables are attempting to explain the same thing, and they must compensate for each other's effects.)

In this study, when one or more components were skipped, it was often observed that some of the regression coefficients for the original predictor variables were of the opposite sign as their correlation with the dependent variable. This indicates that some of the confounding intercorrelation was reintroduced when components were skipped.

Another purpose of principal components regression is to combine the original variables to create a fewer number of new variables containing almost the same information as the original ones. It is desired that the original variables be only those most useful for forecasting so that data for unnecessary variables need not be collected. Since skipping components implies that there are important modes of variability in the original variables that are unrelated to streamflow, one is led to suspect that the combination of varibles may contain extraneous information and not be the best for forecasting. It would seem that for a good combination of variables, all major modes of variability ought to be useful for forecasting.

So, one viewpoint might say yes, keep component five even though components three and four were skipped. The components are computed using only data for the original predictor variables and without regard to the dependent variable; it just so happens that a minor mode of variability (component five) is related to streamflow whereas two larger modes (components three and four) are unrelated to streamflow. Marsden 
and Davis (1968), Haan (1977), and Wortman (1989) have allowed their models to skip components.

The other viewpoint, suggested by McCuen (1985) and the one adopted here, would say no, do not keep component five, and require components to be included in sequence. Skipping components can reintroduce intercorrelation, and it makes more sense conceptually and from a variable screening point of view not to skip components.

The method used here for selecting principal components to include is as follows:

1) Components are added to the model one at a time in sequence, beginning with the one with the largest eigenvalue and progressing in order of decreasing eigenvalue.

2) When the first component with a non-significant regression coefficient (based on a t-test) is found, the components retained are the ones in sequence up to, but not including, the nonsignificant one.

3) Regression coefficients, when expressed in terms of original variables, must have the same algebraic sign as their correlations with the dependent variable. If this condition is not met after a component passes the t-test, the components up to, but not including, the last one added are retained temporarily. Keeping the last component added, further components continue to be added as long as they pass the t-test. The number of components finally retained is the largest number that passes both the $t$-test and the 
sign test. For example, if components 1 and 2 pass the t-test, but one or more coefficients do not pass the sign test, component 3 will still be tried. If component 3 fails the t-test, the final model will contain component 1 only. If component 3 passes the $t-$ test and the sign test, and if component 4 fails the t-test, the final model will contain components 1,2 , and 3 .

Once a combination of predictor variables to evaluate has been selected, this procedure provides properly estimated regression coefficients. How many and which of the (correlated) predictor variables to include requires a search. This topic is discussed in a later section.

\section{CROSS-VALIDATION}

It is well known that a model's performance during the calibration period is often better than its performance during a verification period. In the same way, the standard error for a multiple regression equation can be an overly optimistic measure of the equation's actual forecasting performance. To obtain a more realistic evaluation of an equation's forecasting potential, a cross-validation procedure has been used here. Inspired by the jackknife technique for statistical parameter estimation (Wu 1986) and discussed in some statistics texts (e.g., Kleinbaum et al. 1988), cross-validation is a systematic, iterative variation of split-sample model testing. Beginning with the first year, one year is removed from the calibration data set, and the regression coefficients are calculated. These coefficients are used 
with the data for the withheld year to predict the streamflow for the withheld year. The withheld year is returned to the calibration set, and the next year is removed. The process is repeated through the entire set of years available so that when finished, a set of "forecasts" generated by equations that have not "seen" the year they were forecasting is available. This procedure somewhat mimics the actual forecasting situation where the equation has not been calibrated using the year to be forecasted. In the same manner as the usual regression standard error, a cross-validation standard error (CVSE) can be calculated from these "forecasts." The CVSE, then, is a more realistic measure of the actual forecasting potential of an equation. The CVSE is used as the optimality criterion in the search algorithm for predictor variable combinations, described below.

\section{SYSTEMATIC SEARCH FOR OPTIMAL VARIABLE COMBINATIONS}

Unless there are only a very few variables available, some sort of selection technique to determine which variables to include in a regression equation is necessary to ensure optimality or nearoptimality. One way to ensure that the equation with the smallest standard error has been found is to compute regressions for all possible combinations of variables. For most water supply forecasting applications, the number of variables available makes this computationally infeasible; the number of combinations for $n$ variables is $2^{n}-1$. If standard multiple regression is used, one can use the stepwise technique (or one of its several variants) to select variables. For principal components regression, the stepHise technique could 
conceivably be used to select the principal components to be included for a given combination of predictor variables (although a preferable technique was described earlier), but it does not determine if the given combination of variables is itself optimal.

Haan (1977) and McCuen (1985) discuss a procedure for eliminating predictor variables in principal components regression by examining the magnitudes of the eigenvector values ("loadings" or "scores") for each variable. They suggest that one should go through the eigenvectors, picking out the variable(s) in each eigenvector that has (have) the highest loading(s). If there are any variables that do not have high loadings for any component (eigenvector), those variables may be eliminated. McCuen (1985) suggests including the dependent variable in the calculation of the eigenvectors when going through the variable elimination process; it is excluded when the data are prepared for principal components regression.

This approach may give adequate results, but there are several drawbacks. If the eigenvectors are computed from the predictor variable: only, it is possible that one or more of those variables may not appear important compared to the others, yet it could still be an important predictor for the dependent variable. Eliminating variables in this way never gives those variables a chance to be tested as predictors of the dependent variable. If the dependent variable is included in the calculation of the eigenvectors, it is unclear what extra interpretive value is obtained beyond selecting the variables with the highest correlation coefficients with the dependent variable. One is left with attempting to select variables that have high correlations 
with the dependent variable but have low correlations among themselves. This is an ill-defined process in that there is no way of knowing the optimal trade-off between correlation with the dependent variable and intercorrelation among the predictor variables. In both of these cases, the elimination of variables is not statistically rigorous, requires subjective judgment, and is unsuitable for automated optimization.

A more straightforward and objective technique for selecting variables is to use an automated search to identify optimal or nearoptimal combinations of predictor variables. This eliminates the subjectivity in selecting variables by explicitly testing systematically chosen combinations of variables as predictors of the dependent variable. To this end, a computationally feasible automated search algorithm for principal components regression was developed in this study. This search algorithm is an empirical procedure that evolved from examining how variable combinations were built when all possible combinations were computed beginning with all one-variable equations, then all two-variable equations, etc. In most cases tested, a pattern developed where certain variables persistently appeared in combination with others. Based on these observations, an iterative algorithm was developed that begins by computing all one-variable equations and storing the twenty (or all equations, if there are fewer than twenty variables) with the smallest CVSE. Twenty was an arbitrary number that seemed reasonably large to allow the algorithm a sufficient number of combinations upon which to build; storing a larger number may be beneficial as the number of variables increases into the thirties or forties, but this has not been tested extensively. Two-variable 
combinations are then computed by taking each stored one-variable equation and adding one other variable to it. The number of principal components to retain is determined by the sequential t-test and sign test process discussed above. Each two-variable equation so constructed is retained in the list of twenty if its CVSE is smaller than any one previously stored. The process continues with three-, four-, fivevariable equations and so on until adding one more variable cannot produce a smaller CVSE than the twenty stored ones. The algorithm then stops, and the search is complete.

This search algorithm tends to select for parsimonious models and therefore does not necessarily find the absolute optimum or all combinations of variables with CVSE's between the smallest and the largest in the list of twenty. Models that do not perform well until many variables are included are not reached with this algorithm. The algorithm's greatest utility lies in identifying the strongest variables and in constructing near-optimal parsimonious models.

\section{EXAMPLE OF RESULTS}

The techniques discussed above have been put together into a system of computer programs used by the Soil conservation Service (SCS) to develop forecasting equations for existing and new forecast points. One forecast point, South Fork Boise River at Anderson Ranch Dam (Idaho), will be used here to demonstrate the statistical procedures discussed above and to show the kind of results possible. Results from similar analyses for other basins in the Hest indicate that the magnitude of the improvements in the standard errors obtained for this basin are typical. 
Anderson Ranch Dam (Figure 2) is one of three reservoirs on the Boise River operated by the U. S. Bureau of Reclamation (USBR). Twice monthly beginning in January, the USBR forecasts the date through July inflow volume to the reservoir for operating purposes. Once per month during January through April, the SCS forecasts the April-July and April-september inflow volumes, and in May it forecasts the May-July and May-September inflow volumes; these forecasts are for the benefit of the general agricultural population. For comparison with the USBR's current forecasting procedure, new date-July forecasting equations were developed using the statistical procedures proposed here and no future variables. The equations developed were for the first-of-month forecasts; mid-month forecasting equations were not developed. In addition, new April-July and May-July forecasting equations were developed to compare with the equations heretofore used by the SCS.

The USBR'S current procedure and the previous SCS procedure are illustrated in Tables I and II, respectively. The USBR's procedure is a single equation used throughout the forecast season, calibrated on October-July volume with all data known. The previous SCS procedure is a single equation for forecasting April-July volume from January through April and a second equation for forecasting May-July volume in May. When forecasting with these procedures before April 1 for before the seasonal maximum snow accumulation has occurred), snow data are extrapolated by adding the average accumulation between the date and April 1 (or the maximum) to the current value. Averages are used for future monthly precipitation variables. The construction of these equations is fairly typical of many that have been and are still being 


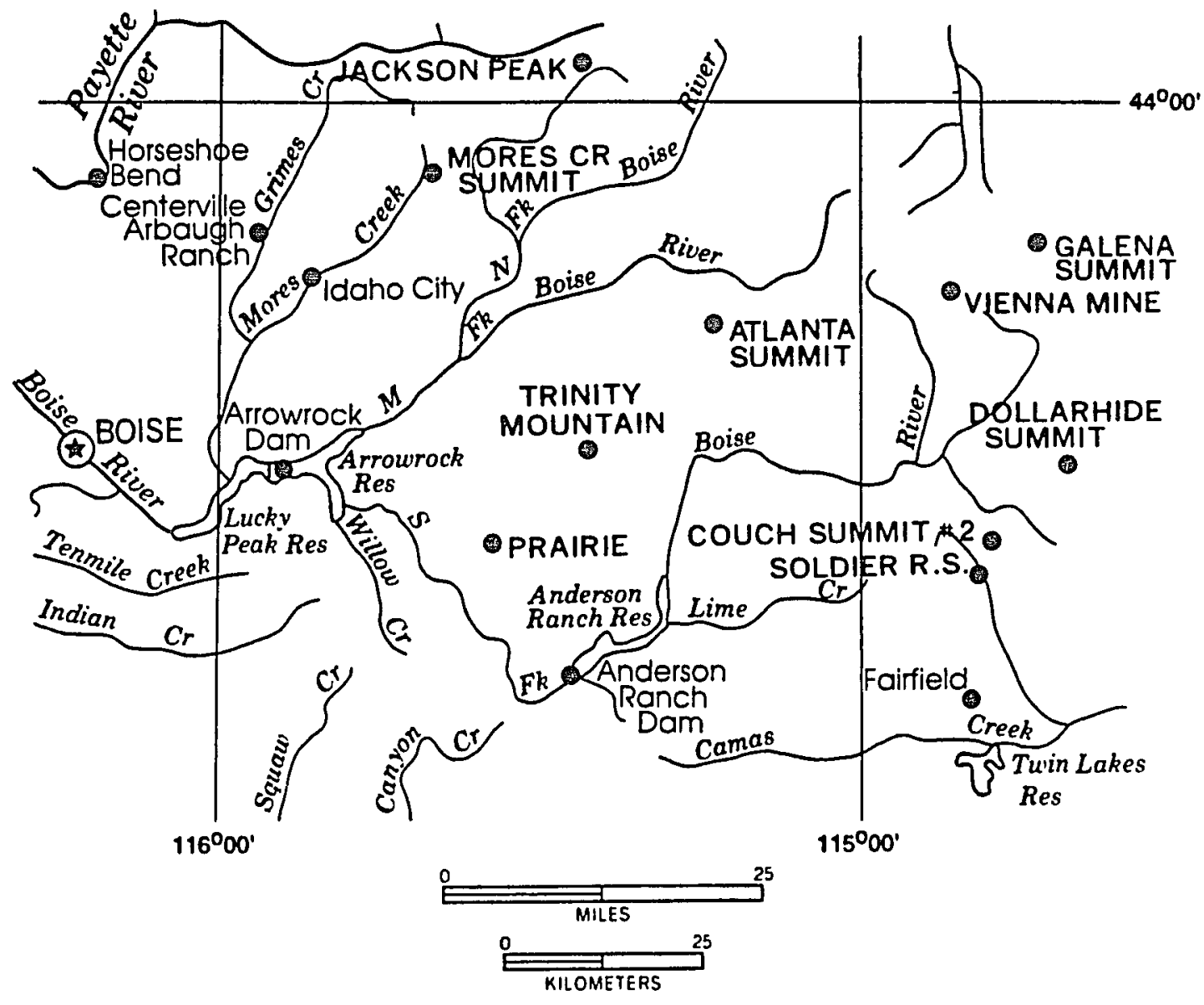

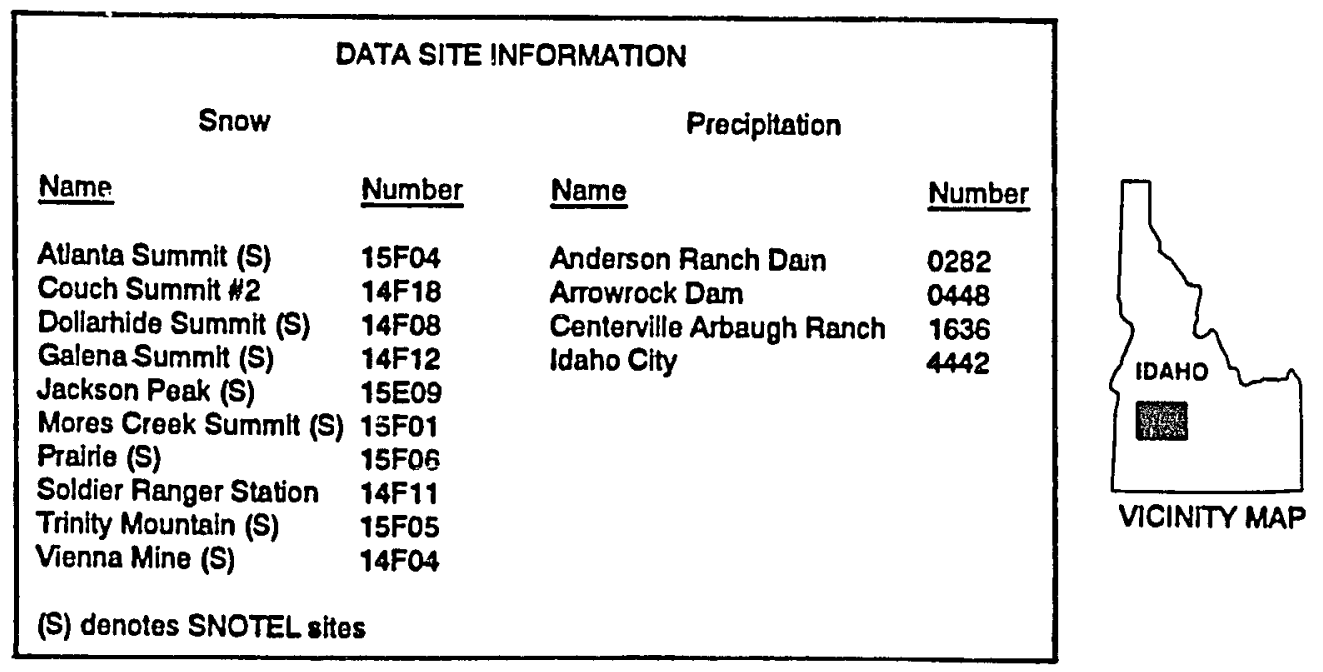

Figure 2. South Fork Boise River at Anderson Ranch Dam watershed location and locations of data sites. 
TABLE I

BUREAU OF RECLAMATION FORECASTING EQUATION, SOUTH FORK BOISE RIVER AT ANDERSON RANCH DAM

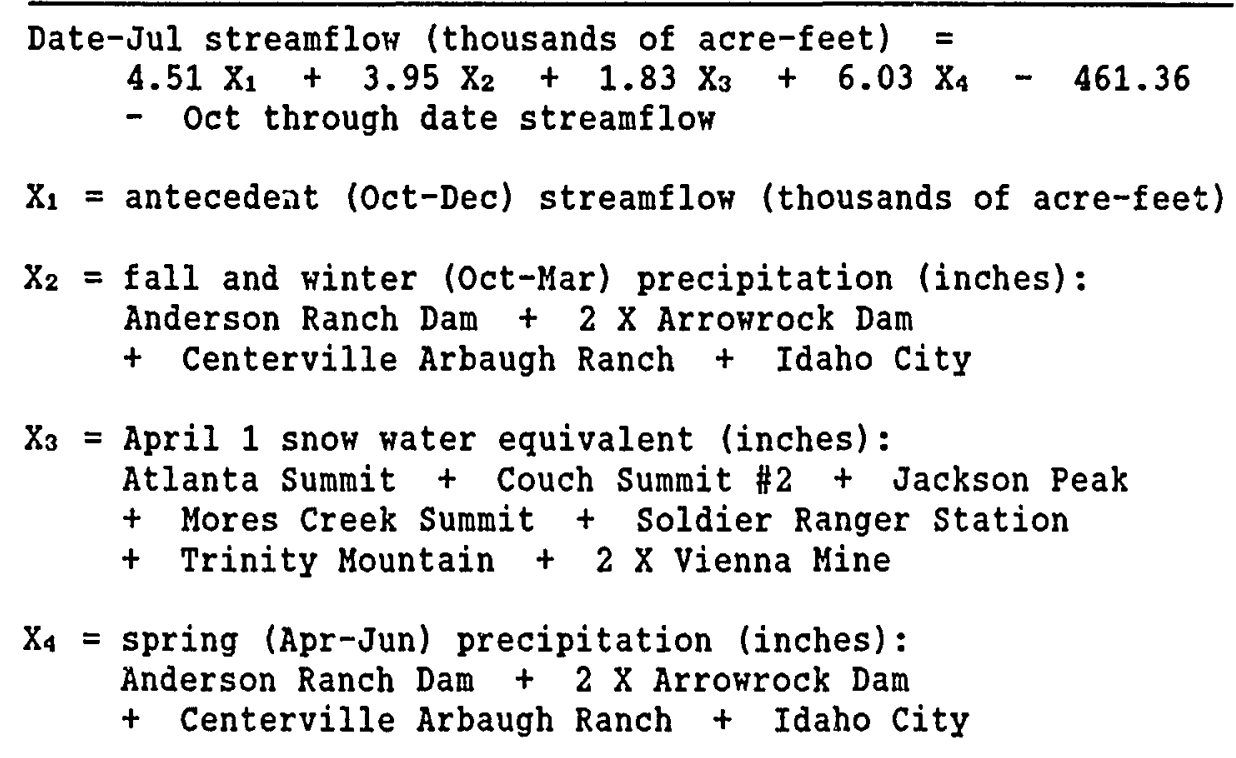

Note: Equation coefficients have been recomputed for this study and are slightly different from the actual values used by the Bureau of Reclamation. The differences are due to (1) calibrating on the period 1961-1988 rather than going back farther in time; and (2) using SNOTEL snow water equivalent instead of manual snow course measurements. This involves all snow sites except Couch Summit \#2 and Soldier Ranger Station. Observed SNOTEL data are only available for the period 1981 to the present. Before 1981, estimates were used based on linear regression relationships between SNOTEL and the co-located snowcourse.

used by forecasting and water management agencies. Note the use of snow and precipitation indexes as discussed in a previous section.

The new equations for Anderson Ranch Dam are shown in Table III. To arrive at these equations, separate analyses using the techniques described earlier were first performed for each forecast month and period. The variables used in the top twenty equations differed 
TABLE II

PREVIOUS SOIL CONSERVATION SERVICE FORECASTING EQUATIONS, SOUTH FORK BOISE RIVER AT ANDERSON RANCH DAM

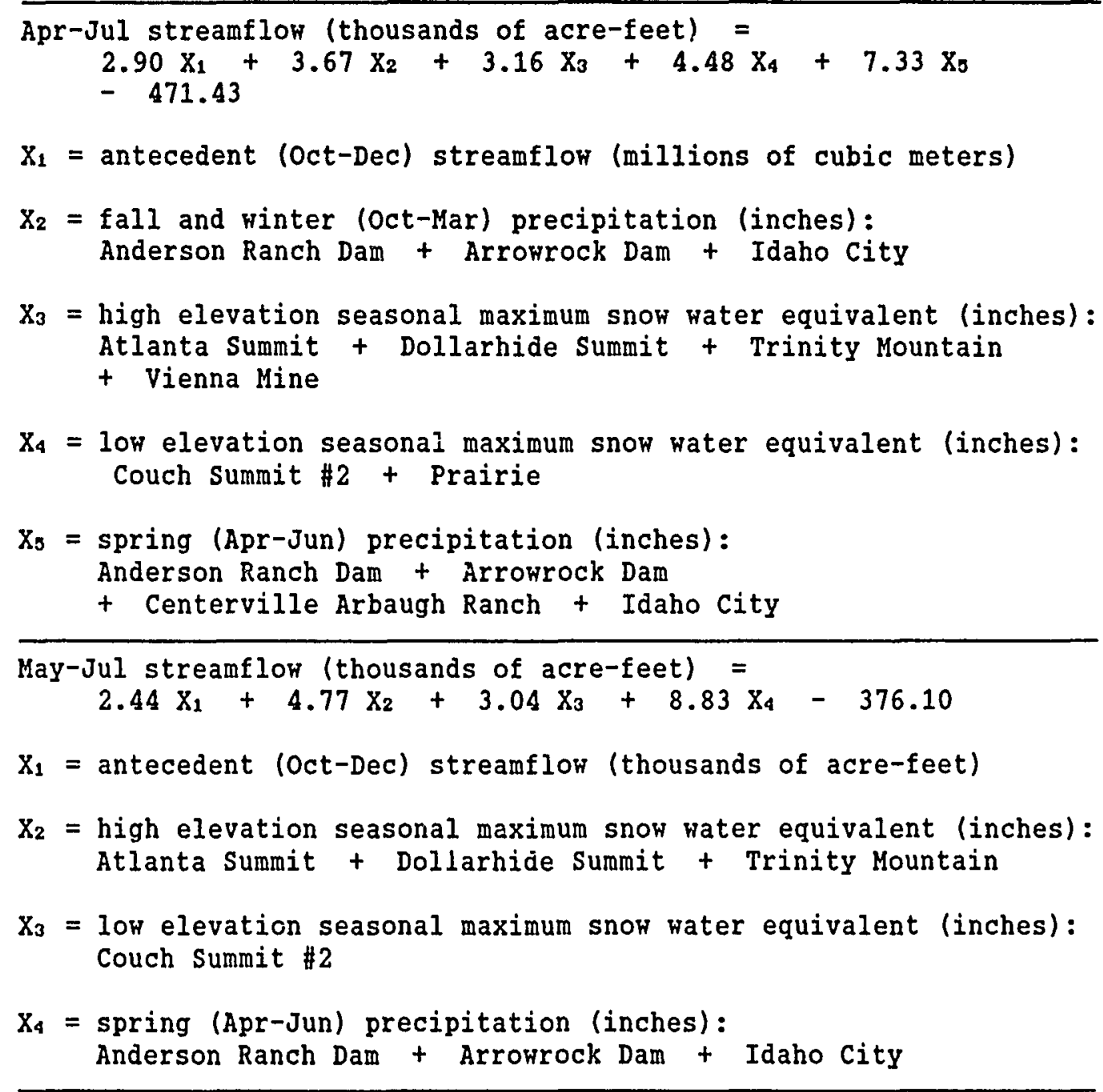

Note: Equation coefficients have been recomputed for this study and are slightly different from the actual values previously used by the Soil Conservation Service. The differences are due to (1) calibrating on the period 1961-1988 rather than going back farther in time; and (2) using SNOTEL snow water equivalent instead of manual snow course measurements. This involves all snow sites except Couch summit \#2 and Prairie. Observed SNOTEL data are only available for the period 1981 to the present. Before 1981, estimates were used based on linear regression relationships between SNOTEL and the co-located snowcourse. 
TABLE III

REGRESSION COEFFICIENTS FOR NEW FORECASTING EQUATIONS, SOUTH FORK BOISE RIVER AT ANDERSON RANCH DAM

\begin{tabular}{|c|c|c|c|c|c|c|c|c|}
\hline \multirow{3}{*}{$\begin{array}{l}\text { station, } \\
\text { month, and } \\
\text { data type }\end{array}$} & \multicolumn{8}{|c|}{ Forecast month and period } \\
\hline & \multicolumn{2}{|c|}{ January } & \multicolumn{2}{|c|}{ February } & \multicolumn{2}{|c|}{ March } & \multirow{2}{*}{$\frac{\text { April }}{\text { Ap-JI }}$} & \multirow{2}{*}{$\frac{\text { May }}{\text { MY-Jl }}$} \\
\hline & Ja-Jl & $A p-J 1$ & Fe-Jl & Ap-JI & $\mathrm{Mr}-\mathrm{J} 1$ & Ap-Jl & & \\
\hline $\begin{array}{l}\text { Anderson } \\
\text { Ranch Dam } \\
\text { Oc pcp. } \\
\text { De pcp. }\end{array}$ & $\begin{array}{l}17.71 \\
15.03\end{array}$ & $\begin{array}{l}16.65 \\
14.12\end{array}$ & $\begin{array}{l}20.48 \\
16.02\end{array}$ & $\begin{array}{l}18.18 \\
15.18\end{array}$ & 12.39 & 11.78 & 14.46 & 10.21 \\
\hline $\begin{array}{l}\text { Arrowrock Dam } \\
\text { Oc pcp. } \\
\text { De pcp. } \\
\text { Mr pcp. }\end{array}$ & $\begin{array}{l}20.84 \\
19.53\end{array}$ & $\begin{array}{l}19.58 \\
18.36\end{array}$ & $\begin{array}{l}20.99 \\
21.44\end{array}$ & $\begin{array}{l}18.59 \\
20.21\end{array}$ & $\begin{array}{l}18.13 \\
16.12\end{array}$ & $\begin{array}{l}17.24 \\
15.32\end{array}$ & $\begin{array}{r}9.97 \\
18.39 \\
11.69\end{array}$ & $\begin{array}{r}8.05 \\
13.20 \\
11.40\end{array}$ \\
\hline $\begin{array}{l}\text { Centerville } \\
\text { Arbaugh Ranch }\end{array}$ & & & & & & & & \\
\hline $\begin{array}{l}\text { Oc pcp. } \\
\text { Mr pcp. } \\
\text { Ap pcp. }\end{array}$ & 10.89 & 10.24 & 9.62 & 8.40 & 10.48 & 9.96 & $\begin{array}{l}3.87 \\
8.12\end{array}$ & $\begin{array}{l}2.98 \\
8.67 \\
7.67\end{array}$ \\
\hline $\begin{array}{c}\text { Idaho City } \\
\text { Oc pcp. } \\
\text { Ja pcp. } \\
\text { Ap pcp. }\end{array}$ & 15.43 & 14.50 & $\begin{array}{r}13.35 \\
2.06\end{array}$ & $\begin{array}{r}11.92 \\
2.69\end{array}$ & $\begin{array}{r}14.40 \\
8.26\end{array}$ & $\begin{array}{r}13.68 \\
7.85\end{array}$ & $\begin{array}{l}7.89 \\
9.25\end{array}$ & $\begin{array}{l}6.35 \\
6.92 \\
9.97\end{array}$ \\
\hline $\begin{array}{l}\text { Atlanta Summit } \\
\text { SNOTEL } \\
\text { Ja SWE } \\
\text { Fe SWE } \\
\text { Mr SWE } \\
\text { Ap SWE }\end{array}$ & 6.08 & 5.72 & 4.50 & 4.35 & 4.22 & 4.01 & 3.33 & 2.56 \\
\hline $\begin{array}{l}\text { Dollarhide } \\
\text { Summit SNOTEL } \\
\text { Ja SWE } \\
\text { Fe SWE } \\
\text { Mr SWE } \\
\text { Ap SWE } \\
\text { MY SWE }\end{array}$ & 7.86 & 7.39 & 5.28 & 5.07 & 5.04 & 4.79 & 4.13 & $\begin{array}{l}3.18 \\
2.77\end{array}$ \\
\hline
\end{tabular}


TABLE III

REGRESSION COEFFICIENTS FOR NEW FORECASTING EQUATIONS, SOUTH FORK BOISE RIVER AT ANDERSON RANCH DAM

(continued)

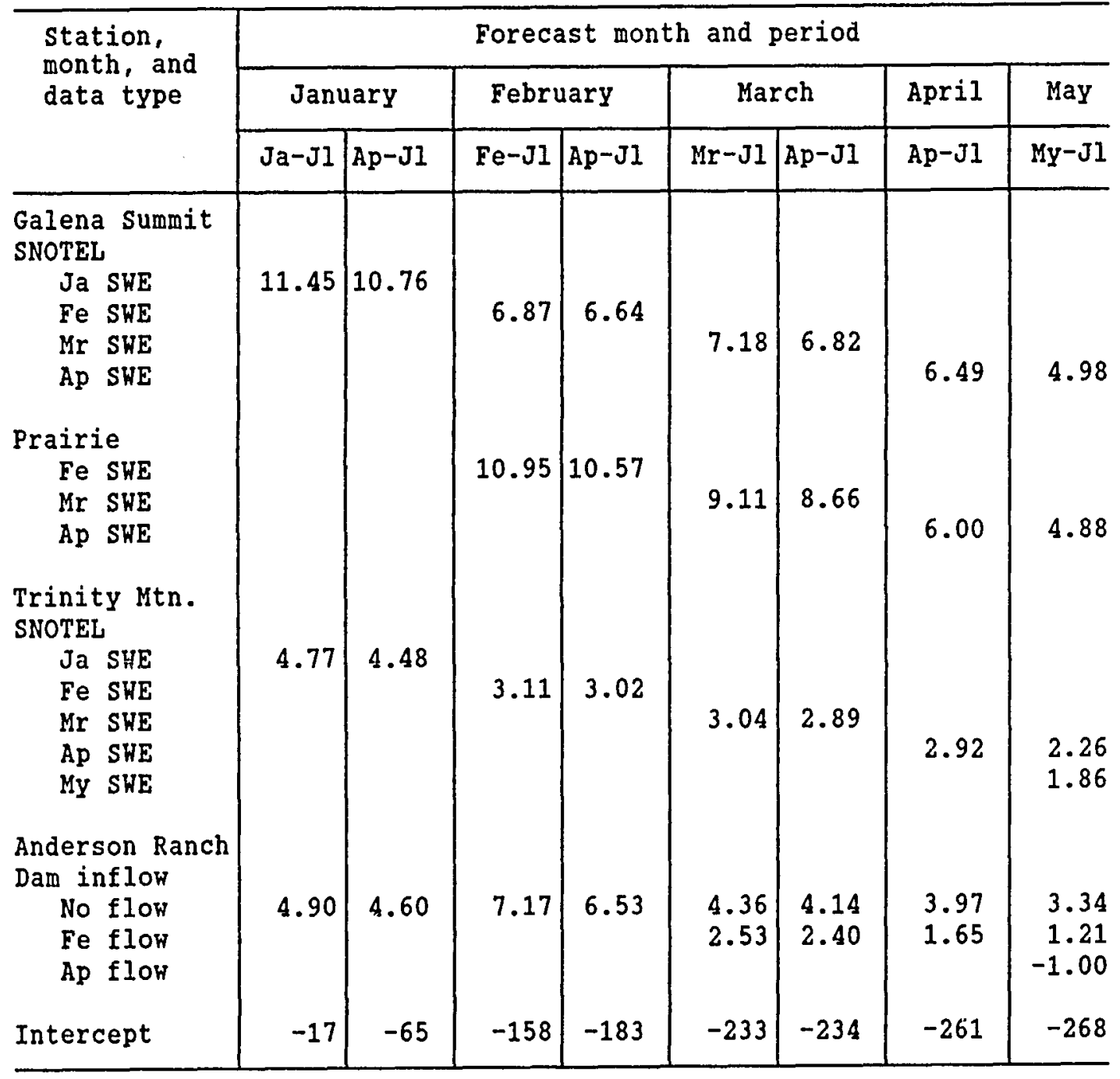


TABLE III

REGRESSION COEFFICIENTS FOR NEW FORECASTING EQUATIONS, SOUTH FORK BOISE RIVER AT ANDERSON RANCH DAM (continued)

\begin{tabular}{|c|c|c|c|c|c|c|c|c|}
\hline \multirow[t]{3}{*}{ statistic } & \multicolumn{8}{|c|}{ Forecast month and period } \\
\hline & \multicolumn{2}{|c|}{ January } & \multicolumn{2}{|c|}{ February } & \multicolumn{2}{|c|}{ March } & April & May \\
\hline & $\mathrm{Ja}-\mathrm{Jl}$ & $A p-J 1$ & $\mathrm{Fe}-\mathrm{Jl}$ & $A p-J 1$ & $\mathrm{Mr}-\mathrm{Jl}$ & $A p-J 1$ & $A p-J 1$ & $\mathrm{MY}-\mathrm{Jl}$ \\
\hline 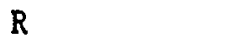 & 0.89 & 0.90 & 0.93 & 0.94 & 0.96 & 0.95 & 0.98 & 0.97 \\
\hline SE & 135 & 119 & 110 & 95 & 84 & 84 & 59 & 56 \\
\hline CVR & 0.87 & 0.89 & 0.91 & 0.92 & 0.94 & 0.94 & 0.97 & 0.96 \\
\hline CVSE & 143 & 126 & 125 & 109 & 95 & 94 & 72 & 69 \\
\hline NPC & 1 & 1 & 3 & 3 & 1 & 1 & 3 & 3 \\
\hline
\end{tabular}

Notes: (1) Calibration period is 1961-1988.

(2) Units are inches for precipitation (pcp.) and snow water equivalent (SWE), and thousands of acre-feet (KAF) for streamflow.

(3) Observed streamflows for calibrating the equations are adjusted for changes in reservoir storage.

(4) The May equation was first calibrated on April-July volume, then observed April flow was subtracted to obtain May-July volume. This was a more accurate way to forecast May-July than to calculate the May-July volume directly. This is why the April flow variable has a coefficient of -1.00 .

(5) Observed SNOTEL data are only available from 1981 to the present. Before 1981, estimates were used based on linear regression relationships between SNOTEL and the co-located snowcourse.

(6) $R$ = correlation coefficient

SE = standard error

CVR = cross-validation correlation coefficient

CVSE = cross-validation standard error

NPC = number of principal components used 
TABLE IV

CROSS-VALIDATION STANDARD ERROR COMPARISON, SOUTH FORK BOISE RIVER AT ANDERSON RANCH DAM

\begin{tabular}{|c|c|c|c|c|c|c|c|c|}
\hline \multirow{2}{*}{$\begin{array}{l}\text { Forecast } \\
\text { month and } \\
\text { period }\end{array}$} & \multicolumn{2}{|c|}{$\begin{array}{c}\text { USBR } \\
\text { equation }\end{array}$} & \multicolumn{2}{|c|}{$\begin{array}{l}\text { Previous } \\
\text { SCS } \\
\text { equations }\end{array}$} & \multicolumn{2}{|c|}{$\begin{array}{l}\text { Selected } \\
\text { new } \\
\text { equations }\end{array}$} & \multicolumn{2}{|c|}{$\begin{array}{c}\text { Rank \#1 } \\
\text { new } \\
\text { equations }\end{array}$} \\
\hline & CVSE & $\begin{array}{l}8 \text { of } \\
\text { avg. }\end{array}$ & CVSE & $\begin{array}{l}\text { \% of } \\
\text { avg. }\end{array}$ & CVSE & $\begin{array}{l}\xi \text { of } \\
\text { avg. }\end{array}$ & CVSE & $\begin{array}{l}\text { \& of } \\
\text { avg. }\end{array}$ \\
\hline $\begin{array}{r}\text { January } \\
\text { Ja-JI } \\
\text { Ap-JI }\end{array}$ & 217.1 & 33 & 171.3 & 30 & $\begin{array}{l}143.0 \\
126.1\end{array}$ & $\begin{array}{l}22 \\
22\end{array}$ & $\begin{array}{l}138.4 \\
131.5\end{array}$ & $\begin{array}{l}21 \\
23\end{array}$ \\
\hline $\begin{array}{c}\text { February } \\
\text { Fe-JI } \\
\text { Ap-JI }\end{array}$ & 191.6 & 30 & 131.7 & 23 & $\begin{array}{l}125.4 \\
108.8\end{array}$ & $\begin{array}{l}20 \\
19\end{array}$ & $\begin{array}{r}114.3 \\
98.4\end{array}$ & $\begin{array}{l}18 \\
17\end{array}$ \\
\hline $\begin{array}{l}\text { March } \\
\text { Mr-J1 } \\
\text { Ap-Jl }\end{array}$ & 159.4 & 26 & 109.4 & 19 & $\begin{array}{l}94.9 \\
94.2\end{array}$ & $\begin{array}{l}15 \\
16\end{array}$ & $\begin{array}{l}89.1 \\
84.8\end{array}$ & $\begin{array}{l}14 \\
15\end{array}$ \\
\hline $\begin{array}{l}\text { April } \\
\text { Ap-JI }\end{array}$ & 82.6 & 14 & 79.2 & 14 & 71.7 & 12 & 60.7 & 11 \\
\hline$\stackrel{\text { May }}{\mathrm{My}-\mathrm{JI}}$ & 84.7 & 18 & 89.3 & 19 & 69.0 & 15 & 60.7 & 13 \\
\hline
\end{tabular}

Notes: (1) Streamflow averages used are for the period 1961-1985.

(2) All equations were calibrated on the period 1961-1988.

(3) Units are thousands of acre-feet (KAF).

somewhat among the forecast months and periods, so the results of each analysis were examined to determine which variables appeared most consistently. By judgment and some trial and error, a set of variables was finally chosen that struck a compromise between optimal CVSE and month-to-month variable consistency.

A comparison of the CVSE's is given in Table IV. The new equations have considerably smaller CVSE's than the USBR and previous SCS equations, particularly for the forecasts before April. Also shown are 
TABLE V

FORECAST CONSISTENCY COMPARISON -- USBR AND NEW EQUATIONS, SOUTH FORK BOISE RIVER AT ANDERSON RANCH DAM

\begin{tabular}{l|c|c|c}
\hline Equations & $\begin{array}{c}\text { Calibration } \\
\text { period }\end{array}$ & $\begin{array}{c}\text { Average number } \\
\text { of direction } \\
\text { changes }\end{array}$ & $\begin{array}{c}\text { Average monthly } \\
\text { forecast change }\end{array}$ \\
\hline $\begin{array}{l}\text { USBR } \\
\text { equation }\end{array}$ & $1961-1988$ & 1.46 & 59.6 \\
$\begin{array}{l}\text { Selected } \\
\text { new } \\
\text { equations }\end{array}$ & $1961-1988$ & 1.54 & 44.9 \\
$\begin{array}{l}\text { Rank \#1 } \\
\text { new } \\
\text { equations }\end{array}$ & $1951-1988$ & 1.43 & 43.2 \\
\hline
\end{tabular}

Notes: (1) Values in table are based only on forecasts generated for the period 1961-1988, even for equations calibrated on a longer period.

(2) Maximum value for direction changes is 3 .

(3) Based on first-of-month forecasts from January through May.

(4) Volumes used are date-July forecasts plus observed January-date flow to give January-July volume each month.

(5) Units for average monthly forecast change are thousands of acre-feet (KAF).

the CVSE's for the top ranking equations from the search algorithm for each month. This shows that the increases in CVSE caused by selecting combinations to provide month-to-month consistency are slight.

Using the two measures discussed earlier (the average number of forecast direction changes and the average monthly forecast change), the month-to-month forecast consistency for the USBR equation is compared to that for the new equations in Table $V$. The maximum value for forecast direction changes is three in this work; the initial trend is 
established by the January and February forecasts, and trend changes are set by the March, April, and May forecasts. When all three sets of equations are calibrated on the 1961-1988 period, the top ranking equations are the most stable by the direction change measure. When the new equations are calibrated on the 1951-1988 period, the selected new equations are more stable than the top ranking equations. In any case, this measure is not greatly different among the three sets of equations. The selected new equations are the most stable according to the average forecast change measure for both calibration periods.

The month-to-month forecast consistency for the previous SCS equations is compared to that for the new equations in Table VI. The previous SCS equations are more stable than the new equations according to the direction change measure but less stable according to the average forecast change measure. Neither set of equations, then, has a clear advantage in stability. The direction change measures for the selected new equations and the top ranking equations show that some stability improvement of this type was made by careful variable selection. The average forecast changes, however, are nearly the same for the two sets of equations. From the comparisons in Tables $V$ and VI, it appears that monthly equations can provide stable forecasts while giving significantly greater accuracy.

SUMMARY

By not using future variables and by using principal components regression, cross-validation, and a search technique, substantial improvements in accuracy over current practice in seasonal streamflow 
TABLE VI

FORECAST CONSISTENCY COMPARISON -- PREVIOUS SCS AND NEW EQUATIONS, SOUTH FORK BOISE RIVER AT ANDERSON RANCH DAM

\begin{tabular}{l|c|c|c}
\hline Equations & $\begin{array}{c}\text { Calibration } \\
\text { period }\end{array}$ & $\begin{array}{c}\text { Average number } \\
\text { of direction } \\
\text { changes }\end{array}$ & $\begin{array}{c}\text { Average monthly } \\
\text { forecast change }\end{array}$ \\
\hline $\begin{array}{l}\text { Previous } \\
\text { SCS } \\
\text { equations }\end{array}$ & $1961-1988$ & 1.32 & 51.4 \\
$\begin{array}{l}\text { Selected } \\
\text { new } \\
\text { equations }\end{array}$ & $1961-1988$ & 1.61 & 43.1 \\
Rank \#1 & $1961-1988$ & 1.54 & 41.8 \\
new \\
equations
\end{tabular}

Notes: (1) Values in table are based only on forecasts generated for the period 1961-1988, even for equations calibrated on a longer period.

(2) Maximum value for direction changes is 3 .

(3) Based on first-of-month forecasts from January through May.

(4) For January through April, volumes used are AprilJuly forecasts. For May, observed April flow was added to the May-July forecast to give an April-July volume.

(5) Units for average monthly forecast change are thousands of acre-feet (KAF).

volume foi:ecasts can be obtained. Month-to-month forecast consistency can be maintained with the use of separate equations for each month by judicious selection of variables to maintain some month-to-month similarity in each month's equation. By using these techniques to develop seasonal volume forecasting equations, improved water management is possible under current decision-making procedures. These improved 
seasonal volume forecasting techniques can also be used as a base from which to judge the success of monthly or full hydrograph forecasts. A comparison of these three forecasting techniques will be given in Chapter V. 
CHAPTER III

MONTHLY STREAMFLOW MODELING

\section{INTRODUCTION}

For some water management purposes, where the timing of the runoff is important, temporal resolution of the streamflow forecast beyond just the seasonal volume can be helpful in decision making. Hydropower production planning and flood control are two examples. Because using a conceptual watershed model to simulate the full (daily) streamflow hydrograph involves considerable effort, a monthly model can provide some increase in resolution but still be relatively simple to use (Alley 1985).

The use of monthly streamflow models began with the so-called "water balance model" of Thornthwaite and Mather $(1955,1957)$. This model was a climatological tool and was not originally used as a streamflow simulation model. It described, by month, the average annual cycle of precipitation, soil moisture, evapotranspiration, and runoff. Generally, this "water balance" is computed for a point, rather than an area. This model has been widely used and has become a standard hydrologic procedure. It has been described in textbooks (e.g., Dunne and Leopold 1978) and has found use in global climate change research (Gleick 1986, 1987). 
Subsequent workers have built upon this idea and have developed models for simulating a monthly time series of streamflow. Palmer (1965) developed a monthly soil moisture accounting model as the foundation of the widely-used Palmer Drought Index. Haan (1972) developed a simple model for simulating monthly streamflows for small watersheds. Alley (1984, 1985) compared the monthly models of Thornthwaite and Mather $(1955,1957)$, Palmer (1965), and one by Thomas (1981) and Thomas et al. (1983) with regard to model conceptualization and one-month-ahead forecasting. Shelton (1985) developed a model that he applied to the Deschutes River in central Oregon. He divided the basin into many sub-basins, each of which was modeled separately. His model also accounted for snow accumulation and melt, which is something most monthly models do not do. Salas et al. (1986) developed a monthly streamflow and soil moisture accounting model, but snow was not included. Mimikou et al. (1991) developed a monthly model, including a snow component, that was applied in southern Europe for global climate change research.

Aside from Alley's (1985) effort, there has been no work in the literature where monthly models have been applied to streamflow forecasting. Alley (1985) limited himself to models that do not account for snow and only did one-month-ahead forecasting. There has been no work in applying this kind of model to forecasting spring and summer snowmelt runoff in the western United States. Such a model would have several advantages in this type of forecasting: (1) provide greater temporal resolution of streamflow than the current seasonal volume forecasts; (2) have more of a physical basis than regression techniques 
and therefore have the potential to perform better, especially in extreme wet or dry years; and (3) be much simpler to calibrate and use than a conceptual watershed model operated on a daily time step. Taking concepts from this previous work, a simple monthly streamflow model that can be used for water supply forecasting was developed and is described below. Also to be discussed are estimation of mean areal inputs to the model (precipitation and temperature), estimation of potential evapotranspiration, and calibration.

The monthly model was used on three basins located in Idaho and Montana. Information on these basins is given in Table VII, and a vicinity map is given in Figure 3. These three basins represent a range in size and physical setting within the northern part of the West, where streamflow is dominated by snowmelt runoff. They are also soil Conservation Service water supply forecast points and have been the locations for previous modeling efforts using conceptual watershed models. Calibration results from the monthly model are given in the last section of this chapter; comparisons with regression-based seasonal volume forecasts and with conceptual modeling results are given in Chapter v.

MONTHLY STREAMFLOW SIMULATION MODEL

The conceptualization of the monthly model developed here is an amalgamation of several monthly or simple daily models used by other workers. These models will be discussed below, then the model developed here will be described. 
TABLE VII

BASINS MODELED

\begin{tabular}{|c|c|c|c|c|c|}
\hline \multirow[t]{2}{*}{$\begin{array}{l}\text { Stream and } \\
\text { gaging point }\end{array}$} & \multirow[t]{2}{*}{$\begin{array}{l}\text { Drainage } \\
\text { Area } \\
\text { (sq. mi.) }\end{array}$} & \multicolumn{2}{|c|}{$\begin{array}{c}\text { Average } \\
\text { Hater Year } \\
\text { Runoff }\end{array}$} & \multirow{2}{*}{$\begin{array}{l}\text { Coeff. } \\
\text { of Var. } \\
\text { of } \\
\text { annual } \\
\text { flow }\end{array}$} & \multirow[t]{2}{*}{$\frac{A p-J l}{O c-S e}$} \\
\hline & & $\mathrm{KAF}$ & in. & & \\
\hline $\begin{array}{l}\text { St. Joe River } \\
\text { at Calder, ID }\end{array}$ & 1030 & 1707 & 31.1 & 0.26 & 0.69 \\
\hline $\begin{array}{l}\text { Ruby River above } \\
\text { reservoir near } \\
\text { Alder, MT }\end{array}$ & 538 & 141 & 4.9 & 0.25 & 0.59 \\
\hline $\begin{array}{l}\text { Lower Hillow } \\
\text { Creek near } \\
\text { Hall, MT }\end{array}$ & 73 & 19 & 4.8 & 0.40 & 0.72 \\
\hline
\end{tabular}

Notes: (1) $\mathrm{KAF}=$ thousands of acre-feet.

(2) Ap-Jl/Oc-Se is the ratio of spring runoff to annual runoff.

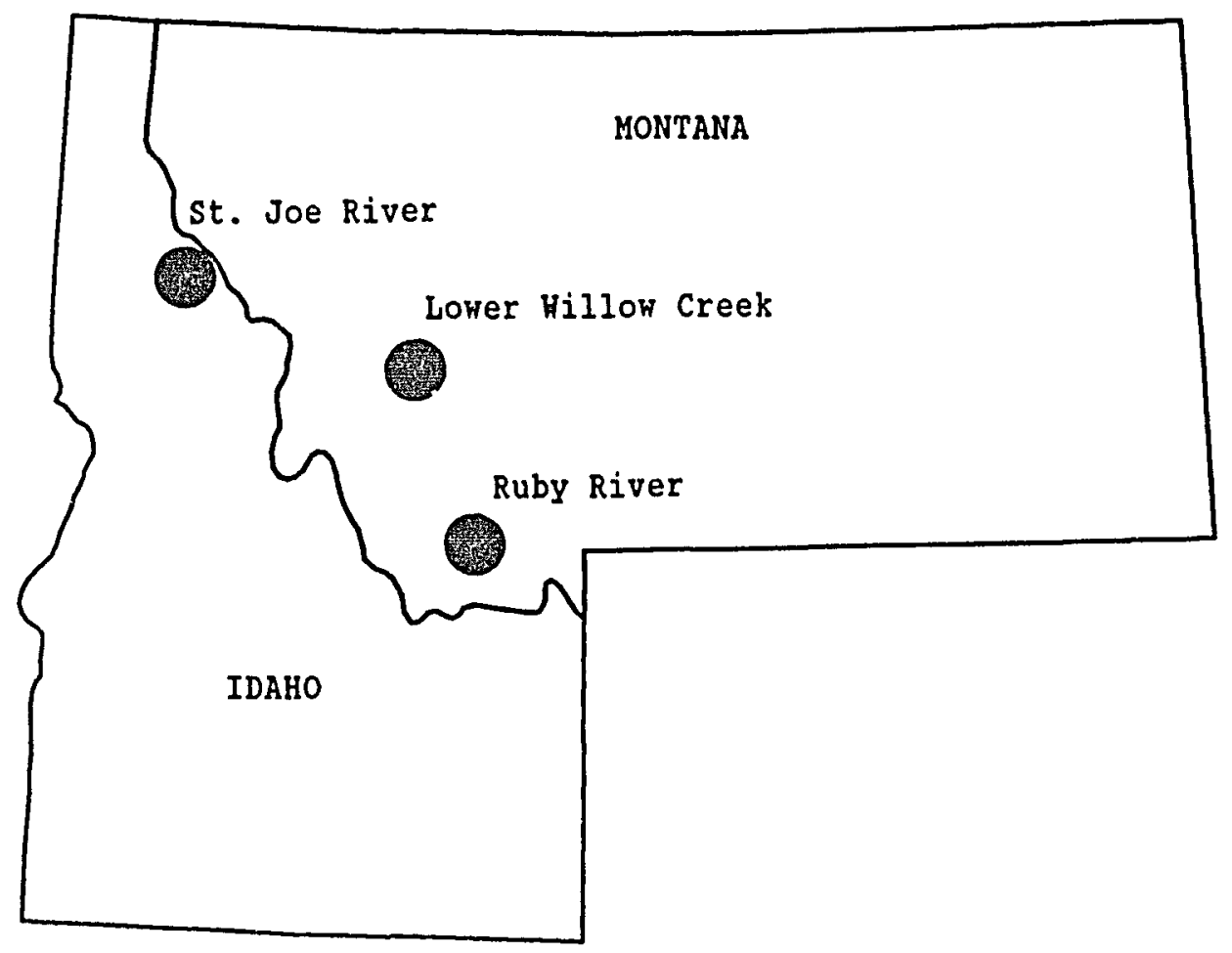

Figure 3. Vicinity map for basins modeled. 


\section{Previous Models}

The Thornthwaite-Mather model (Thornthwaite and Mather 1955, 1957; Alley 1984, 1985) is the original of this type of model. It has two water storages, a soil storage and what is termed a "water surplus" storage. The soil storage has a finite capacity and releases water to the water surplus storage by overflow. The water surplus has infinite capacity and behaves as a linear reservoir loutflow is proportional to the amount in storage). Runoff is the outflow from this storage. Evapotranspiration occurs at the potential rate as long as precipitation equals or exceeds this rate; otherwise, evapotranspiration removes water from the soil storage. Snow storage was originally handled in a very simple manner. If the monthly average temperature was below $-1{ }^{\circ} \mathrm{C}$, all precipitation was assumed to fall as snow. When monthly average temperature rose above $-1^{\circ} \mathrm{C}$, snowmelt began, and the volume in storage was depleted according to a preset distribution over the current and subsequent months. In a later study, van Hylckama (1958) developed another technique to deal with snow. This will be explained in more detail later.

Haan (1972) also uses a two-storage system. Both storages have finite capacities, with the upper storage fixed at a capacity of one inch. Evapotranspiration removes water first from the upper storage and secondarily from the lower storage. Runoff is generated either by overflowing the two storages or by precipitation exceeding the infiltration rate. 
The model developed by Shelton (1985) uses three soil storages and a snow storage. The soil storages are labelled as soil capillary water, transient groundwater, and perennial groundwater. Evapotranspiration removes water from the snow and soil capillary water storages. Water flows from the soil capillary water storage to the transient groundwater storage only by overflow. The transient groundwater storage can provide runoff by overflowing its maximum capacity. It also continuously releases water to the perennial groundwater storage. The perennial groundwater storage has no maximum capacity, and it continuously releases water to runoff. Snow accumulation and melt are handled with a multiple linear regression relationship, where snow on the ground is a function of snow on the ground for the previous month and precipitation and temperature for the current month.

The model of Salas et al. (1986) also uses three soil storages. These represent surface, unsaturated zone, and saturated zone storage. The storages behave as linear reservoirs. Only the unsaturated zone storage has a maximum capacity. Evapotranspiration removes water from the surface and unsaturated zone storages. Water infiltrates to the unsaturated zone from the surface storage and to the saturated zone from the unsaturated zone. Runoff is the outflow from the surface and saturated zone storages. There is no accounting for snow.

The model developed by Mimikou et al. (1991) was used for assessing the hydrologic effects of climate change. It has three soil storages, representing surface detention, soil moisture, and groundwater storage. The surface detention storage releases water either to evaporation or to infiltration. The soil and groundwater storages behave as linear 
reservoirs. In addition, the soil storage has a maximum capacity and loses water to evaporation. The model also accounts for snow accumulation and melt.

A model used for hydrochemical modeling of the Birkenes catchment in Norway (Christophersen et al. 1982; Christophersen and Neal 1990) was intended for daily simulations but is another example of a simple conceptualization. This model has two soil storages and, as modified by McDonnell and Buttle (1987), a snow storage. Both soil storages behave as linear reservoirs. It differs from the Thornthwaite-Mather model in that the upper reservoir drains continuously rather than only by overflow, and the lower reservoir has a maximum capacity.

This list of models, while not all-inclusive, gives a good sampling of the conceptualizations commonly used. In these models, there are many similarities in structure but some differences in the functional forms used to describe water fluxes and in the physical interpretation attached to each structural element. The linear reservoir, for example, is a common element in these and other, more complex models (Huggins and Burney 1982; U. S. Army Corps of Engineers 1987); in fact, it is a classical building block for even the earliest of watershed models (Dooge 1959, 1973). Soil storages, however, often have different nominal physical associations. For example, the models of Salas et al. (1986) and Mimikou et al. (1991) interpret the uppermost soil storage as water ponded on the surface of the soil; Haan (1972) interprets it as the first inch of water stored in the soil itself; Shelton (1985) labels it the root zone; Thornthwaite and Mather (1955, 1958) consider the upper storage as the entire soil profile. These associations are 
sometimes rather loosely stated, so strict physical interpretations are difficult to make. In fact, strict physically-based relationships and interpretations in a monthly model are not really possible because the computational time step is so large compared to the continuous dynamics of a watershed. The structural elements of these models are only crude simplifications of the real system. Such a model can, however, approximate the major modes of the temporally- and spatially-integrated behavior of the watershed.

\section{Proposed Model}

After examining the models described above, a monthly model was developed that incorporated the important features of these models and overcame the major shortcomings that would hinder usefulness for water supply forecasting in the western United States. The model developed here, then, is an amalgamation of these models and includes a snow component. It is therefore believed that this model should perform at least as well as, and probably better than, any of the individual models discussed above. The model is illustrated in Figure 4 , and its parameters and state variables are listed in Table VIII. The model is described below.

Snow Component. Temperature is used in this model as the sole index of heat exchange driving snow accumulation and melt. Other factors, such as humidity, solar radiation, and wind, are also important, but data for these variables are generally unavailable. Recognizing this, snowmelt models with a daily or smaller computational time step using only temperature have been developed for operational 

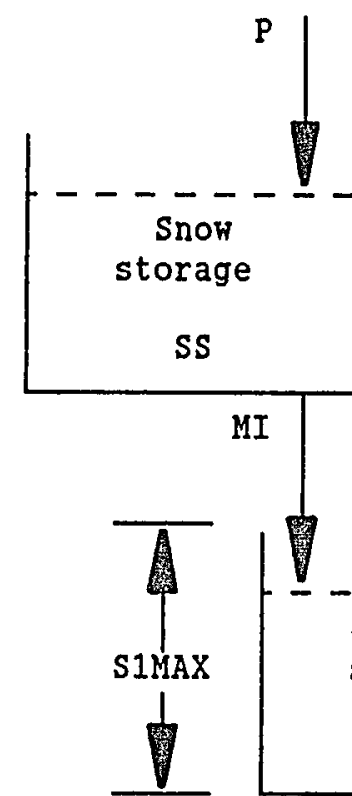

MI

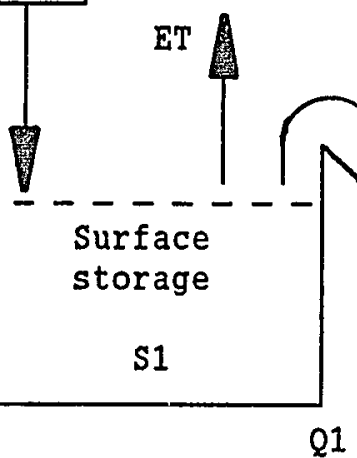

Q1

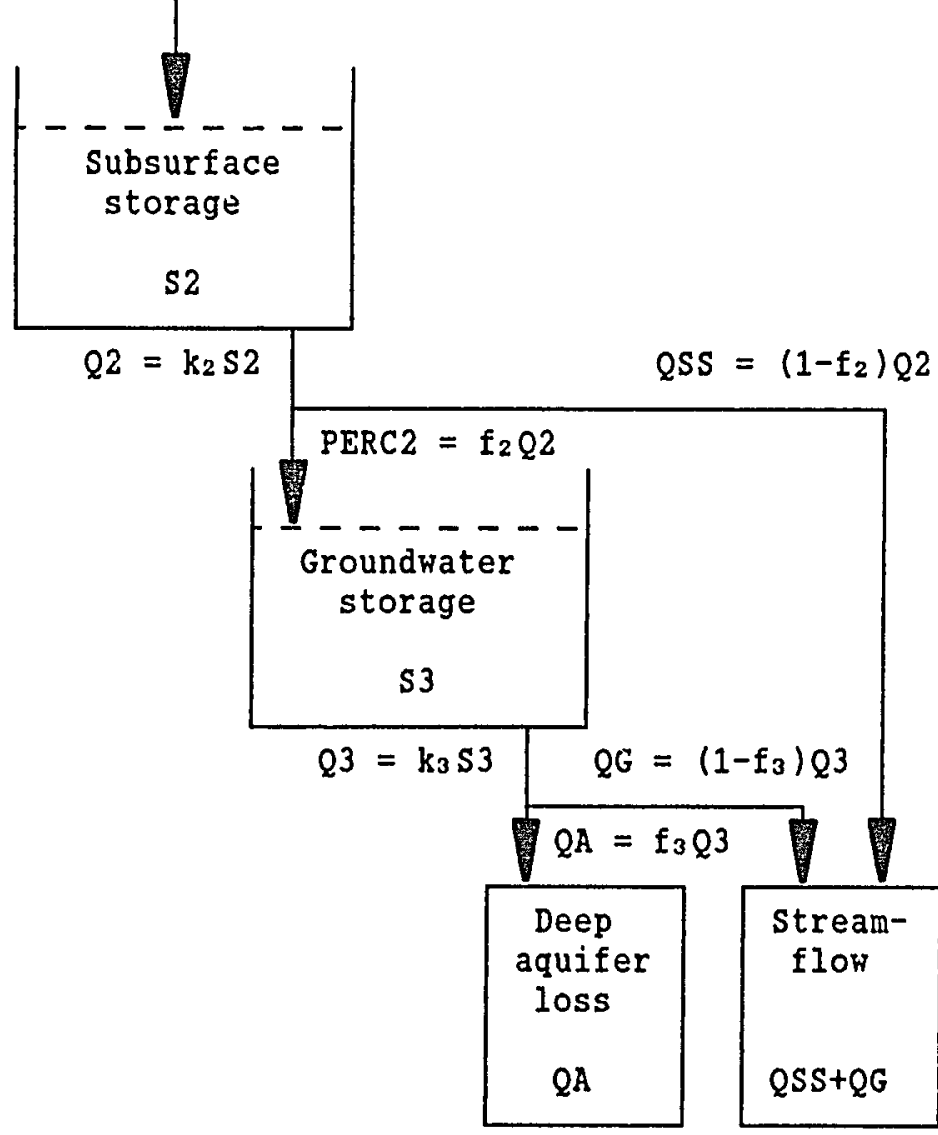

Figure 4. Monthly streamflow simulation model. 
TABLE VIII

MONTHLY STREAMFLOH SIMULATION MODEL --

PARAMETERS, STATE VARIABLES, INPUT DATA, AND OUTPUT

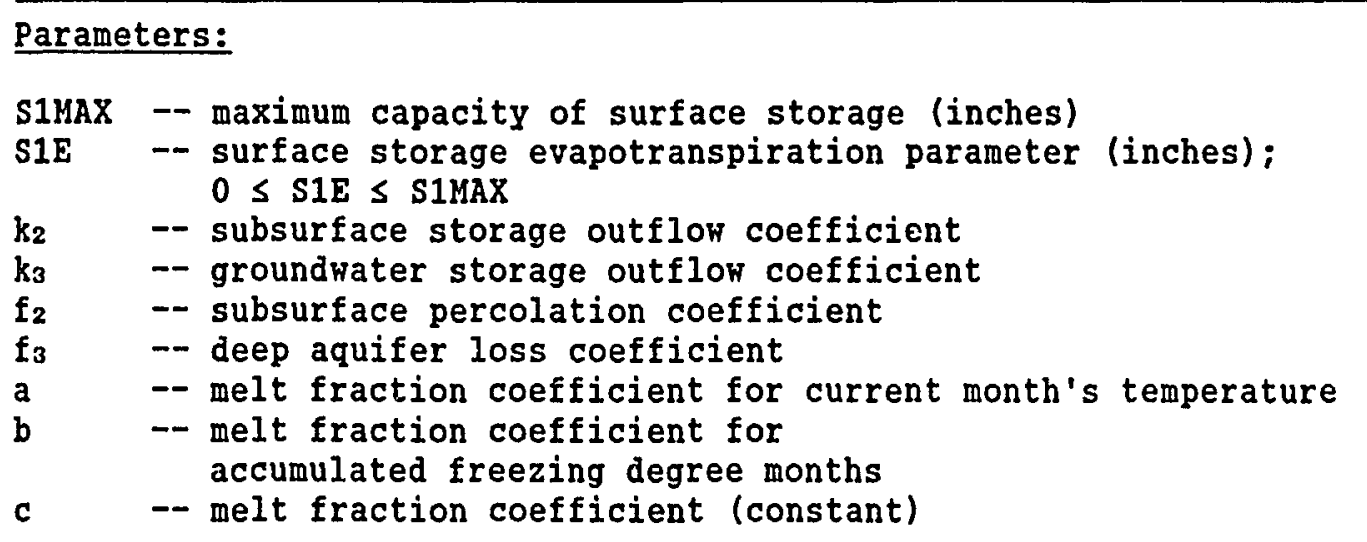

State variables:

$\mathrm{SS}_{1} \quad$-- snow storage at the end of month $i$ (inches)

S11 -- surface storage at the end of month $i$ (inches)

S21 -- subsurface storage at the end of month $i$ (inches)

S31 -- groundwater storage at the end of month $i$ (inches)

Input data -- watershed characteristics:

AREA -- watershed area (square miles)
PECOR1 -- Thornthwaite potential evapotranspiration correction
factors; twelve values, one per month
TAVG - - long-term monthly average mean areal temperatures $\left({ }^{\circ} \mathrm{C}\right) ;$
twelve values, one per month

Input data -- time series:

$P_{1} \quad--$ mean areal precipitation during month $i$ (inches)

$\mathrm{T}_{1} \quad--$ mean areal temperature during month $i\left({ }^{\circ} \mathrm{C}\right)$

$\mathrm{QO}_{1}$-- observed streamflow during month $i$ (thousands of acre-feet)

output:

QSS 1 -- subsurface flow during month $i$ (thousands of acre-feet)

$Q G_{1} \quad$-- groundwater flow during month $i$ (thousands of acre-feet)

$\mathrm{QC}_{1} \quad-$ computed streamflow during month $i$ (thousands of acre-feet) 
forecasting (Anderson 1968, 1973; U. S. Army Corps of Engineers 1987). These models, however, are too complex to be used with a monthly time step. A simpler conceptualization was therefore developed for the monthly model.

As mentioned previously, Shelton (1985) used multiple linear regression to calculate snow accumulation and melt. A more physically appealing and parsimonious technique, however, can be based on the concepts of "available water" and "melt fraction," which were used by van Hylckama (1958) in his snow algorithm for the Thornthwaite-Mather model. "Available water" is simply the snow water equivalent at the end of the previous month plus the current month's precipitation. The fraction of this available water not retained as snow is called the "melt fraction." More precisely,

$$
M F_{1}=1-\frac{S S_{1}}{S S_{1-1}+P_{1}}
$$

where $M F_{1}$ is the melt fraction for month $i, S_{1}$ is the snow storage (water equivalent) at the end of month $i$, and $P_{1}$ is the precipitation for month $i$. The denominator in the above equation is the "available water."

The snow algorithm developed by van Hylckama (1958) was based on statistical relationships between the melt fraction and the current month's temperature, the following month's temperature, and the available water. His results were presented in the form of two nomograms, one for snow accumulation and one for melt situations. While this algorithm represented an improvement over what had been done in the 
Thornthwaite-Mather model, it needed modification to be used in the present work for several reasons. First, the statistical relationships were developed for areas in the eastern United States and most likely are not applicable to the Hest. Second, his relationships would be difficult to reproduce because only nomograms, not equations are given. Third, the rationale for and necessity of including the following month's temperature and the available water in his statistical relationships are unclear. Fourth, using the following month's temperature is not desirable in a forecasting context. Initially, the relationship between melt fraction and the concurrent month's temperature was examined using data from soil Conservation Service SNOTEL sites. For each month of the available record at a site, one has snow water equivalent at the beginning of the month, monthly precipitation, and average monthly temperature. A monthly series of melt fractions and average monthly temperatures can be calculated for all SNOTEL sites in or near the watershed of interest.

The data generally cluster into two groups, fall and spring. This is illustrated for the st. Joe River in Figure 5. Because the fall snow accumulation has not yet been through a winter, it will not be as cold as the spring snowpack. Therefore, for a given monthly temperature, higher melt fractions will occur in the fall than in the spring because less energy is required to warm the pack up to freezing temperature, and more energy can be used to supply the latent heat of fusion for melting the snow. One possibility, then, would be to use different functions for the two seasons. 


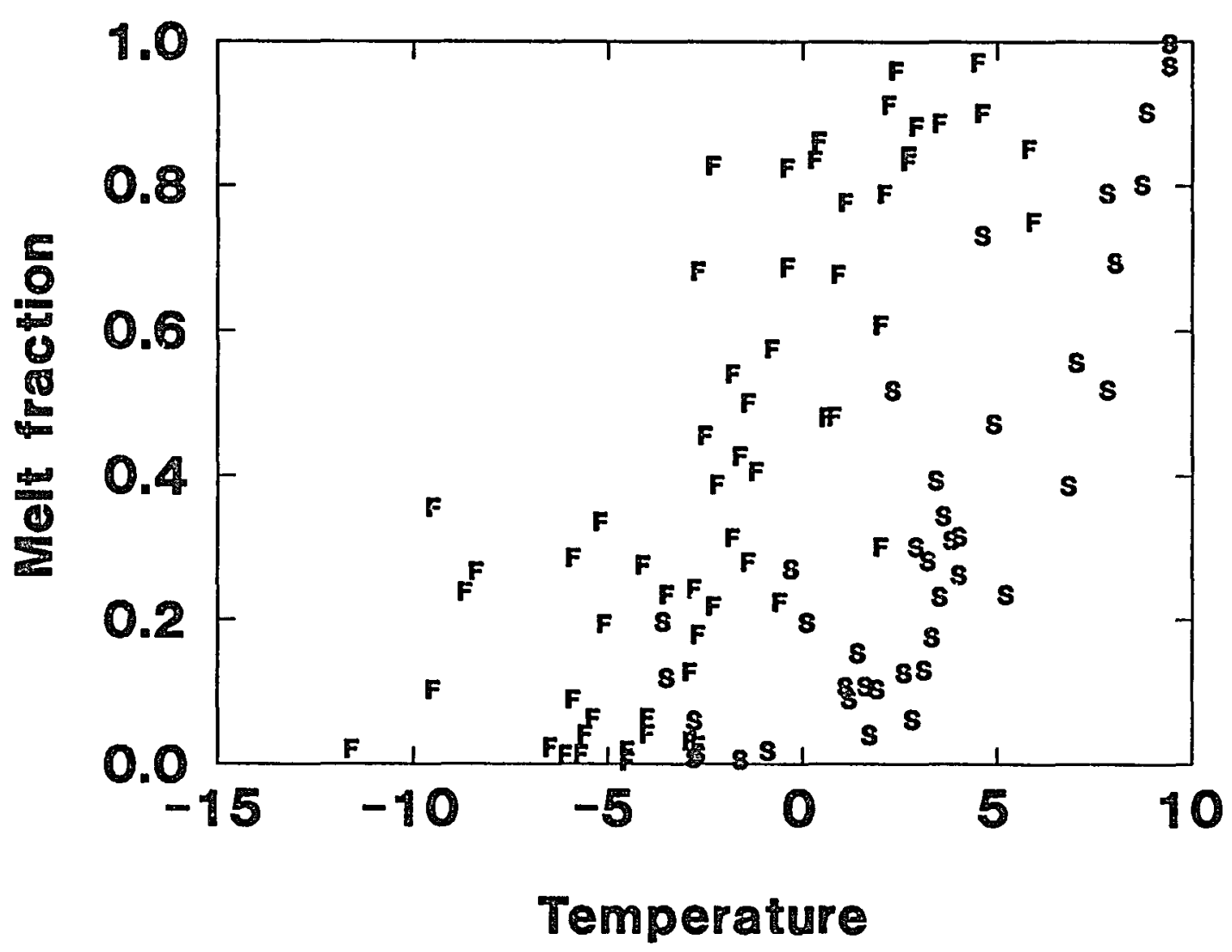

Figure 5. Melt fraction vs. concurrent month's temperature $\left({ }^{\circ} \mathrm{C}\right)$, St. Joe River. $F=$ fall (October-January), $s=$ spring (February-June).

A shortcoming of using the season to discriminate between functions to use for calculating the melt fraction, however, is that it relies on the consistency of weather patterns. That is, it would work only if temperatures behave similarly from year to year. This happens to be the case in many areas of the Hest, so such a simple conceptualization would work most of the time. If unusual weather patterns occurred that did not coincide with the temporal assumptions built into the melt fraction function, however, the model would perform poorly. This, in fact, is one of the weaknesses of regression models; they work well most of the 
time because weather patterns tend to be consistent in time, and regression is well-suited to exploit this regularity. In unusual years, however, regression models fail because their foundation is undercut. It would be preferable to base the melt fraction function on the physical process rather than on the time of year. The physical process in this case is that the temperature of the snowpack affects the amount of melt as well as the current month's temperature. Including an index of snowpack temperature in the melt fraction function, then, would be more realistic.

Accumulated freezing degree months is used in this model to index the snowpack temperature. This is defined as:

$$
F D M_{1}=F D M_{1-1}-T_{1}
$$

where FDM 1 is the accumulated freezing degree months in month $i$ and $T_{1}$ is the temperature $\left({ }^{\circ} \mathrm{C}\right)$ in month $i$. If $F M_{1}$ so calculated is less than zero, it is set to zero. That is, accumulated freezing degree months is the sum of the degrees below freezing for all previous months. The melt fraction is modeled as a linear function of current month's temperature and the accumulated freezing degree months through the previous month:

$$
M F_{1}=a T_{1}+b F M_{1-1}+c
$$

where $a, b$, and $c$ are coefficients estimated either from examining SNOTEL data plots as described above or during model calibration. The correlation coefficient of the above equation ranged from 0.79 to 0.92 using SNOTEL data for the three test basins. This melt fraction is used to calculate the snow storage at the end of month $i$ as follows: 


$$
S S_{1}=\left(1-M F_{1}\right)\left(S S_{1-1}+P_{1}\right)
$$

Water not retained by the snow storage becomes moisture input to the soil storage system, that is,

$$
M I_{1}=M_{1}\left(S S_{1-1}+P_{1}\right)
$$

where $\mathrm{MI}_{1}$ is the moisture input to the first soil storage (see next section on soil moisture accounting).

Soil Moisture Accounting. The monthly models reported in the literature have varying numbers of water storages and linkages among storages to represent the movement of water through the soil. The model developed in this work was an attempt to incorporate as many features as possible from these models for the sake of generality.

Three soil moisture storages were chosen for this model. This was common among the models reviewed and seems to strike a good balance between parsimony (to minimize the number of model parameters) and model flexibility (to allow the model to behave similarly to the real system). These were labelled surface, subsurface, and groundwater storage. These are not strict physical interpretations, but they are rather intended to suggest a basic, though fuzzy, correspondence with moisture storage at different depths in the soil profile.

The surface storage (S1) has a finite capacity (parameter s1MAX) and releases water to the subsurface storage only when it overflows. Experimentation with the surface storage having continuous outflow was unsatisfactory, as base flow in the late summer and fall was not modeled well. Evapotranspiration removes water from the surface storage at the 
potential rate if surface storage is above the parameter S1E $10 \leq$ S1E $\leq$ SIMAX) and at a linearly decreasing rate when the surface storage is below S1E; evapotranspiration is zero when the surface storage is empty. This relation is commonly used (e.g., Salas et al. 1986 and Koch et al. 1987) and is illustrated in Figure 6.

The subsurface (\$2) and groundwater (\$3) storages act as linear reservoirs, that is, the outflow is directly proportional to the amount in storage, or

$$
Q=k S
$$

where $Q$ is the outflow rate, $S$ is the amount in storage, and $k$ is the storage coefficient. The outflows from these two storages are partitioned into a component that goes to streamflow and a part that goes to the next storage below. For groundwater storage, this next storage below is termed "deep aquifer loss," water that is lost to the system, presumably by the exportation of water out of the basin by deep aquifers. Neither of the storages has a maximum capacity.

The soil moisture accounting equations used in this model are derived from solving the differential equations that describe the behavior of the soil storages. These equations are derived below. The surface storage (S1) has one input -- the moisture input calculated in the snow algorithm -- and two outputs -- overflow and evapotranspiration. When the contents of $S 1$ are greater than S1E, the behavior of $\mathrm{S} 1$ is described by: 


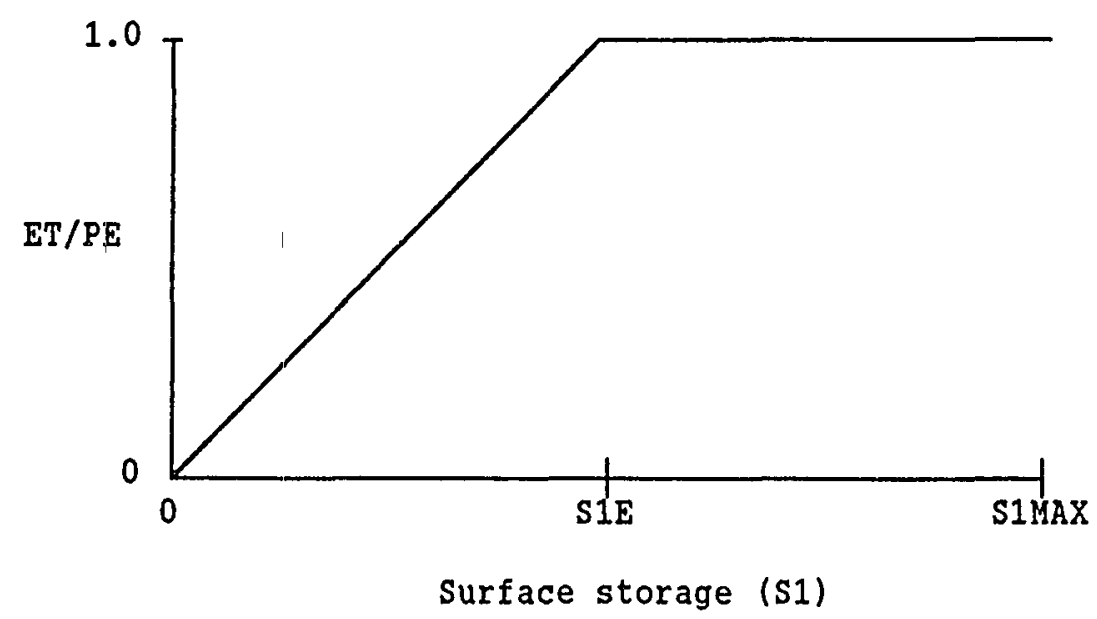

Figure 6. Monthly streamflow simulation model soil moisture-evapotranspiration relationship.

$$
\frac{d S 1}{d t}=M I-P E
$$

where $M I=$ mojsture input and $P E=$ potential evapotranspiration. When the contents of $S 1$ arelless than S1E, the behavior is described by:

$$
\frac{d S 1}{d t}=M I-\frac{(P E)(S 1)}{S 1 E}
$$

Assuming that the inputs and outputs occur at constant rates during the month, the solutions of the above differential equations are:

$$
S 1_{1}=S 1_{1-1}+M I_{1}-P E_{1}
$$

for S1E $\leq S 1<S 1 M A X$, and

$$
S 1_{1}=\frac{M I_{1} S 1 E}{P E_{1}}\left(1-e^{-\left(P E_{1} / S 1 E\right)}\right)+S 1_{1-1} e^{-\left(P E_{1} / S 1 E\right)}
$$


for $0 \leq S 1<S 1 E$. In either case, if $P E_{1}=0$, then

$$
S 1_{1}=S 1_{1-1}+M I_{1}
$$

If S1 so calculated exceeds S1MAX, the excess becomes input to subsurface storage.

The subsurface storage (S2) has one input -- overflow from surface storage -- and one output -- the linear reservoir outflow. The differential equation describing its behavior is:

$$
\frac{d S 2}{d t}=21-k_{2} S 2
$$

where $Q 1$ = overflow from $\mathrm{S} 1$ and $\mathrm{k}_{2}$ = subsurface storage constant. Again assuming that the moisture fluxes occur at constant rates during the month, the solution of the differential equation is:

$$
S 2_{1}=\frac{Q 1_{1}}{k_{2}}\left(1-e^{-k_{2}}\right)+S 22_{1-1} e^{-k_{2}}
$$

The outflow from subsurface storage for the month is simply calculated by:

$$
Q 21=Q 1_{1}-S 2_{1}+S 2_{1-1}
$$

The subsurface outflow is partitioned into a fraction that goes directly to streamflow and a fraction that percolates to groundwater. So,

$$
\begin{gathered}
\operatorname{PERC2}_{1}=\mathrm{f}_{2} \mathrm{Q2}_{1} \\
\mathrm{QSS}_{1}=\left(1-\mathrm{f}_{2}\right) Q 2_{1}
\end{gathered}
$$


where PERC2 = percolation from subsurface to groundwater storages, QSS = outflow from subsurface storage to streamflow, and $f_{2}=$ subsurface percolation coefficient.

The groundwater storage behaves analogously to the subsurface storage, except that the storage and percolation coefficients have different values. So, the differential equation describing groundwater storage is:

$$
\frac{d S 3}{d t}=\text { PERC2 }-k_{3} S 3
$$

whose solution is:

$$
S 3_{1}=\frac{P E R C 21}{k_{3}}\left(1-e^{-k_{3}}\right)+S 3_{1-1} e^{-k_{3}}
$$

The outflow from groundwater storage for the month is:

$$
Q 3_{1}=\text { PERC21 }-S 3_{1}+S 3_{1-1}
$$

The groundwater outflow is partitioned into a fraction that goes directly to streamflow and a fraction that percolates to deep aquifers and is lost to the watershed. So,

$$
\begin{gathered}
Q A_{1}=f_{3} Q 3_{1} \\
Q G_{1}=\left(1-f_{3}\right) Q 3_{1}
\end{gathered}
$$


where $Q A=$ outflow from groundwater storage to deep aquifers, $Q G=$ outflow from groundwater storage to streamflow, and $f_{3}=$ groundwater percolation coefficient.

The total streamflow for the month is the sum of the subsurface and groundwater contributions, that is,

$$
Q_{1}=Q S S_{1}+Q G_{1}
$$

There is no direct surface contribution to streamflow, so overland flow during intense precipitation is not included in this model. This type of runoff cannot really be handled well in a monthly model because overland flow occurs on a time frame of minutes to hours. Mather (1981) attempted to include overland flow using the Thornthwaite-Mather model, but he had to introduce a procedure from the Soil Conservation Service (1972b) and perform the calculations on a daily basis. This seems to defeat the purpose of a simple monthly model; if overland flow is an important process, then a more complex model with shorter computational time steps would be more appropriate. In any event, this flow component is unimportant in most areas of the West, where snowmelt runoff is dominant (the Southwest is a notable exception).

Data Requirements. The input data required by this model are modest, consisting of monthly precipitation and monthly average temperature at the available hydrometeorological sites. In this rork, these sites are Soil Conservation Service SNOTEL sites and National Weather Service cooperative network sites. These data are routinely available and require little or no additional effort to collect beyond what is required for regression procedures. Observed monthly streamflow 
data are required for model calibration, and data up to the forecast date are useful, but not required, to check model performance before making streamflow forecasts.

\section{MEAN AREAL PRECIPITATION}

In streamflow modeling, the watershed can be depicted as a single unit, divided into elevation zones, or divided into small, relatively homogeneous sub-units. Regardless of how the watershed is modeled, estimates of average precipitation over one or more areas are required.

The classical techniques of estimating mean areal preciptation (MAP) include Thiessen polygons and the isohyetal method (Linsley et al. 1975). While these techniques are relatively simple and straightforward, they have simplistic assumptions about the spatial correlation and variability of precipitation, can be subjective, and are not necessarily optimal.

A more recent technique for estimating MAP is the use of kriging. Kriging is an optimal spatial interpolation procedure for estimating the values of a variable at unmeasured points from nearby measurements. It was first developed for use in the mining industry and has subsequently found widespread use in geology and hydrology (where it is often called "geostatistics"). Nany references exist describing the theory and applications of kriging; ones relating to precipitation include Delfiner and Delhomme (1975), Chua and Bras (1982), Creutin and obled (1982), Bastin et al. (1984), Bastin and Gevers (1985), Lebel et al. (1987), Lebel and Laborde (1988), and Dingman et al. (1988). Textbook descriptions of kriging appear in Bras and Rodriguez-Iturbe (1985), 
McCuen and Snyder (1986), and Journel (1989). Appendix B summarizes the aspects of kriging theory relevant to this work.

The precipitation estimates from kriging as well as the other techniques are obtained from a weighted sum of measurements at a number of stations in or near the watershed. The methods differ in how the weights are determined. Kriging is an optimal estimator in that the spatial correlation structure is explicitly modeled through the variogram, and the weights on the measurements are derived so as to give minimum variance in the estimate. Kriging was used here, as it is objective, statistically rigorous, and performs as well as or better than other estimation techniques (Tabios and Salas 1985).

In mountainous areas, orographic effects complicate the estimation of MAP. Kriging requires a stationary field for estimation, that is, there must be no systematic trend or "drift" in the mean or variance of the process. This is not the case in mountainous areas, where precipitation generally increases with elevation. Chua and Bras (1982) give two methods for dealing with this nonstationarity. One uses a technique involving generalized covariances, and the other detrends the data before performing the kriging. The latter method was chosen here because it gave better results for Chua and Bras (1982), it was the method used by Dingman et al. (1988), and it is more straightforward.

Following Chua and Bras (1982) and Dingman et al. (1988), a linear precipitation-elevation relationship was used here. It appeared acceptable in the test basins used in this study, and without a denser data network than is available, it is difficult to justify a more complex relationship. Some evidence suggests, however, that other 
factors besides elevation need to be considered. Hanson (1982) found that separate linear relationships were required for sites on the windward and leeward sides of topographic barriers in a small research watershed in southwest Idaho. Again in Idaho, Winters et al. (1989) used a lifting index based on topography and prevailing wind direction to help describe spatial variability in average annual precipitation. Refining the relationship to detrend the precipitation field is worthy of future investigation.

The residuals from the above detrending procedure are the data used in the kriging algorithm. To perform kriging, the variogram must first be modeled. McCuen and snyder (1986) list several functional forms commonly used to model the variogram, including linear, exponential, and spherical. After examining many empirical variograms calculated from monthly precipitation in the basins used in this work, a linear variogram appeared to be adequate. Variograms that flatten out as the distance between stations increases are more commonly used le.g., Chua and Bras [1982] used a spherical variogram), although Karlinger and Skrivan (1981) used a linear variogram to describe mean annual precipitation in Montana and Hyoming.

A convenient property of a linear variogram is that the kriging weights are independent of the slope and intercept of the line. This is so because the coefficients in the kriging system of equations for two different linear variograms are simply linear functions of one another; this does not change the solution. Since the variogram is a function of distances between stations, the kriging weights can be obtained by using these distances themselves as the coefficients in the kriging system of 
equations. If there are no missing data at the precipitation stations, then the kriging weights can be calculated once for each point to be estimated, and this set of weights can be used for all months and years.

\section{MAP Procedure}

The calculation procedure adopted here follows that of Chua and Bras (1982), Bastin et al. (1984), and Bastin and Gevers (1985). First, latitudes, longitudes, and elevations are determined for the precipitation stations to be used and for a rectangular grid of points over the watershed of interest. Next, linear regression relationships between precipitation and elevation are calculated for each month of each year available. Separate relationships for every month in the time series were used instead of average monthly relationships because wind directions and storm types may not always be the same for a given month across all years. This was confirmed in the test basins used in this study, where the slopes and intercepts varied greatly from year to year for a given month. This result was also found by Chua and Bras (1982), who encountered considerable storm-to-storm variability in the precipitation-elevation relationship. These linear trends are subtracted from the observed precipitation data, and the residuals are then available for kriging.

The kriging algorithm (Appendix B) is applied to estimate the precipitation residual at each grid point. Based on the elevations of the grid points, the linear trend is added to the kriged values to give the estimated precipitation of the grid points. The MAP is then 
calculated as the arithmetic average of the estimated precipitation at all the grid points.

MEAN AREAL TEMPERATURE

The estimation of mean areal temperature (MAT) is entirely analogous to the estimation of MAP. A linear temperature-elevation relationship is appropriate, and a linear variogram appears adequate. The same procedure for estimating MAP, then, was also used to estimate MAT .

POTENTIAL EVAPOTRANSPIRATION

Potential evapotranspiration is a highly complex phenomenon and depends on a number of factors such as temperature, relative humidity, wind, and solar radiation. There are many techniques for estimating potential evapotranspiration with varying data requirements. Reviews of these techniques are given by Jensen (1973) and Saxton and McGuinness (1982) .

For the monthly model used in this work, it was desired that the only input data required would be precipitation and temperature. This necessitated the use of an evapotranspiration method based solely on temperature, even though this is an acknowledged oversimplification. The most well-known such method is that used in the Thornthwaite-Mather model. This method was developed for areas in the eastern United States and is primarily a statistical, rather than a physically-based, model. Despite its generally recognized shortcomings, it is widely used and gives adequate results in many cases. This method was used by Shelton 
(1985) and is used in the SSARR model (U. S. Army Corps of Engineers 1987).

The Thornthwaite method calculates potential evapotranspiration as follows:

$$
\mathrm{PE}_{1}=1.6\left[\frac{10 \mathrm{~T}_{1}}{\mathrm{AHI}}\right]^{\mathrm{a}} \mathrm{ADJ}_{1}
$$

where $\mathrm{PE}_{1}(\mathrm{~cm} / \mathrm{mo})$ and $\mathrm{T}_{1}\left({ }^{\circ} \mathrm{C}\right)$ are, as previously, potential evapotranspiration and temperature for month $i$. AHI is the annual heat index, which is the sum of the twelve monthly heat indexes:

$$
I_{1}=\left[\frac{\overline{T_{1}}}{5}\right]^{1.514}
$$

where $I_{1}$ is the heat index for month $i$ and $\bar{T}_{1}\left({ }^{\circ} \mathrm{C}\right)$ is the long-term average temperature for month $i$. $I_{1}=0$ for $\bar{T}_{1} \leq 0$. The exponent a is calculated as:

$$
a=\left(6.751 \times 10^{-7}\right) I^{3}-\left(7.711 \times 10^{-5}\right) I^{2}+\left(1.792 \times 10^{-2}\right) I+0.492
$$

$A D J_{1}$ is an adjustment factor for month $i$, which accounts for the variation of sunshine duration with latitude. These values are tabulated in Thornthwaite and Mather (1957) and in U. S. Army Corps of Engineers (1987).

The adequacy of the Thornthwaite method for this work was tested by comparing the calculated values to pan evaporation at several sites in 
the general region of the test watersheds used. In the comparisons, a pan coefficient of 0.7 was used; this is a common value (Linsley et al. 1975). The results of these comparisons for selected years are shown in Figures 7 through 11. The Thornthwaite method corresponded very well with the pan data (times the coefficient) for Sandpoint, Hungry Horse, and Dillon. It gave values smaller than the pan data for Moscow and Arrowrock Dam. Sandpoint, Hungry Horse, and Dillon are all in cool, mountainous areas. This indicated that the Thornthwaite method was adequate for the monthly modeling in the test watersheds. The use of the method in warmer, drier, and lower elevation areas than these is a subject for future investigation.

\section{CALIBRATION}

Calibration is the process of estimating the values of model parameters. It is a non-trivial task and is crucial to the success of any modeling effort. Research since the mid-1960's has illuminated the need for automated, objective, optimal parameter estimation techniques instead of trial-and-error parameter adjustment and subjective assessments of goodness-of-fit. An automated calibration procedure requires a search algorithm and an objective function to optimize.

Several studies have tested the ability of both direct and gradient search algorithms to identify parameter values in hydrologic models (Ibbitt and O'Donnell 1971; Johnston and Pilgrim 1976; Pickup 1977; Gupta and Sorooshian 1985; Hendrickson et al. 1988). Most conclude that direct search algorithms are more robust and less susceptible to irregularities in the response surface than are gradient search 


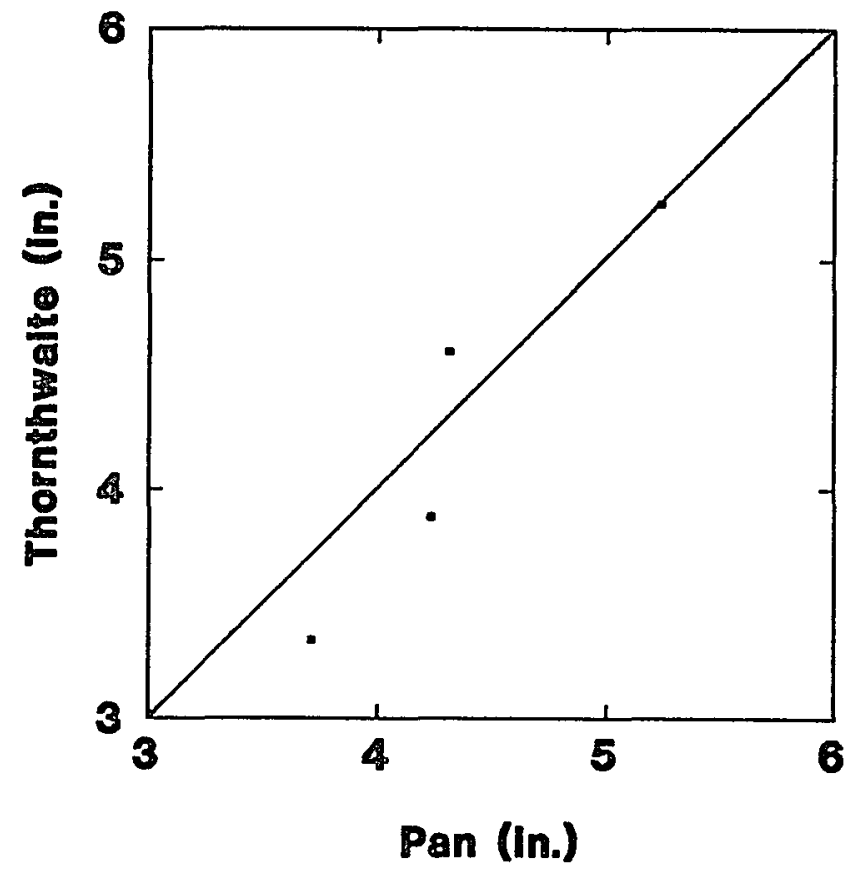

Figure 7. Thornthwaite vs. pan (times 0.7) evapotranspiration, Sandpoint, Idaho, 1990.

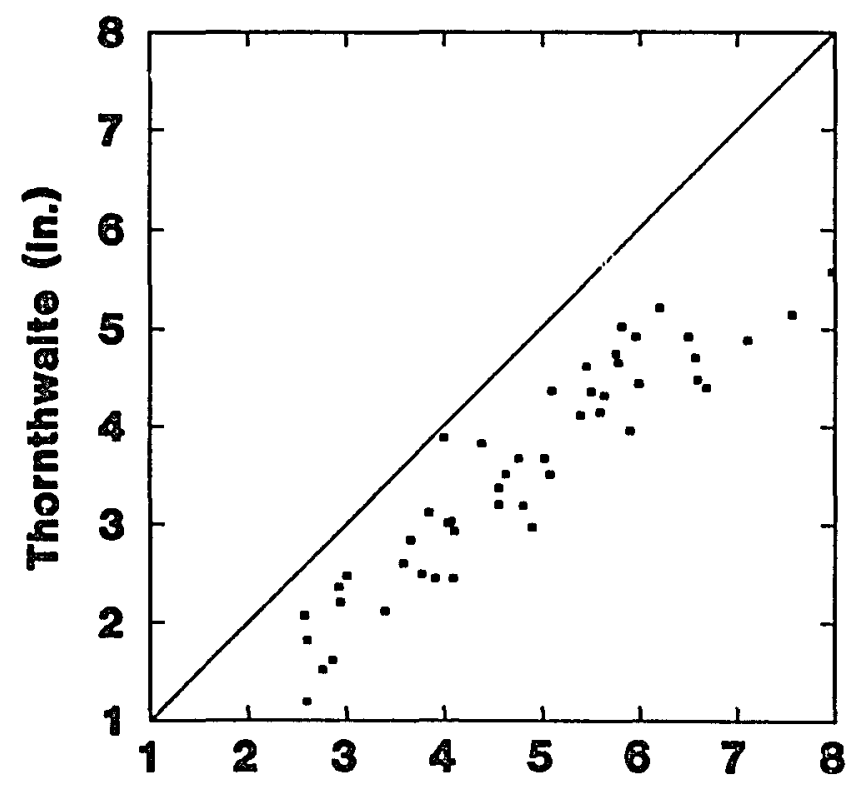

Pan (in.)

Figure 8. Thornthwaite vs. pan (times 0.7) evapotranspiration, Moscow, Idaho, 1983-1990. 


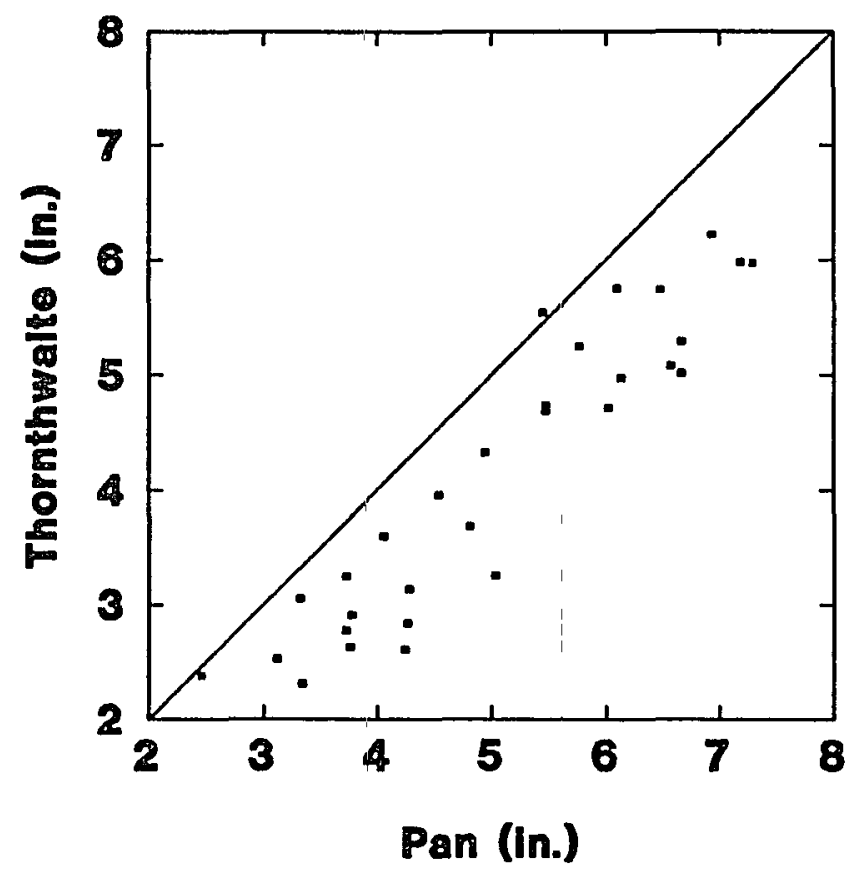

Figure 9. Thornthwaite vs. pan (times 0.7 )

evapotranspiration, Arrowrock Dam, Idaho, 1983-1990.

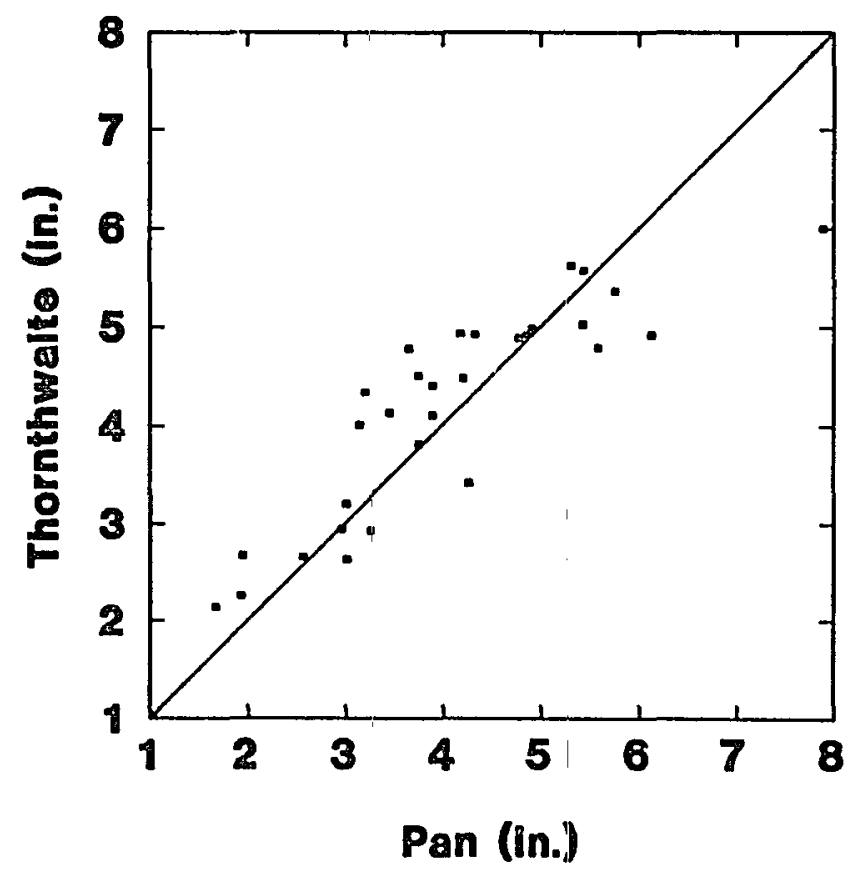

Figure 10. Thornthwaite vs, pan (times 0.7 )

evapotranspiration, Hungry Horse Dam, Montana, 1983-1990. 


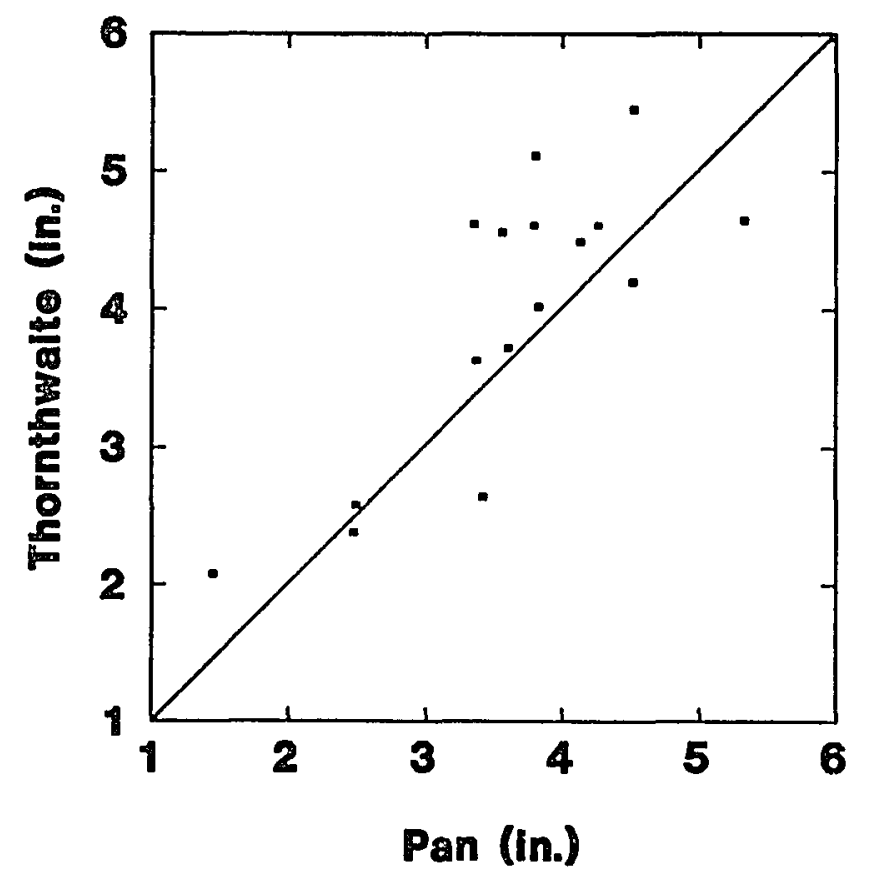

Figure 11. Thornthwaite vs. pan (times 0.7 ) evapotranspiration, Dillon, Montana, 1983-1986.

algorithms, which depend on derivatives. The most recent research on appropiriate objective functions has focused on ways to deal with error autocorrelation| and heteioscedasticity (Sorooshian and Dracup 1980; Sorooshian 1981; Sorooshian et al. 1982; Sorooshian et al. 1983; Troutman 1985).| Simple least squares, the most commonly used objective function, ignores these statistical properties of the errors. The problem, however, presents itself most in models with time steps of a day or less (Leavesley et al. 1983). In his work with monthly models, Alley (1984, 1985) often found significant, although low, autocorrelation in the errors and used an objective function based on a lag-1 autoregressive model for the differences between the logarithms of observed and calculated flows. He also admitted, however, that he 
obtained similar or better results when the error autocorrelation was assumed to be zero. For a monthly model, then, a strong case cannot be made that error autocorrelation is important, and simple least squares was used as the objective function for the monthly model developed in the present work.

Based on these research results, an automated search procedure was used to determine parameter values for the monthly model. The simplex method (not to be confused with linear programming) of Nelder and Mead (1965), a direct search procedure, was used to minimize the sum of squared differences between computed and observed monthly flows. Briefly, the method begins the search with an initial "simplex," that is, a geometrical figure in $\mathrm{M}$-dimensional parameter space defined by $\mathrm{N}+1$ points (vertices). In response to the value of the objective function at each vertex, the simplex undergoes changes in shape by expansions or contractions of the vertices. In this way, the simplex conforms itself to the objective function surface and moves its way toward the minimum. Press et al. (1988) liken its behavior to that of an amoeba. The rotating directions method of Rosenbrock (1960), another commonly used direct search procedure, was also tried initially, but it had more difficulty converging on a parameter set than the Nelder and Mead (1965) algorithm. All nine model parameters were fitted with this automatic calibration routine for the test basins used in this study.

\section{EXTENDED STREAMFLOW PREDICTION PROCEDURE}

In this work, the monthly model was calibrated using all available years of historical data within the calibration data sets being tested. 
Then, the Extended Streamflow Prediction (ESP) procedure (described in Chapter I) was used to simulate forecasts on the first of each month during January through June. The precipitation and temperature sequence for the year being forecast was excluded from the ESP analysis.

\section{RESULTS}

The monthly model was calibrated to the st. Joe River (Idaho), the Ruby River (Montana), and Lower Hillow Creek (Montana), as mentioned in the beginning of this chapter (see Table VII and Figure 3). Modeling was attempted but abandoned on a fourth basin, the Big Lost River in central Idaho, because mean areal precipitation values appeared unreasonably large. Most of the basin is on the lee side (considering the prevailing winter wind direction) of a mountain range, producing complex orographic effects. The linear precipitation-elevation relationship appears to be inadequate in this case. It also appears that the available data network is inadequate to describe the complex precipitation field.

The model parameter values are given in Table IX, and the data sites used for the three test basins are listed in Table X. For the Ruby River and Lower Willow Creek, the model was calibrated for three different time periods. The first calibration used all available years of data, the second covered a time period corresponding to previous conceptual modeling efforts, and the third covered a subset of years for a split sample calibration/verification test. Plots of observed vs. computed flows for the calibrations using all available years of data are given in Figures 12 through 14. In general, the simulations were 
TABLE IX

PARAMETER VALUES FOR MONTHLY MODEL

\begin{tabular}{l|l|l|l|l|l|l|l|l}
\hline S1MAX & S1E & $k_{2}$ & $k_{3}$ & $f_{2}$ & $f_{3}$ & $a$ & $b$ & $c$ \\
\hline
\end{tabular}

St. Joe River (1983-1990):

\begin{tabular}{l|l|l|l|l|l|l|l|l}
\hline 4.9 & 4.8 & 4.100 & 0.064 & 0.410 & 0.530 & 0.0563 & -0.0057 & 0.2332 \\
\hline
\end{tabular}

Ruby River (1972-1990):

\begin{tabular}{l|l|l|l|l|l|l|l|l}
\hline 4.7 & 4.2 & 4.100 & 0.060 & 0.810 & 0.640 & 0.1060 & -0.0010 & 0.1330 \\
\hline
\end{tabular}

Ruby River (1980-1986):

\begin{tabular}{l|l|l|l|l|l|l|l|l}
\hline 5.5 & 4.5 & 4.000 & 0.080 & 0.780 & 0.630 & 0.0969 & -0.0010 & 0.1980 \\
\hline
\end{tabular}

Ruby River (1972-1981):

\begin{tabular}{l|l|l|l|l|l|l|l|l}
\hline 4.1 & 4.1 & 4.180 & 0.056 & 0.820 & 0.660 & 0.1230 & -0.0010 & 0.0278 \\
\hline
\end{tabular}

Lower Hillow Creek (1968-1990):

\begin{tabular}{l|l|l|l|l|l|l|l|l}
\hline 10.3 & 6.7 & 3.590 & 0.017 & 0.580 & 0.480 & 0.1243 & -0.0010 & 0.1770 \\
\hline
\end{tabular}

Lower Willow Creek (1972-1978):

\begin{tabular}{l|l|l|l|l|l|l|l|l}
\hline 11.1 & 8.9 & 7.874 & 0.059 & 0.601 & 0.627 & 0.1006 & -0.0010 & 0.1635 \\
\hline
\end{tabular}

Lower Willow Creek (1968-1980):

\begin{tabular}{l|l|l|l|l|l|l|l|l}
\hline 10.6 & 7.6 & 3.620 & 0.025 & 0.566 & 0.588 & 0.1273 & -0.0010 & 0.1350 \\
\hline
\end{tabular}

quite satisfactory. Further model results and model intercomparisons are given in Chapter $v$. 
TABLE X

PRECIPITATION AND TEMPERATURE DATA SITES USED IN MONTHLY MODELING

\begin{tabular}{l|l|l|l}
\hline \multirow{2}{*}{ Basin } & \multicolumn{3}{|c}{ Data site } \\
\cline { 2 - 4 } & \multicolumn{1}{|c|}{ Name } & Number & Elev. \\
\hline St. Joe River & Saint Maries & 8062 & 2220 \\
& Lookout SNOTEL & $15 B 02 S$ & 5140 \\
& Hoodoo Basi S SNOTEL & $15 \mathrm{C10S}$ & 6050 \\
& Lost Lake SNOTEL & $15 \mathrm{~B} 14 \mathrm{~S}$ & 6110 \\
& & & \\
Ruby River & Virginia City & 8597 & 5773 \\
& Alder 17 S & 0110 & 5800 \\
& Divide SNOTEL & 12 E07S & 7800 \\
& Clover Meadow SNOTEL & $11 D 08 \mathrm{~S}$ & 8800 \\
Lower Willow & Drummond Aviation & 2500 & 3943 \\
Creek & Combination SNOTEL & $13 \mathrm{C33S}$ & 5600 \\
& Black Pine SNOTEL & $13 \mathrm{C13S}$ & 7210 \\
\hline
\end{tabular}

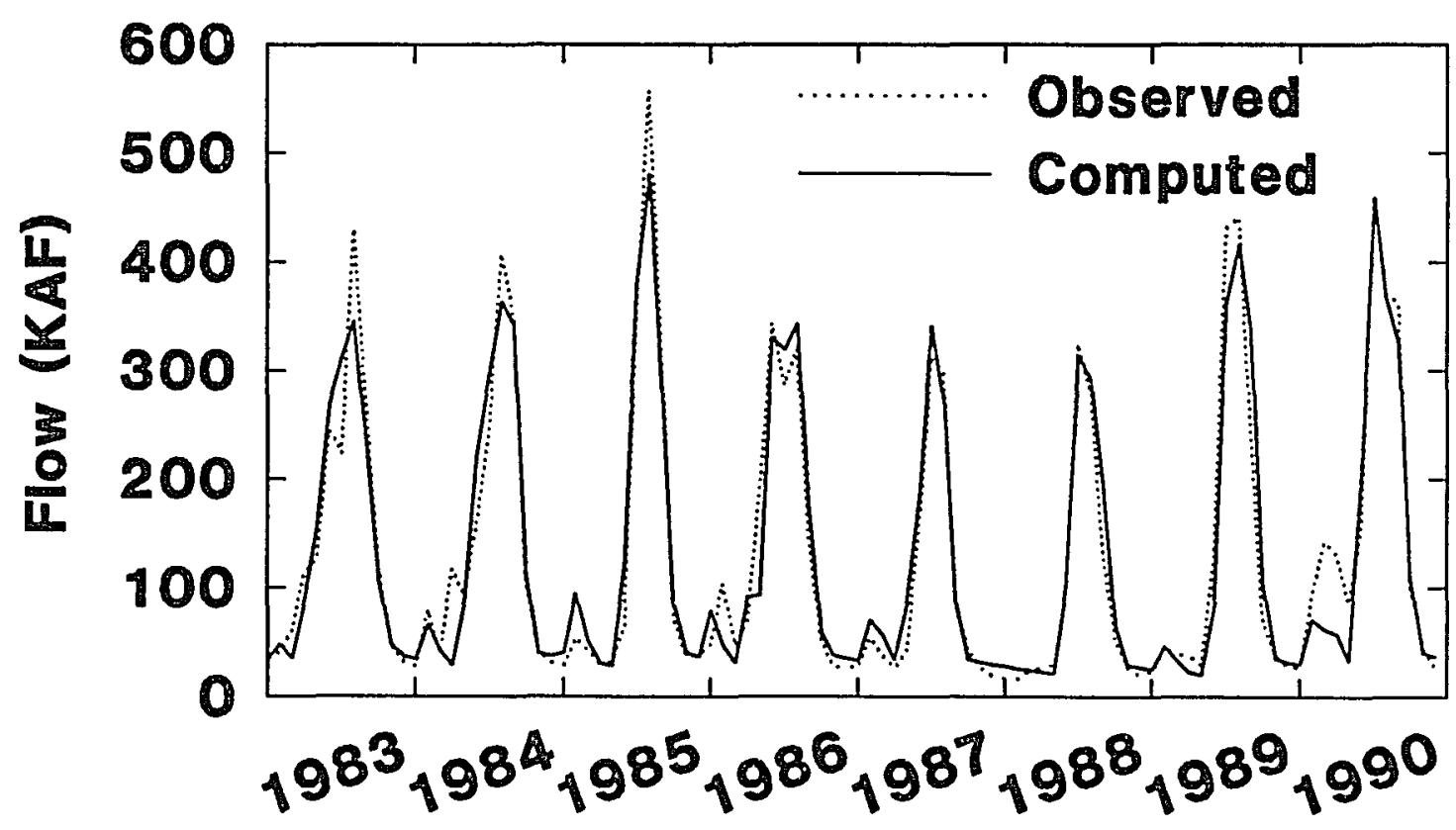

\section{Water year}

Figure 12. Observed and computed flows

from monthly streamflow model, st. Joe River. $\mathrm{KAF}=$ thousands of acre-feet. 


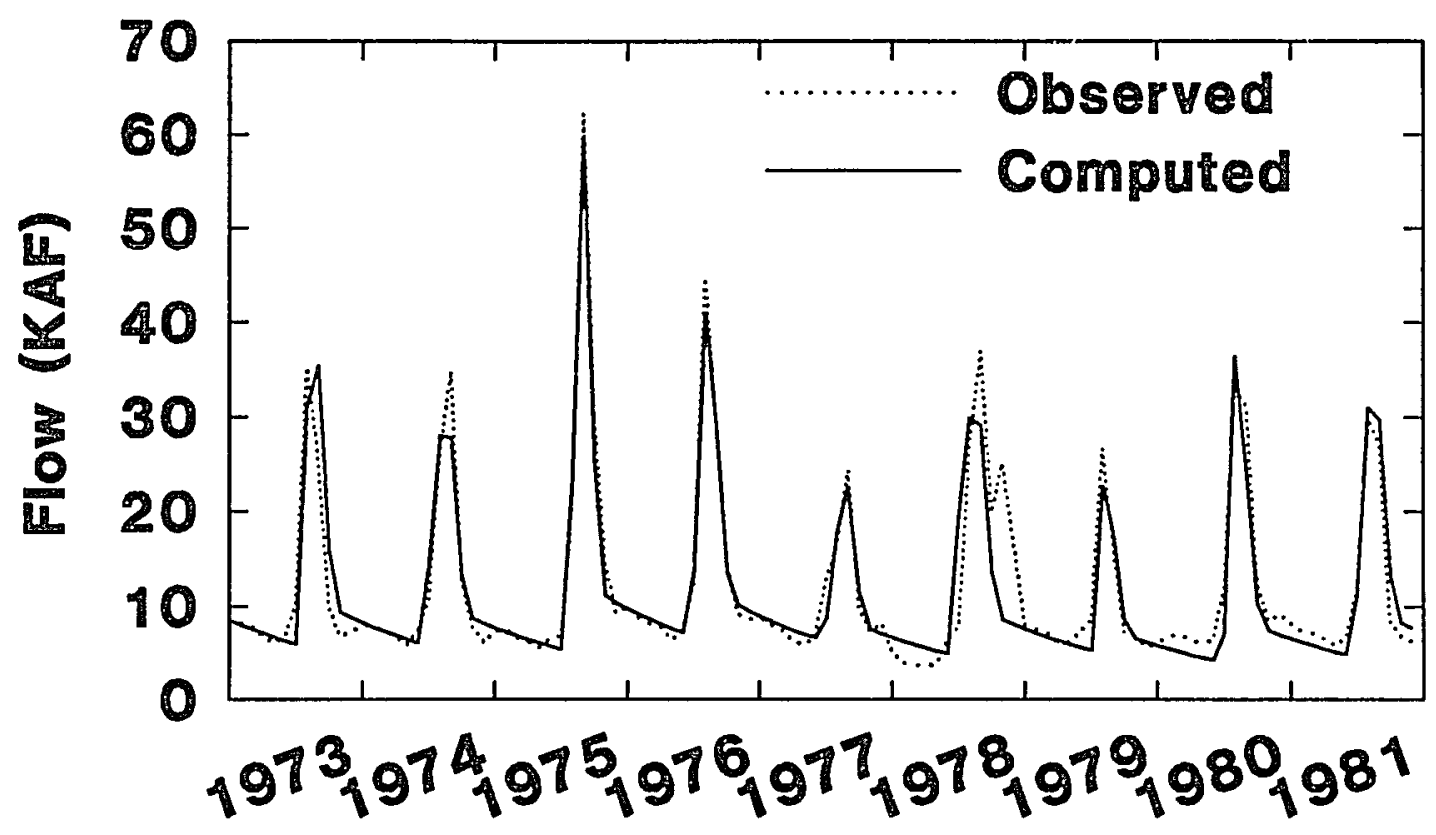

Water year

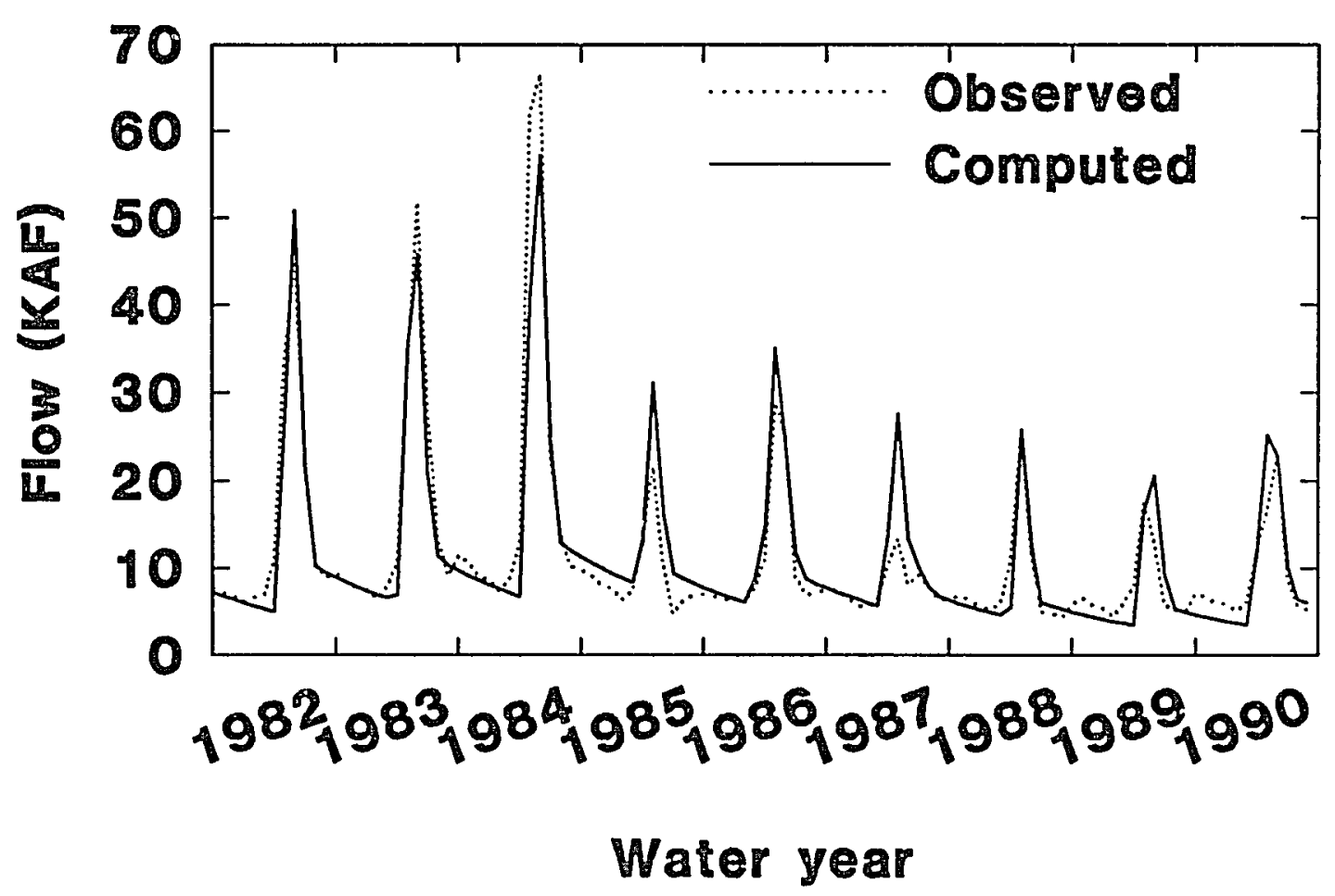

Figure 13. Observed and computed flows

from monthly streamflow model, Ruby River. $\mathrm{KAF}=$ thousands of acre-feet. 


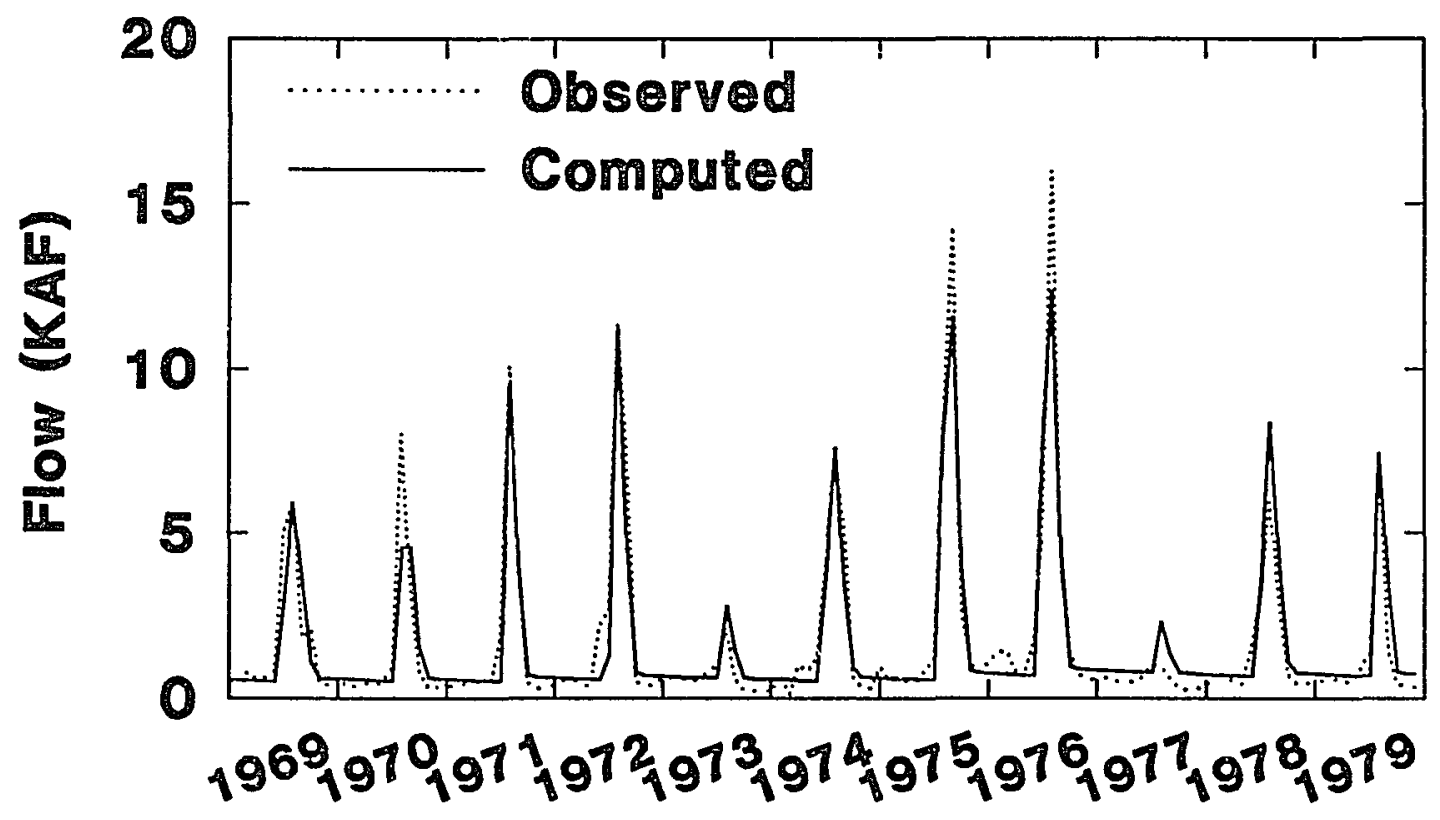

Water year

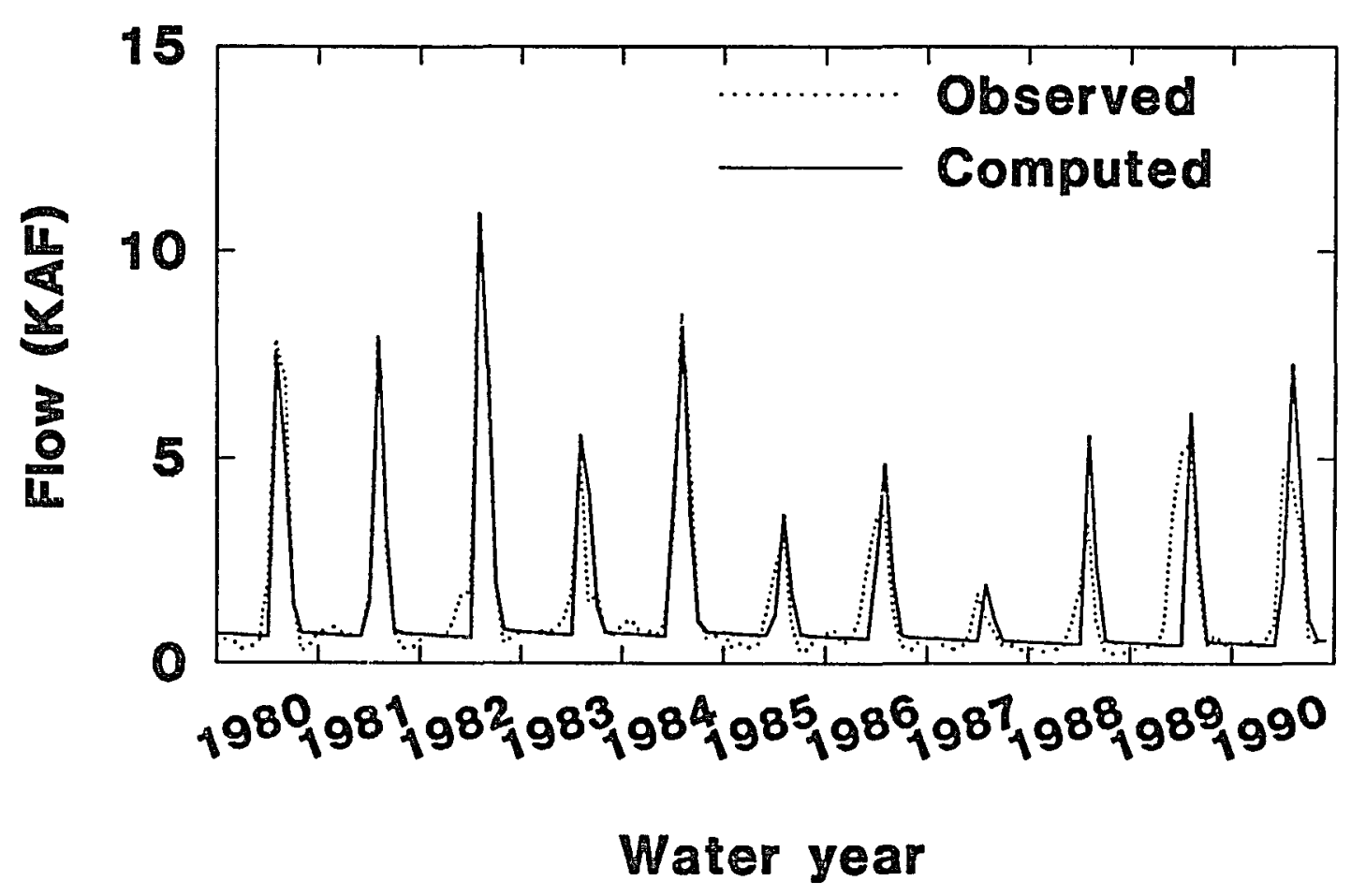

Figure 14. Observed and computed flows

from monthly streamflow model, Lower Willow Creek.

$\mathrm{KAF}=$ thousands of acre-feet. 
CHAPTER IV

CONCEPTUAL WATERSHED MODELING

INTRODUCTION

The intent in this study was not to develop another conceptual watershed model (numerous ones have already been developed) but rather to compare the simulation and forecasting ability of existing models with that of regression procedures and the monthly model developed here. Conceptual modeling results from previous studies were obtained for this purpose. These will be described below, and model comparisons will be presented in chapter $\mathrm{V}$.

The models from which results were obtained are the streamflow Synthesis and Reservoir Regulation (SSARR) model (U. S. Army Corps of Engineers 1987) and the National Weather Service River Forecast System (NWSRFS). Within the latter, the components used were the HYDRO-17 snow accumulation and melt model (Anderson 1968, 1973) and the Sacramento soil moisture accounting model (Burnash et al. 1973). Both SSARR and NWSRFS attempt to account, on a daily basis, for the major physical processes occurring in a watershed (see Chapter I), but there are differences in conceptualizations. SSARR is a bit more empirical, and it relies heavily on table look-up relationships to characterize the watershed. While this gives the freedom to specify any functional shape desired, it precludes the use of automatic calibration procedures, which 
require that the functional forms be specified and parameterized. NWSRFS is fully parameterized and does have automatic calibration capability, although the model structure can pose some calibration difficulties (Sorooshian and Gupta 1983; Gupta and Sorooshian 1983; Hendrickson et al. 1988). Diagrams of SSARR, HYDRO-17, and the Sacramento models are given in Figures 15,16 , and 17, respectively; these provide a general idea of the scope and complexity of these models.

ST. JOE RIVER

The SSARR model was calibrated to the St. Joe River at Calder watershed as part of a study sponsored by the Soil Conservation Service to develop and test a multisite stochastic climate generation scheme (Koch and Garen 1992). This scheme was designed to provide sequences of daily precipitation and temperature to be used instead of historical sequences in ESP-type forecasts. As the SSARR model has no automated parameter estimation capability, calibration was done by trial-and-error adjustment, judging the goodness-of-fit by visual inspection of plots of computed and observed daily flows. The study period was 1982-1990, the period length limited by the record of Soil Conservation Service SNOTEL sites. The data sites used were the same as those used in the monthly model (Chapter III). A plot of monthly computed and observed flows from the calibration is given in Figure 18.

The watershed was divided into five elevation zones $(2200-3650$, 3650-4350, 4350-4920, 4920-5570, and 5570-7000 feet), each containing roughly $20 \%$ of the drainage area. Model parameter values and table 


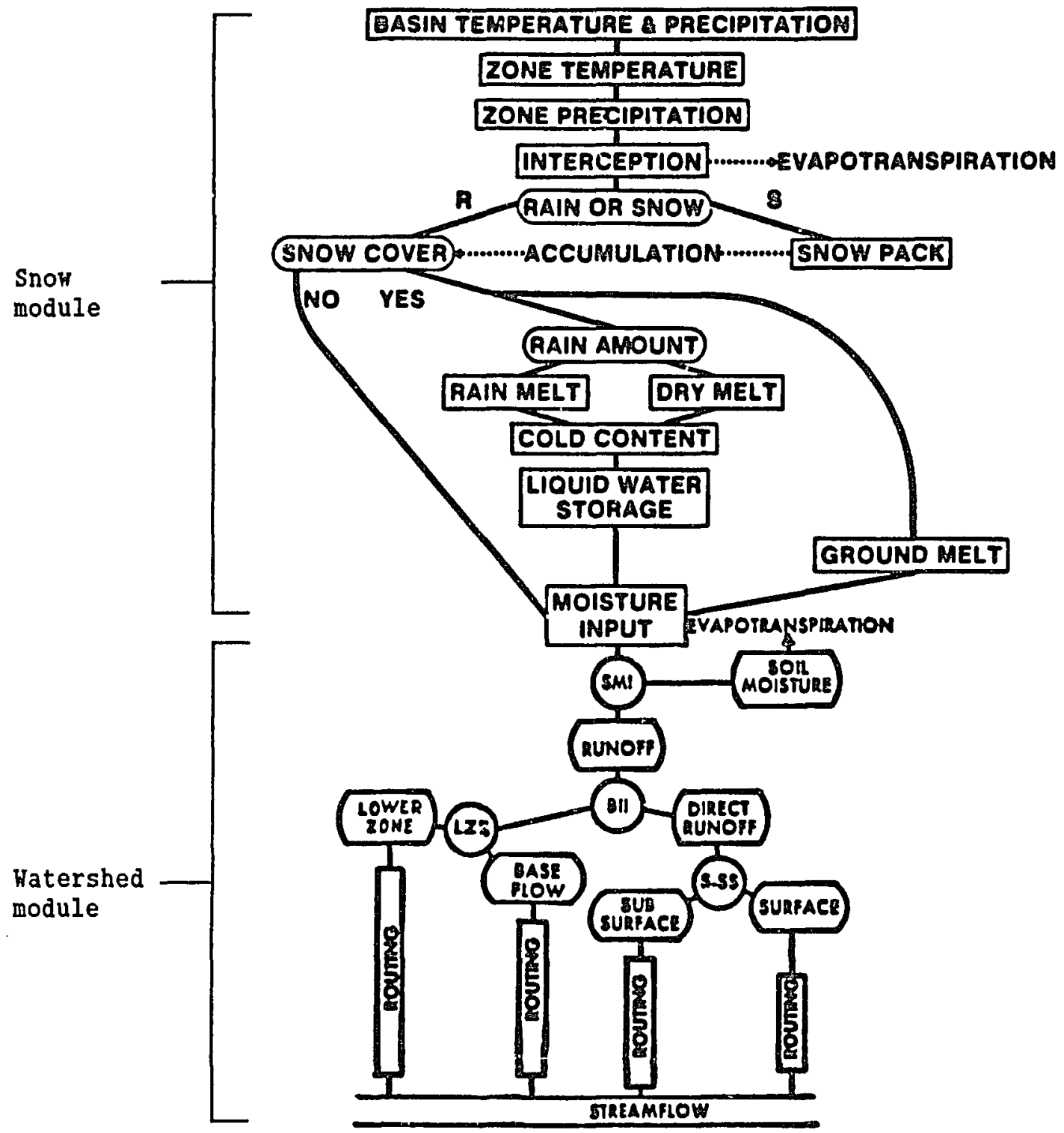

Figure 15. SSARR model flow chart.

Source: U. S. Arny Corps of Engineers (1987). 


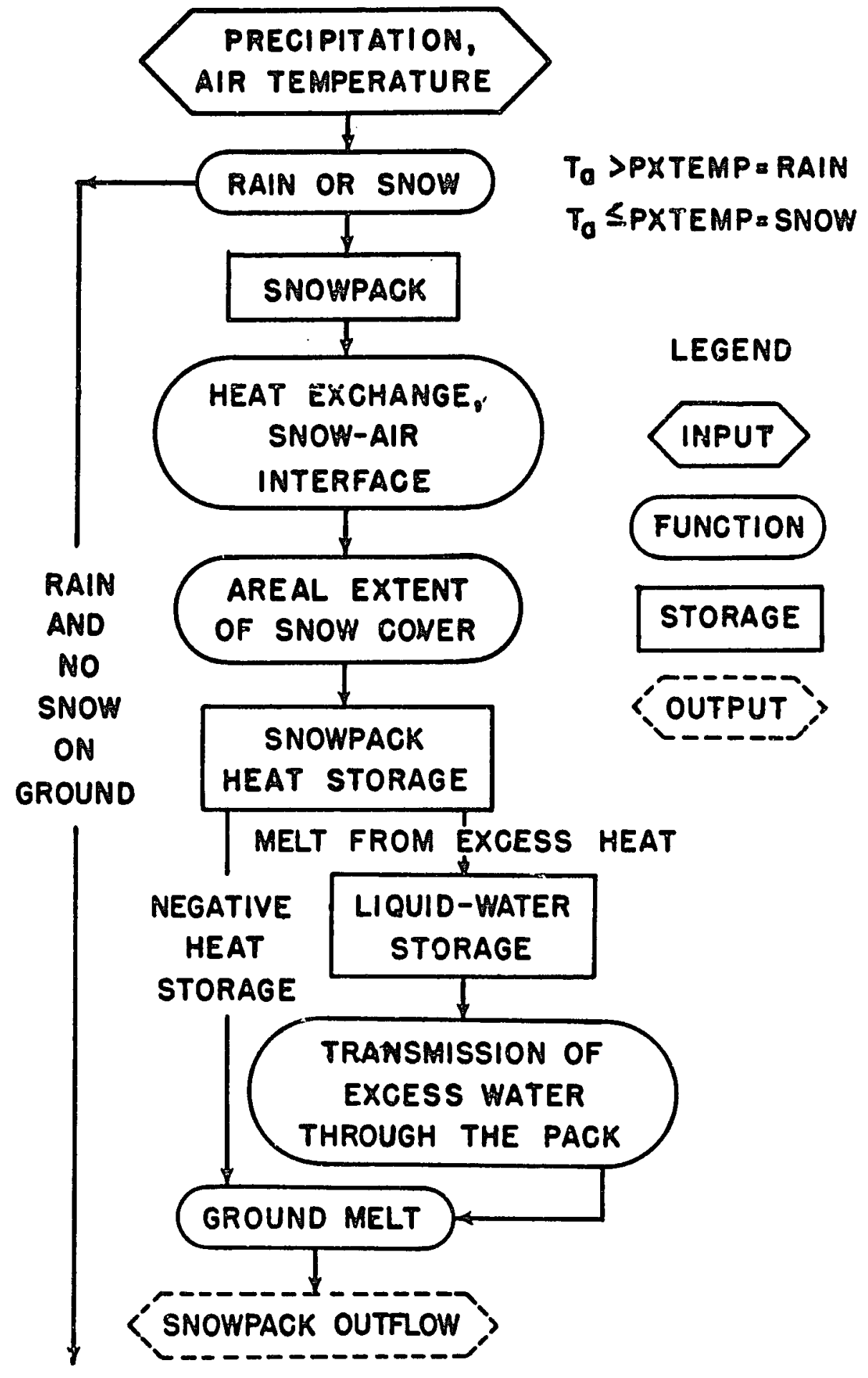

Figure 16. NWSRFS snow accumulation and melt model (HYDRO-17) flow chart. Source: Anderson (1973). 

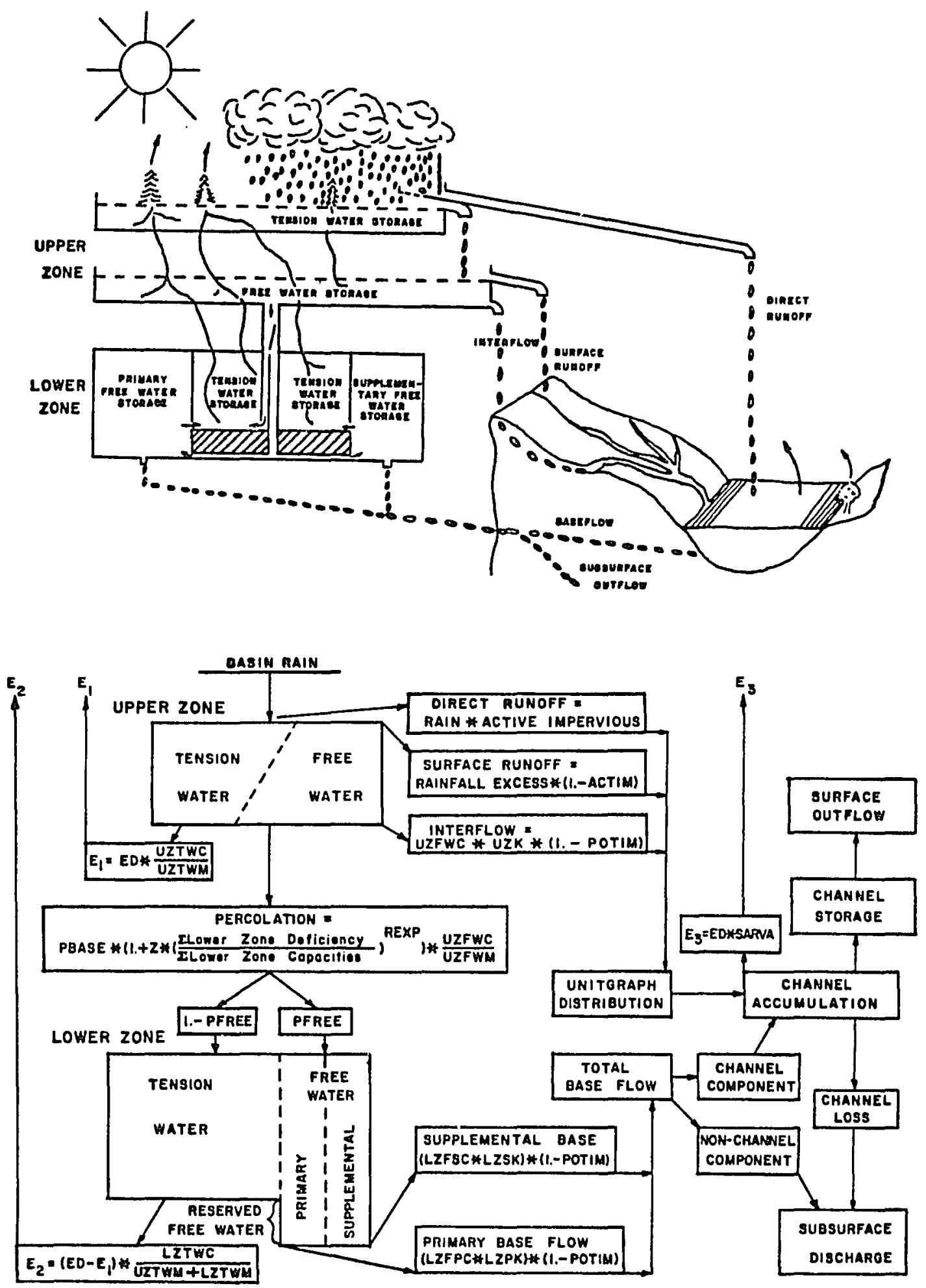

Figure 17. NHSRFS soil moisture accounting (Sacramento) model schematic and flow chart. Source: Burnash et al. (1973). 


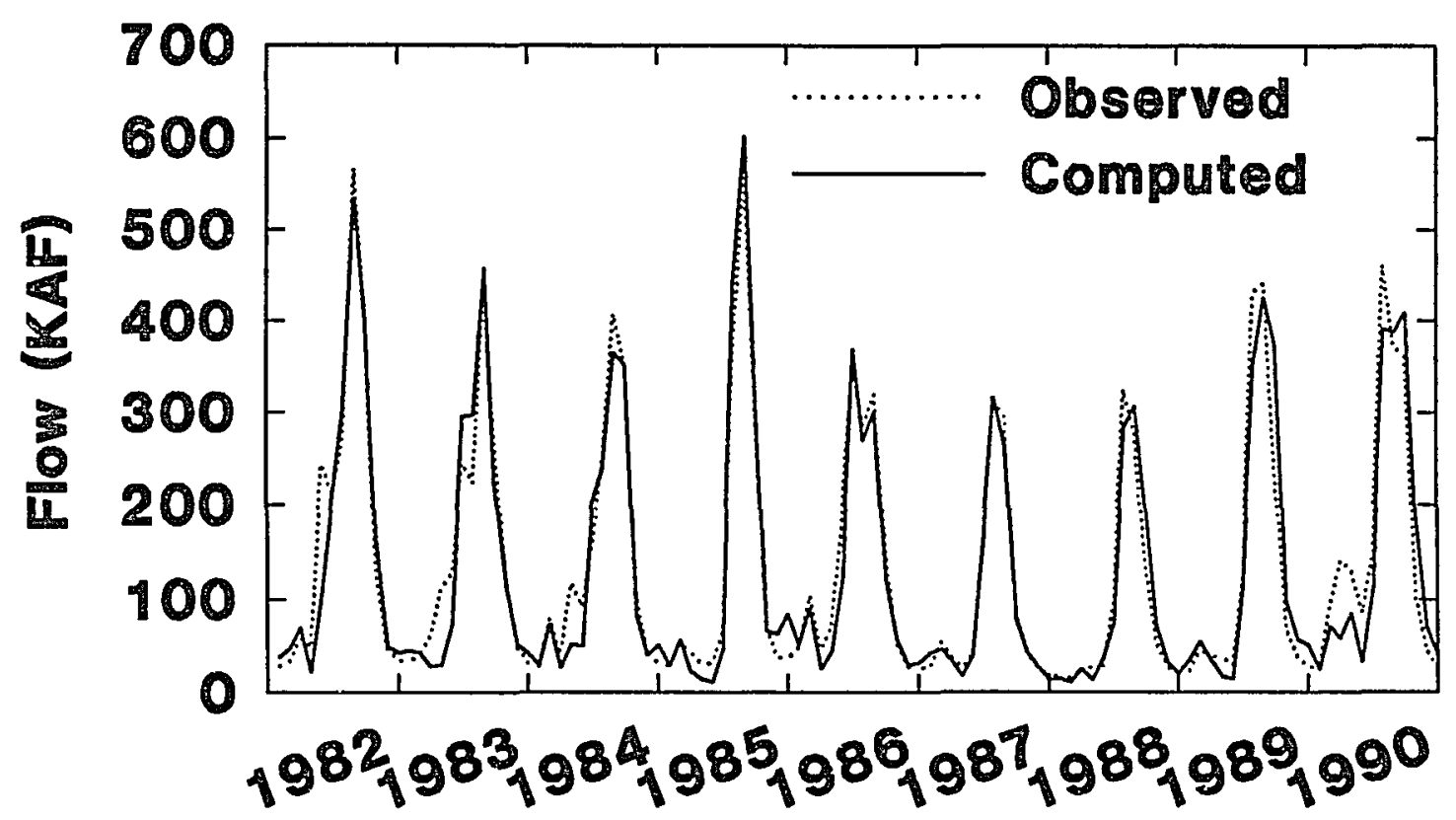

\section{Water yoar}

Figure 18. Observed and computed monthly flows from SSARR model calibration, St. Joe River. $\mathrm{KAF}=$ thousands of acre-feet.

relationships were the same for all five zones, with the exception of the temperature-evapotranspiration relationships. As these were based on the Thornthwaite method, they were dependent on long-term average monthly temperatures, which are elevation-dependent. Average monthly temperatures for the 1982-1990 period were calculated for each zone from the mean areal temperatures developed for model input (see below). These average temperatures allowed separate temperatureevapotranspiration relationships to be developed for each zone using the Thornthwaite method.

To obtain daily mean areal precipitation and temperature values for input to the SSARR model, the procedure for monthly data (Chapter III) 
had to be modified. With monthly data, the precipitation-elevation and temperature-elevation relationships were calculated separately for each individual month in the time series. It was felt that it would be undesirable to do this for each individual day in the time series, as the relationships would be susceptible to large fluctuations due to differensos in the observation times at the data sites, differences in data precision (Saint Maries precipitation is reported to the hundredths of an inch, SNOTEL data to the tenths), and randomness in precipitation that might cause the data sites not to represent the true spatial picture on any given day. Time aggregation can smooth out these fluctuations. To this end, precipitation and temperature data were aggregated into consecutive seven-day periods for calculation of their relationships with elevation. The same relationship was applied to all days within each period. Seven days was judged to be of sufficient length to provide stable precipitation-elevation and temperatureelevation relationships but still preserve the time-dependent and stormdependent variations in these relationships. The use of mean areal precipitation and temperature inputs calculated in this way represents a new and non-traditional facet to this otherwise standard-practice modeling effort.

\section{RUBY RIVER}

In support of improving the operation of Ruby Reservoir, the Ruby River was modeled by the Agricultural Research Service using SSARR. Computed monthly flows were obtained for the period 1980-1986 (K. Cooley, unpublished data). Although fer details about the modeling 
effort were readily available, these data were accepted as being representative of the kind of results typically obtained พith a traditional application of a conceptual watershed model. A plot of computed and observed monthly flows is given in Figure 19.

\section{LOWER WILLOW CREEK}

Lower Hillow Creek was the site of a study conducted by the Agricultural Research Service to test the usefulness of a conceptual watershed model for streamflow forecasting and to explore the use of SNOTEL data in watershed modeling (Cooley 1986a,b). The National Weather Service River Forecast System (NWSRFS) model was used. The model was calibrated on the period 1973-1978 and was tested on the period 1979-1984. This again represents a traditional application of a conceptual model. A plot of computed and observed monthly flows from both the calibration and test periods is given in Figure 20 . 


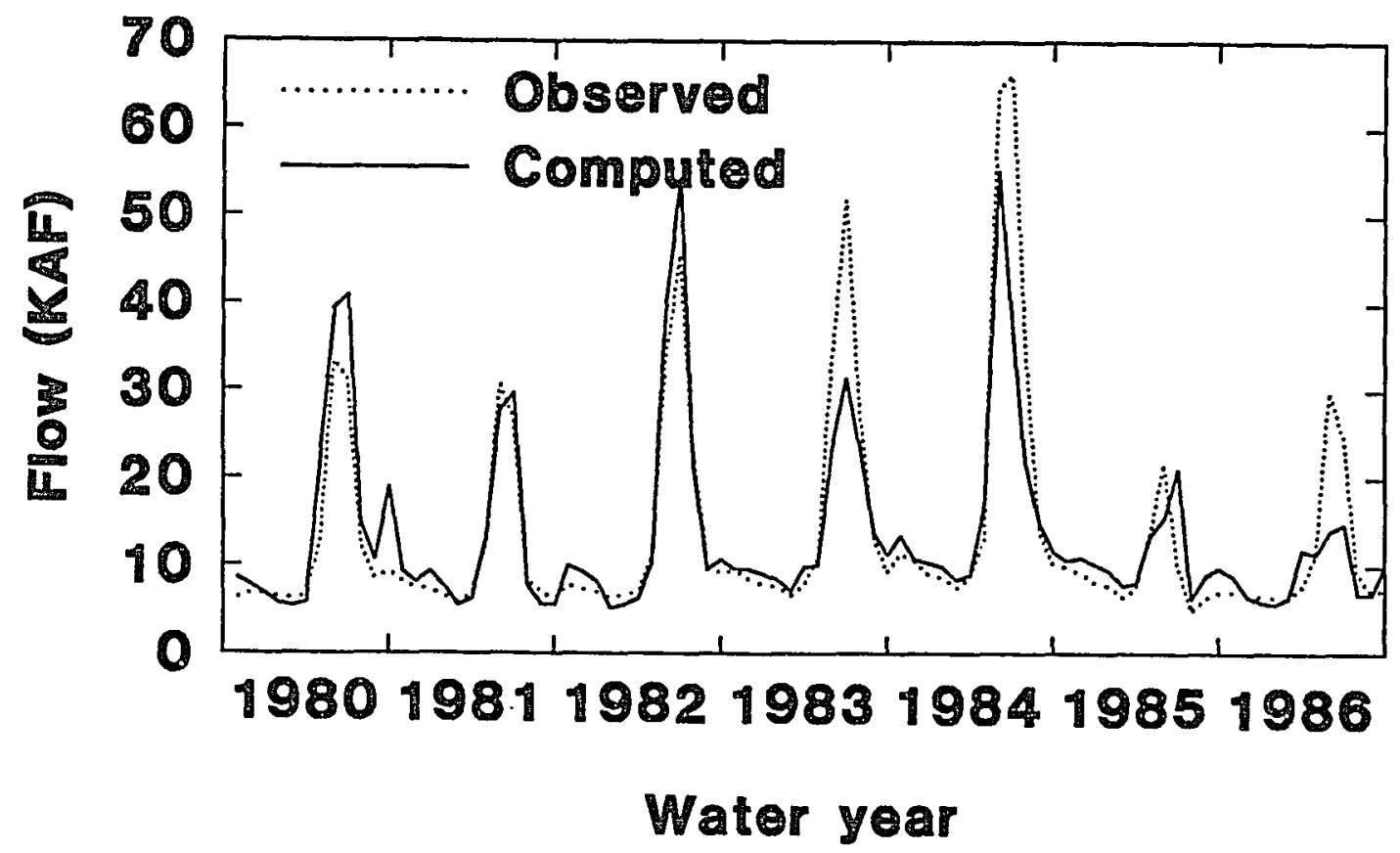

Figure 19. Observed and computed monthly flows from SSARR model calibration, Ruby River. $\mathrm{KAF}=$ thousands of acre-feet.

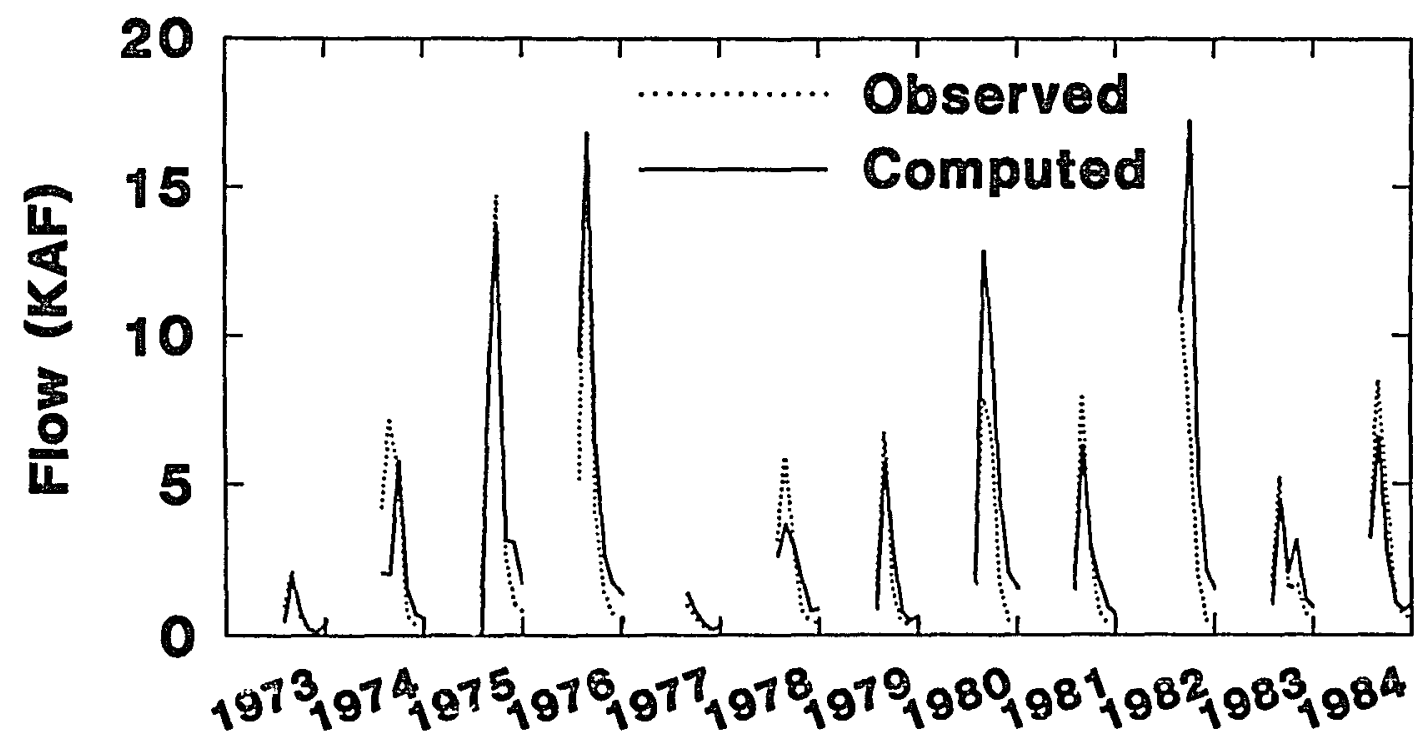

\section{Water year}

Figure 20. Observed and computed monthly flows from NHSRFS model calibration and test, Lower Hillow Creek. KAF = thousands of acre-feet. 


\section{CHAPTER V}

\section{MODELING AND FORECASTING RESULTS}

\section{INTRODUCTION}

Results from regression, the monthly model, and conceptual watershed models are compared below for the three test basins. Both the ability to reproduce observed flows during the calibration period and the ability to forecast are evaluated. The mean absolute error is used as the comparison statistic. This is adequate to compare model results and avoids the problem of determining degrees of freedom, which is unclear for conceptual watershed models.

\section{ST. JOE RIVER}

Two types of comparisons were made to evaluate how well each of the three modeling techniques fared on the st. Joe River. The first is a comparison of the simulation errors from the final model calibrations for the SSARR and monthly models. The second is a comparison of Extended Streamflow Prediction (ESP) forecasts from the SSARR and monthly models with the residual errors from the development of the current Soil Conservation Service regression forecasting equations, which were developed using the techniques described in Chapter II. While the first test is informative, the second test is more telling 
here: it does not matter so much if a model can simulate well when all input data are known if it cannot forecast well.

The ESP forecast for a given forecast date was produced by running the model from the forecast date through the end of september with each available historical precipitation and temperature sequence (1982-1990) except the year being forecast. The mean of the resultant streamflow sequences was the ESP forecast. So, for example, the February 1, 1989 ESP forecast was produced by first running the model through January 31 , 1989 and saving the values of the model state variables. Then, using these values as initial conditions, the model was run eight times using the historical data for the years 1982-1988 and 1990, and the mean of the streamflow sequences was calculated. This process was used to develop ESP forecasts for six forecast dates (first of the month for January-June) for each year of data available except 1982; this year was used in the monthly model as a "warm-up" period to help make the model results independent of the initial conditions.

The regression equations were calibrated on the period 1961-1990. As is often the case, data suitable for regression are available for a longer period than data suitaile for monthly or conceptual modeling. In these forecast comparisons, it was decided to allow regression to benefit from this extra information, because this is one advantage regression really does have.

The forecast test is not completely satisfactory in that in a real forecasting situation, the model will not have been calibrated using the year being forecast, as was the case in these tests. This, however, was the closest that one could expediently come to testing the forecasting 
ability of the three methods. As the regression equations contained no future variables (Chapter II), it was felt that the predictions from the calibration of the equations were on roughly equal footing with the ESP forecasts from the SSARR and monthly models.

The simulation results from the final calibrations of the SSARR and monthly models are given in Table XI. For all of the seasonal periods and most of the individual months, the monthly model had smaller errors than SSARR. If the SSARR model could have been optimized by an automatic calibration routine, however, it is possible that the mean errors would be closer to those of the monthly model.

Mean absolute errors for ESP forecasts and regression predictions of seasonal volumes are given in Table XII. In all months except January, the regression predictions were the most accurate of the three methods. The monthly model was superior to SSARR for all months except May, and performance was mixed for June.

To be able to compare monthly flows from the SSARR and monthly models with regression, a simple disaggregation of the regression predictions of seasonal volume was done. From the historical streamflow record, the average ratios of each month's flow to the seasonal volume were calculated; these are given in Table XIII. The seasonal volume was multiplied by each of the monthly fractions to arrive at monthly disaggregated flows. Although more complex disaggregation schemes have been used (Pei et al. 1988; Reese and Krzysztofowicz 1989), an almost identical approach was used by Krzysztofowicz and Reese (1989), and at this point in the investigation, nothing more complex was warranted. 
TABLE XI

MEAN ABSOLUTE ERRORS FROM CALIBRATION OF SSARR

AND MONTHLY MODEL, ST. JOE RIVER, 1983-1990

\begin{tabular}{l||r|r||r|r}
\hline \multicolumn{1}{l||}{ Period } & \multicolumn{2}{c||}{ SSARR } & \multicolumn{2}{c}{$\begin{array}{l}\text { Monthly } \\
\text { Model }\end{array}$} \\
\cline { 2 - 5 } \multicolumn{1}{l||}{} & KAF & \multicolumn{1}{c}{$\begin{array}{l}\text { \% of } \\
\text { avg. }\end{array}$} & KAF & $\begin{array}{l}\text { \% of } \\
\text { avg. }\end{array}$ \\
\hline Oct & 6.0 & 20 & 8.9 & 29 \\
Nov & 8.3 & 17 & 20.6 & 42 \\
Dec & 22.5 & 29 & 19.3 & 25 \\
Jan & 34.7 & 43 & 28.9 & 36 \\
Feb & 32.6 & 34 & 29.9 & 32 \\
Mar & 27.1 & 20 & 34.8 & 25 \\
Apr & 46.8 & 16 & 37.4 & 13 \\
May & 27.9 & 6 & 37.0 & 8 \\
Jun & 40.2 & 13 & 36.1 & 12 \\
Jul & 21.5 & 24 & 13.3 & 15 \\
Aug & 10.6 & 27 & 3.5 & 9 \\
Sep & 15.7 & 54 & 6.5 & 22 \\
& & & & \\
Apr-Jul & 68.1 & 6 & 45.0 & 4 \\
Apr-Sep & 87.6 & 7 & 47.9 & 4 \\
May-Jul & 75.4 & 9 & 72.4 & 8 \\
May-Sep & 91.4 & 10 & 71.7 & 8 \\
Jun-Jul & 59.0 & 15 & 42.0 & 11 \\
Jun-Sep & 74.2 & 16 & 44.6 & 10 \\
\hline
\end{tabular}

Notes: (1) $\mathrm{KAF}=$ thousands of acre-feet.

(2) Streamflow averages used are for the period 1961-1990.

Mean absolute errors for ESP forecasts and regression predictions of monthly flows are given in Table XIV. The disaggregated regression flows have smaller errors than either SSARR or the monthly model most of the time. The monthly model has smaller errors more of ten than SSARR, but it does not have an overwhelming advantage. 
TABLE XII

MEAN ABSOLUTE ERRORS FOR ESP AND REGRESSION FORECASTS, ST. JOE RIVER, 1983-1990 -- SEASONAL VOLUMES

\begin{tabular}{|c|c|c|c|c|c|c|c|}
\hline \multirow[t]{2}{*}{$\begin{array}{l}\text { Forecast } \\
\text { Month }\end{array}$} & \multirow[t]{2}{*}{$\begin{array}{c}\text { Forecast } \\
\text { Period }\end{array}$} & \multicolumn{2}{|c|}{ SSARR } & \multicolumn{2}{|c|}{$\begin{array}{l}\text { Monthly } \\
\text { Model }\end{array}$} & \multicolumn{2}{|c|}{ Regression } \\
\hline & & RAF & $\begin{array}{l}8 \text { of } \\
\text { avg. }\end{array}$ & $\mathrm{KAF}$ & $\begin{array}{l}\% \text { of } \\
\text { avg. }\end{array}$ & $\mathrm{KAF}$ & $\begin{array}{l}\% \text { of } \\
\text { avg. }\end{array}$ \\
\hline Jan & $\begin{array}{l}\text { Apr-Jul } \\
\text { Apr-Sep }\end{array}$ & $\begin{array}{l}203 \\
222\end{array}$ & $\begin{array}{l}17 \\
18\end{array}$ & $\begin{array}{l}171 \\
181\end{array}$ & $\begin{array}{l}15 \\
15\end{array}$ & $\begin{array}{l}187 \\
193\end{array}$ & $\begin{array}{l}16 \\
16\end{array}$ \\
\hline Feb & $\begin{array}{l}\text { Apr-Jul } \\
\text { Apr-Sep }\end{array}$ & $\begin{array}{l}120 \\
143\end{array}$ & $\begin{array}{l}10 \\
12\end{array}$ & $\begin{array}{l}120 \\
124\end{array}$ & $\begin{array}{l}10 \\
10\end{array}$ & $\begin{array}{l}88 \\
93\end{array}$ & $\begin{array}{l}8 \\
8\end{array}$ \\
\hline Mar & $\begin{array}{l}\text { Apr-Jul } \\
\text { Apr-Sep }\end{array}$ & $\begin{array}{l}134 \\
151\end{array}$ & $\begin{array}{l}11 \\
12\end{array}$ & $\begin{array}{l}106 \\
114\end{array}$ & $\begin{array}{l}9 \\
9\end{array}$ & $\begin{array}{l}78 \\
83\end{array}$ & $\begin{array}{l}7 \\
7\end{array}$ \\
\hline Apr & $\begin{array}{l}\text { Apr-Jul } \\
\text { Apr-Sep }\end{array}$ & $\begin{array}{l}119 \\
135\end{array}$ & $\begin{array}{l}10 \\
11\end{array}$ & $\begin{array}{r}98 \\
105\end{array}$ & $\begin{array}{l}8 \\
8\end{array}$ & $\begin{array}{l}75 \\
84\end{array}$ & $\begin{array}{l}6 \\
7\end{array}$ \\
\hline May & $\begin{array}{l}\text { May-Jul } \\
\text { May-Sep }\end{array}$ & $\begin{array}{r}95 \\
112\end{array}$ & $\begin{array}{l}11 \\
12\end{array}$ & $\begin{array}{l}109 \\
115\end{array}$ & $\begin{array}{l}12 \\
12\end{array}$ & $\begin{array}{l}63 \\
72\end{array}$ & $\begin{array}{l}7 \\
8\end{array}$ \\
\hline Jun & $\begin{array}{l}\text { Jun-Jul } \\
\text { Jun-Sep }\end{array}$ & $\begin{array}{l}69 \\
86\end{array}$ & $\begin{array}{l}17 \\
18\end{array}$ & $\begin{array}{l}73 \\
80\end{array}$ & $\begin{array}{l}18 \\
17\end{array}$ & $\begin{array}{l}34 \\
41\end{array}$ & $\begin{array}{l}9 \\
9\end{array}$ \\
\hline
\end{tabular}

Notes: (1) $\mathrm{KAF}=$ thousands of acre-feet.

(2) Streamflow averages used are for the period 1961-1990.

TABLE XIII

MONTHLY FRACTIONS FOR DISAGGREGATING SEASONAL VOLUMES INTO MONTHLY FLOHS, ST. JOE RIVER

\begin{tabular}{c|c|c|c|c|c|c}
\hline \multirow{2}{*}{ Period } & \multicolumn{6}{|c}{ Month } \\
\cline { 2 - 7 } & Apr & May & Jun & Jul & Aug & Sep \\
\hline Apr-Sep & 0.242 & 0.390 & 0.238 & 0.072 & 0.032 & 0.025 \\
May-Sep & & 0.518 & 0.311 & 0.094 & 0.043 & 0.034 \\
Jun-Sep & & & 0.641 & 0.196 & 0.091 & 0.071 \\
\hline
\end{tabular}


TABLE XIV

MEAN ABSOLUTE ERRORS FOR ESP AND REGRESSION FORECASTS, ST. JOE RIVER, 1983-1990 - MONTHLY FLOWS

\begin{tabular}{|c|c|c|c|c|c|c|c|}
\hline \multirow[t]{2}{*}{$\begin{array}{l}\text { Forecast } \\
\text { Month }\end{array}$} & \multirow[t]{2}{*}{$\begin{array}{l}\text { Forecast } \\
\text { Period }\end{array}$} & \multicolumn{2}{|c|}{ SSARR } & \multicolumn{2}{|c|}{$\begin{array}{l}\text { Monthly } \\
\text { Model }\end{array}$} & \multicolumn{2}{|c|}{$\begin{array}{l}\text { Regression } \\
\text { (disagg.) }\end{array}$} \\
\hline & & $\mathrm{KAF}$ & $\begin{array}{l}8 \text { of } \\
\text { avg. }\end{array}$ & $\mathrm{KAF}$ & $\mid \begin{array}{ll}\% & \text { of } \\
\text { avg. }\end{array}$ & KAF & $\begin{array}{l}8 \text { of } \\
\text { avg. }\end{array}$ \\
\hline Jan & $\begin{array}{l}\text { Jan } \\
\text { Feb } \\
\text { Mar } \\
\text { Apr } \\
\text { May } \\
\text { Jun } \\
\text { Jul } \\
\text { Aug } \\
\text { Sep }\end{array}$ & $\begin{array}{r}37.9 \\
41.3 \\
77.8 \\
92.5 \\
34.1 \\
102.1 \\
39.6 \\
13.7 \\
15.5\end{array}$ & $\begin{array}{r}47 \\
44 \\
56 \\
32 \\
7 \\
33 \\
44 \\
35 \\
53\end{array}$ & $\begin{array}{r}40.2 \\
47.2 \\
82.1 \\
82.2 \\
51.2 \\
84.8 \\
29.2 \\
7.3 \\
7.3\end{array}$ & $\begin{array}{l}50 \\
50 \\
59 \\
29 \\
11 \\
28 \\
33 \\
19 \\
25\end{array}$ & $\begin{array}{r}73.4 \\
79.0 \\
93.1 \\
31.2 \\
8.8 \\
4.3\end{array}$ & $\begin{array}{l}25 \\
16 \\
30 \\
35 \\
23 \\
15\end{array}$ \\
\hline Feb & $\begin{array}{l}\text { Feb } \\
\text { Mar } \\
\text { Apr } \\
\text { May } \\
\text { Jun } \\
\text { Jul } \\
\text { Aug } \\
\text { Sep }\end{array}$ & $\begin{array}{l}26.2 \\
81.0 \\
73.5 \\
49.9 \\
79.1 \\
30.0 \\
10.8 \\
14.7\end{array}$ & $\begin{array}{l}28 \\
58 \\
26 \\
10 \\
26 \\
34 \\
28 \\
50\end{array}$ & $\begin{array}{r}38.8 \\
80.0 \\
61.2 \\
55.5 \\
74.0 \\
26.3 \\
5.8 \\
7.1\end{array}$ & $\begin{array}{l}41 \\
58 \\
21 \\
11 \\
24 \\
29 \\
15 \\
24\end{array}$ & $\begin{array}{r}76.9 \\
62.4 \\
68.8 \\
22.7 \\
5.0 \\
4.4\end{array}$ & $\begin{array}{l}27 \\
13 \\
22 \\
25 \\
13 \\
15\end{array}$ \\
\hline Mar & $\begin{array}{l}\text { Mar } \\
\text { Apr } \\
\text { May } \\
\text { Jun } \\
\text { JuI } \\
\text { Aug } \\
\text { Sep }\end{array}$ & $\begin{array}{l}50.5 \\
82.0 \\
52.3 \\
72.8 \\
29.3 \\
10.1 \\
14.1\end{array}$ & $\begin{array}{l}36 \\
28 \\
11 \\
24 \\
33 \\
26 \\
48\end{array}$ & $\begin{array}{r}64.1 \\
64.6 \\
65.4 \\
72.8 \\
26.8 \\
5.8 \\
6.7\end{array}$ & $\begin{array}{l}46 \\
22 \\
14 \\
24 \\
30 \\
15 \\
23\end{array}$ & $\begin{array}{r}77.2 \\
54.1 \\
63.9 \\
21.8 \\
4.5 \\
3.7\end{array}$ & $\begin{array}{l}27 \\
11 \\
21 \\
24 \\
12 \\
13\end{array}$ \\
\hline Apr & $\begin{array}{l}\text { Apr } \\
\text { May } \\
\text { Jun } \\
\text { Jul } \\
\text { Aug } \\
\text { Sep }\end{array}$ & $\begin{array}{r}68.5 \\
54.7 \\
68.1 \\
26.2 \\
9.4 \\
13.6\end{array}$ & $\begin{array}{l}24 \\
11 \\
22 \\
29 \\
24 \\
46\end{array}$ & $\begin{array}{r}61.7 \\
54.2 \\
78.8 \\
29.2 \\
5.7 \\
6.8\end{array}$ & $\begin{array}{l}21 \\
11 \\
26 \\
33 \\
15 \\
23\end{array}$ & $\begin{array}{r}79.1 \\
52.6 \\
66.9 \\
22.2 \\
4.6 \\
4.5\end{array}$ & $\begin{array}{l}27 \\
11 \\
22 \\
25 \\
12 \\
15\end{array}$ \\
\hline May & $\begin{array}{l}\text { May } \\
\text { Jun } \\
\text { Jul } \\
\text { Aug } \\
\text { Sep }\end{array}$ & $\begin{array}{r}42.4 \\
43.9 \\
21.8 \\
9.2 \\
12.8\end{array}$ & $\begin{array}{r}9 \\
14 \\
24 \\
24 \\
44\end{array}$ & $\begin{array}{r}53.0 \\
67.2 \\
25.2 \\
5.5 \\
6.5\end{array}$ & $\begin{array}{l}11 \\
22 \\
28 \\
14 \\
22\end{array}$ & $\begin{array}{r}32.4 \\
54.9 \\
18.8 \\
4.8 \\
2.5\end{array}$ & $\begin{array}{r}7 \\
18 \\
21 \\
12 \\
9\end{array}$ \\
\hline
\end{tabular}


TABLE XIV

MEAN ABSOLUTE ERRORS FOR ESP AND REGRESSION FORECASTS, ST. JOE RIVER, 1983-1990 -- MONTHLY FLOHS (continued)

\begin{tabular}{|c|c|c|c|c|c|c|c|}
\hline \multirow[t]{2}{*}{$\begin{array}{l}\text { Forecast } \\
\text { Month }\end{array}$} & \multirow[t]{2}{*}{$\begin{array}{c}\text { Forecast } \\
\text { Period }\end{array}$} & \multicolumn{2}{|c|}{ SSARR } & \multicolumn{2}{|c|}{$\begin{array}{l}\text { Monthly } \\
\text { Model }\end{array}$} & \multicolumn{2}{|c|}{$\begin{array}{c}\text { Regression } \\
\text { (disagg.) }\end{array}$} \\
\hline & & $\mathrm{KAF}$ & $\begin{array}{l}\% \text { of } \\
\text { avg. }\end{array}$ & $\mathrm{KAF}$ & $\left|\begin{array}{ll}8 & \text { of } \\
\text { avg. }\end{array}\right|$ & $\mathrm{KAF}$ & $\begin{array}{l}\% \text { of } \\
\text { avg. }\end{array}$ \\
\hline Jun & $\begin{array}{l}\text { Jun } \\
\text { JuI } \\
\text { Aug } \\
\text { Sep }\end{array}$ & $\begin{array}{l}53.1 \\
23.8 \\
10.1 \\
13.7\end{array}$ & $\begin{array}{l}17 \\
27 \\
26 \\
47\end{array}$ & $\begin{array}{r}55.7 \\
22.0 \\
5.1 \\
6.7\end{array}$ & $\begin{array}{l}18 \\
25 \\
13 \\
23\end{array}$ & $\begin{array}{r}40.3 \\
9.8 \\
3.5 \\
4.1\end{array}$ & $\begin{array}{r}13 \\
11 \\
9 \\
14\end{array}$ \\
\hline
\end{tabular}

Notes: (1) KA.F = thousands of acre-feet.

(2) Streamflow averages used are for the period 1961-1990.

RUBY RIVER

The first test for the Ruby River was to compare calibration errors for SSARR and the monthly model for the period 1980-1986. Computed flows for the SSARR model were obtained from the modeling effort by the Agricultural Research Service (Chapter IV). The mean absolute errors for the two models are given in Table XV. The SSARR results had rather large errors in 1983 and 1984, so mean absolute errors were also calculated for the five year period excluding these two years. In both cases, the monthly model had smaller errors than SSARR for all seasons and almost all months.

The second test compared the monthly model ESP forecast errors with the errors from regression, the latter obtained from the development of the current forecasting equations (calibration period 1961-1989). Regression predictions in May for the May-July and May-September seasons 
TABLE XV

MEAN ABSOLUTE ERRORS FROM CALIBRATION OF SSARR AND MONTHLY MODEL, RUBY RIVER, 1980-1986

\begin{tabular}{|c|c|c|c|c|c|c|c|c|}
\hline \multirow[t]{3}{*}{ Period } & \multicolumn{4}{|c|}{$1980-1986$} & \multicolumn{4}{|c|}{$\begin{array}{l}\text { Excluding } \\
1983 \text { and } 1984\end{array}$} \\
\hline & \multicolumn{2}{|c|}{ SSARR } & \multicolumn{2}{|c|}{$\begin{array}{c}\text { Monthly } \\
\text { Model }\end{array}$} & \multicolumn{2}{|c|}{ SSARR } & \multicolumn{2}{|c|}{$\begin{array}{c}\text { Monthly } \\
\text { Model }\end{array}$} \\
\hline & KAF & $\mid \begin{array}{ll}\gamma & \text { of } \\
\text { avg. }\end{array}$ & $\mathrm{KAF}$ & $\begin{array}{l}8 \text { of } \\
\text { avg. }\end{array}$ & $\mathrm{KAF}$ & $\begin{array}{l}\% \text { of } \\
\text { avg. }\end{array}$ & $\mathrm{KAF}$ & $\begin{array}{l}8 \text { of } \\
\text { avg. }\end{array}$ \\
\hline $\begin{array}{l}\text { Oct } \\
\text { Nov } \\
\text { Dec } \\
\text { Jan } \\
\text { Feb } \\
\text { Mar } \\
\text { Apr } \\
\text { May } \\
\text { Jun } \\
\text { Jul } \\
\text { Aug } \\
\text { Sep }\end{array}$ & $\begin{array}{r}1.48 \\
0.98 \\
1.27 \\
1.08 \\
0.74 \\
1.23 \\
2.24 \\
8.11 \\
12.83 \\
3.78 \\
1.22 \\
2.99\end{array}$ & $\begin{array}{l}19 \\
13 \\
18 \\
17 \\
12 \\
18 \\
22 \\
29 \\
41 \\
28 \\
14 \\
39\end{array}$ & $\begin{array}{l}0.89 \\
0.82 \\
0.90 \\
0.90 \\
0.98 \\
1.57 \\
3.67 \\
7.64 \\
5.12 \\
3.09 \\
1.07 \\
1.21\end{array}$ & $\begin{array}{l}12 \\
11 \\
13 \\
14 \\
16 \\
23 \\
36 \\
27 \\
16 \\
23 \\
12 \\
16\end{array}$ & $\begin{array}{l}1.64 \\
1.12 \\
1.27 \\
1.11 \\
0.74 \\
1.31 \\
2.19 \\
7.39 \\
8.33 \\
1.78 \\
1.42 \\
3.50\end{array}$ & $\begin{array}{l}21 \\
15 \\
18 \\
17 \\
12 \\
19 \\
21 \\
26 \\
27 \\
13 \\
16 \\
46\end{array}$ & $\begin{array}{l}0.81 \\
0.80 \\
1.09 \\
0.95 \\
1.29 \\
1.38 \\
3.85 \\
6.47 \\
4.92 \\
2.56 \\
1.13 \\
1.00\end{array}$ & $\begin{array}{l}10 \\
11 \\
16 \\
15 \\
22 \\
20 \\
38 \\
23 \\
16 \\
19 \\
13 \\
13\end{array}$ \\
\hline $\begin{array}{l}\text { Apr-Jul } \\
\text { Apr-Sep } \\
\text { May-Jul } \\
\text { May-Sep } \\
\text { Jun-Jul } \\
\text { Jun-Sep }\end{array}$ & $\begin{array}{l}22.16 \\
23.92 \\
21.61 \\
23.37 \\
15.82 \\
17.00\end{array}$ & $\begin{array}{l}27 \\
24 \\
30 \\
26 \\
35 \\
28\end{array}$ & $\begin{array}{r}11.24 \\
12.35 \\
10.64 \\
11.41 \\
7.10 \\
8.40\end{array}$ & $\begin{array}{l}14 \\
12 \\
15 \\
13 \\
16 \\
14\end{array}$ & $\begin{array}{r}14.56 \\
18.00 \\
13.13 \\
16.57 \\
9.00 \\
11.63\end{array}$ & $\begin{array}{l}18 \\
18 \\
18 \\
19 \\
20 \\
19\end{array}$ & $\begin{array}{r}10.37 \\
12.25 \\
9.94 \\
11.35 \\
7.03 \\
9.16\end{array}$ & $\begin{array}{l}12 \\
12 \\
14 \\
13 \\
16 \\
15\end{array}$ \\
\hline
\end{tabular}

Notes: (1) $\mathrm{KAF}=$ thousands of acre-feet.

(2) Streamflow averages used are for the period 1961-1990.

and in June for the June-July and June-September seasons were unavailable, so comparisons were made only for the April-July and AprilSeptember seasons forecast in January through April. The results for seasonal volumes are given in Table XVI. The seasonal volumes from regression were disaggregated into monthly flows lising the same simple fractioning scheme as used for the St. Joe River. The monthly fractions 
TABLE XVI

MEAN ABSOLUTE ERRORS FOR MONTHLY MODEL ESP AND REGRESSION FORECASTS, RUBY RIVER, 1973-1989 -- SEASONAL VOLUMES

\begin{tabular}{c||c||c|c|c|c}
\hline \multirow{2}{*}{$\begin{array}{c}\text { Forecast } \\
\text { Month }\end{array}$} & $\begin{array}{c}\text { Forecast } \\
\text { Period }\end{array}$ & \multicolumn{2}{|c|}{$\begin{array}{c}\text { Monthly } \\
\text { Model }\end{array}$} & \multicolumn{2}{c}{ Regression } \\
\cline { 3 - 6 } & & KAF & $\begin{array}{l}\text { \% of } \\
\text { avg. }\end{array}$ & KAF & $\begin{array}{l}\text { \% of } \\
\text { avg. }\end{array}$ \\
\hline \multirow{4}{*}{ Jan } & Apr-Jul & 22.3 & 27 & 16.4 & 20 \\
& Apr-Sep & 26.6 & 27 & 20.0 & 20 \\
& & & & & \\
Feb & Apr-Jul & 22.5 & 27 & 16.6 & 20 \\
& Apr-Sep & 26.0 & 26 & 20.3 & 21 \\
& & & & & \\
Mar & Apr-Jul & 22.3 & 27 & 15.7 & 16 \\
& Apr-Sep & 24.9 & 25 & 18.8 & 19 \\
Apr & Apr-Jul & 19.6 & 24 & 15.2 & 18 \\
& Apr-Sep & 23.1 & 23 & 18.2 & 18 \\
\hline
\end{tabular}

Notes: (1) $\mathrm{KAF}=$ thousands of acre-feet.

(2) Streamflow averages used are for the period 1961-1990.

TABLE XVII

MONTHLY FRACTIONS FOR DISAGGREGATING SEASONAL VOLUMES INTO MONTHLY FLOWS, RUBY RIVER

\begin{tabular}{c|c|c|c|c|c|c}
\hline \multirow{2}{*}{ Period } & \multicolumn{6}{|c|}{ Month } \\
\cline { 2 - 7 } & Apr & May & Jun & Ju1 & Aug & Sep \\
\hline Apr-Sep & 0.114 & 0.288 & 0.300 & 0.131 & 0.088 & 0.080 \\
\hline
\end{tabular}

are given in Table XVII, and a comparison of monthly mean absolute errors is given in Table XVIII. In almost all comparisons, errors from regression were smaller than those from the monthly model.

The third test compared the prediction errors of the monthly model and regression for a nine year period excluded from the calibration 
TABLE XVIII

MEAN ABSOLUTE ERRORS FOR MONTHLY MODEL ESP AND DISAGGREGATED REGRESSION FORECASTS, RUBY RIVER, 1973-1989 -- MONTHLY FLOWS

\begin{tabular}{|c|c|c|c|c|c|}
\hline \multirow[t]{2}{*}{$\begin{array}{l}\text { Forecast } \\
\text { Month }\end{array}$} & \multirow[t]{2}{*}{$\begin{array}{l}\text { Forecast } \\
\text { Period }\end{array}$} & \multicolumn{2}{|c|}{$\begin{array}{l}\text { Monthly } \\
\text { Model }\end{array}$} & \multicolumn{2}{|c|}{$\begin{array}{r}\text { Regression } \\
\text { (disagg.) }\end{array}$} \\
\hline & & $\mathrm{KAF}$ & $\left|\begin{array}{ll}8 & \text { of } \\
\text { avg. }\end{array}\right|$ & $\mathrm{KAF}$ & $\begin{array}{l}8 \text { of } \\
\text { avg. }\end{array}$ \\
\hline Jan & $\begin{array}{l}\text { Apr } \\
\text { May } \\
\text { Jun } \\
\text { Jul } \\
\text { Aug } \\
\text { Sep }\end{array}$ & $\begin{array}{r}2.61 \\
7.63 \\
12.56 \\
6.26 \\
3.04 \\
1.93\end{array}$ & $\begin{array}{l}25 \\
27 \\
40 \\
46 \\
35 \\
25\end{array}$ & $\begin{array}{r}2.78 \\
6.18 \\
10.47 \\
4.96 \\
2.62 \\
1.80\end{array}$ & $\begin{array}{l}27 \\
22 \\
33 \\
37 \\
30 \\
24\end{array}$ \\
\hline Feb & $\begin{array}{l}\text { Apr } \\
\text { May } \\
\text { Jun } \\
\text { Ju! } \\
\text { Aug } \\
\text { Sep }\end{array}$ & $\begin{array}{r}2.68 \\
7.99 \\
12.20 \\
6.13 \\
2.96 \\
1.84\end{array}$ & $\begin{array}{l}26 \\
29 \\
39 \\
45 \\
34 \\
24\end{array}$ & $\begin{array}{r}2.62 \\
6.34 \\
10.54 \\
4.94 \\
2.62 \\
1.71\end{array}$ & $\begin{array}{l}26 \\
23 \\
34 \\
36 \\
30 \\
22\end{array}$ \\
\hline Mar & $\begin{array}{l}\text { Apr } \\
\text { May } \\
\text { Jun } \\
\text { Jul } \\
\text { Aug } \\
\text { Sep }\end{array}$ & $\begin{array}{r}2.93 \\
8.32 \\
12.13 \\
5.92 \\
2.86 \\
1.79\end{array}$ & $\begin{array}{l}29 \\
30 \\
39 \\
44 \\
33 \\
24\end{array}$ & $\begin{array}{r}2.89 \\
6.03 \\
10.14 \\
4.81 \\
2.53 \\
1.66\end{array}$ & $\begin{array}{l}28 \\
22 \\
32 \\
35 \\
29 \\
22\end{array}$ \\
\hline Apr & $\begin{array}{l}\text { Apr } \\
\text { May } \\
\text { Jun } \\
\text { JuI } \\
\text { Aug } \\
\text { Sep }\end{array}$ & $\begin{array}{r}3.16 \\
8.03 \\
11.32 \\
5.68 \\
2.76 \\
1.72\end{array}$ & $\begin{array}{l}31 \\
29 \\
36 \\
42 \\
32 \\
23\end{array}$ & $\begin{array}{l}3.12 \\
6.93 \\
9.60 \\
4.50 \\
2.43 \\
1.65\end{array}$ & $\begin{array}{l}30 \\
25 \\
31 \\
33 \\
28 \\
22\end{array}$ \\
\hline
\end{tabular}

Notes: (1) KAF = thousands of acre-feet.

(2) Streamflow averages used are for the period 1961-1990.

period. The monthly model was calibrated on the period 1972-1981, and the regression equations were calibrated both on the 1972-1981 and the 1961-1981 periods. The test period was 1982-1990. The second regression calibration was done because, as with the st. Joe River, data 
TABLE XIX

MEAN ABSOLUTE ERRORS FOR APRIL MONTHLY MODEL ESP AND REGRESSION FORECASTS, RUBY RIVER, 1982-1990 TEST PERIOD

\begin{tabular}{|c|c|c|c|c|c|c|}
\hline \multirow[t]{3}{*}{ Period } & \multirow{2}{*}{\multicolumn{2}{|c|}{$\begin{array}{c}\text { Monthly } \\
\text { Model }\end{array}$}} & \multicolumn{4}{|c|}{ Regression } \\
\hline & & & \multicolumn{2}{|c|}{$\begin{array}{c}1972-1981 \\
\text { calib. }\end{array}$} & \multicolumn{2}{|c|}{$\begin{array}{c}1961-1981 \\
\text { calib. }\end{array}$} \\
\hline & $\mathrm{KAF}$ & $\begin{array}{ll}8 & \text { of } \\
\text { avg. }\end{array}$ & $\mathrm{KAF}$ & $\mid \begin{array}{ll}8 & \text { of } \\
\text { avg. }\end{array}$ & KAF & $\begin{array}{l}8 \text { of } \\
\text { avg. }\end{array}$ \\
\hline $\begin{array}{l}\text { Apr } \\
\text { May } \\
\text { Jun } \\
\text { Jul } \\
\text { Aug } \\
\text { Sep }\end{array}$ & $\begin{array}{r}2.73 \\
8.41 \\
14.69 \\
6.66 \\
2.00 \\
1.13\end{array}$ & $\begin{array}{l}27 \\
30 \\
47 \\
49 \\
23 \\
15\end{array}$ & $\begin{array}{r}1.79 \\
7.84 \\
14.20 \\
6.19 \\
1.98 \\
1.08\end{array}$ & $\begin{array}{l}17 \\
28 \\
45 \\
46 \\
23 \\
14\end{array}$ & $\begin{array}{r}2.34 \\
7.20 \\
12.22 \\
5.27 \\
1.60 \\
0.86\end{array}$ & $\begin{array}{l}23 \\
26 \\
44 \\
39 \\
18 \\
11\end{array}$ \\
\hline $\begin{array}{l}\text { Apr-JuI } \\
\text { Apr-Sep }\end{array}$ & $\begin{array}{l}24.7 \\
27.7\end{array}$ & $\begin{array}{l}30 \\
28\end{array}$ & $\begin{array}{l}23.8 \\
28.4\end{array}$ & $\begin{array}{l}29 \\
29\end{array}$ & $\begin{array}{l}20.0 \\
22.8\end{array}$ & $\begin{array}{l}24 \\
23\end{array}$ \\
\hline
\end{tabular}

Notes: (1) $\mathrm{KAF}=$ thousands of acre-feet.

(2) Streamflow averages used are for the period 1961-1990.

suitable for regression were available for a longer period than for the monthly model, and this allowed the additional data to be used. The results of this split sample test for April forecasts are given in Table XIX. Except for the April-September period using the 1972-1981 calibration, regression errors are smaller than monthly model errors. The differences between the two are not large, however, for the 19721981 regression calibration. This would indicate that the basic mathematical technique of the monthly model has merit, and that it can perform almost on a par with regression when the two are put on an equal footing with respect to the calibration data available. 
LOWER WILLOW CREEK

The first test for Lower Willow Creek was to perform the same analysis with the monthly model as Cooley $(1986 a, b)$ did with the National Heather Service River Forecast System (NWSRFS) model. That is, the monthly model was calibrated on the period 1973-1978 (1972 was used as a "warm-up" year, but the objective function did not include these prediction errors) and tested on the period 1979-1984. The mean absolute errors for both periods are compared with Cooley's (1986a,b) results in Table XX. For almost all seasons and individual months in both the calibration and test periods, the monthly model had smaller errors than NWSRFS.

The second test compared the errors for the ESP forecasts from the monthly model with the errors from regression. The results for seasonal volumes are given in Table XXI. The seasonal volumes from regression were also disaggregated into monthly flows as before. The monthly fractions are given in Table XXII, and a comparison of monthly mean absolute errors is given in Table XXIII. In almost all comparisons, errors from regression were smaller than those from the monthly model.

A third test compared mean absolute errors for seasonal volumes, where the regression equations were calibrated on the period 1961-1980, the monthly model was calibrated on the period 1968-1980, and both were tested on the period 1981-1989. As with the St. Joe and Ruby Rivers, data suitable for regression existed for a longer period than for the monthly model, so these data were used in the regression model. This test was done for January and April forecasts, and the results are given 
TABLE XX

MEAN ABSOLUTE ERRORS FOR NWSRFS AND MONTHLY MODEL, LOWER WILLOW CREEK

\begin{tabular}{|c|c|c|c|c|c|c|c|c|}
\hline \multirow[t]{3}{*}{ Period } & \multicolumn{4}{|c|}{$\begin{array}{c}1973-1978 \\
\text { calibration period }\end{array}$} & \multicolumn{4}{|c|}{$\begin{array}{l}\text { 1979-1984 } \\
\text { test period }\end{array}$} \\
\hline & \multicolumn{2}{|c|}{ NWSRFS } & \multicolumn{2}{|c|}{$\begin{array}{l}\text { Monthly } \\
\text { Model }\end{array}$} & \multicolumn{2}{|c|}{ NWSRFS } & \multicolumn{2}{|c|}{$\begin{array}{l}\text { Monthly } \\
\text { Model }\end{array}$} \\
\hline & $\mathrm{KAF}$ & $\left|\begin{array}{cc}8 & \text { of } \\
\text { avg. }\end{array}\right|$ & $\mathrm{KAF}$ & $\begin{array}{l}\% \text { of } \\
\text { avg. }\end{array}$ & $\mathrm{KAF}$ & $\begin{array}{l}\% \text { of } \\
\text { avg. }\end{array}$ & $\mathrm{KAF}$ & $\begin{array}{l}8 \text { of } \\
\text { avg. }\end{array}$ \\
\hline $\begin{array}{l}\text { Apr } \\
\text { May } \\
\text { Jun } \\
\text { Jul } \\
\text { Aug } \\
\text { Sep }\end{array}$ & $\begin{array}{l}1.46 \\
1.51 \\
0.69 \\
0.62 \\
0.66 \\
0.44\end{array}$ & $\begin{array}{r}56 \\
22 \\
18 \\
74 \\
157 \\
96\end{array}$ & $\begin{array}{l}0.64 \\
1.01 \\
0.77 \\
0.33 \\
0.26 \\
0.24\end{array}$ & $\begin{array}{l}25 \\
15 \\
20 \\
39 \\
62 \\
52\end{array}$ & $\begin{array}{l}0.34 \\
1.79 \\
2.88 \\
1.48 \\
0.78 \\
0.53\end{array}$ & $\begin{array}{r}13 \\
27 \\
76 \\
176 \\
186 \\
115\end{array}$ & $\begin{array}{l}0.91 \\
0.82 \\
1.37 \\
0.24 \\
0.18 \\
0.10\end{array}$ & $\begin{array}{l}35 \\
12 \\
36 \\
29 \\
43 \\
22\end{array}$ \\
\hline $\begin{array}{l}\text { Apr-Jul } \\
\text { Apr-Sep } \\
\text { May-Jul } \\
\text { May-Sep } \\
\text { Jun-Jul } \\
\text { Jun-Sep }\end{array}$ & $\begin{array}{l}3.19 \\
3.32 \\
1.73 \\
2.21 \\
1.15 \\
2.02\end{array}$ & $\begin{array}{l}23 \\
22 \\
15 \\
18 \\
25 \\
37\end{array}$ & $\begin{array}{l}1.75 \\
3.51 \\
1.77 \\
1.98 \\
0.94 \\
1.14\end{array}$ & $\begin{array}{l}13 \\
24 \\
16 \\
16 \\
20 \\
21\end{array}$ & $\begin{array}{l}3.20 \\
3.71 \\
5.16 \\
6.06 \\
4.36 \\
5.47\end{array}$ & $\begin{array}{l}23 \\
25 \\
45 \\
49 \\
95 \\
99\end{array}$ & $\begin{array}{l}2.17 \\
4.08 \\
1.82 \\
1.67 \\
1.38 \\
1.34\end{array}$ & $\begin{array}{l}16 \\
28 \\
16 \\
14 \\
30 \\
24\end{array}$ \\
\hline
\end{tabular}

Notes: (1) $\mathrm{KAF}=$ thousands of acre-feet.

(2) Streamflow averages used are for the period 1961-1990.

in Table XXIV. Again, regression had smaller errors than the monthly model. 
TABLE XXI

MEAN ABSOLUTE ERRORS FOR MONTHLY MODEL ESP AND REGRESSION FORECASTS, LOWER WILLOH CREEK, 1969-1989 -- SEASONAL VOLUMES

\begin{tabular}{|c|c|c|c|c|c|}
\hline \multirow[t]{2}{*}{$\begin{array}{l}\text { Forecast } \\
\text { Month }\end{array}$} & \multirow[t]{2}{*}{$\begin{array}{l}\text { Forecast } \\
\text { Period }\end{array}$} & \multicolumn{2}{|c|}{$\begin{array}{c}\text { Monthly } \\
\text { Model }\end{array}$} & \multicolumn{2}{|c|}{ Regression } \\
\hline & & KAF & $\begin{array}{l}8 \text { of } \\
\text { avg. }\end{array}$ & $\mathrm{KAF}$ & $\begin{array}{l}\% \text { of } \\
\text { avg. }\end{array}$ \\
\hline Jan & $\begin{array}{l}\text { Apr-Jul } \\
\text { Apr-Sep }\end{array}$ & $\begin{array}{l}5.9 \\
6.1\end{array}$ & $\begin{array}{l}42 \\
41\end{array}$ & $\begin{array}{l}3.6 \\
3.6\end{array}$ & $\begin{array}{l}26 \\
24\end{array}$ \\
\hline Feb & $\begin{array}{l}\text { Apr-Jul } \\
\text { Apr-Sep }\end{array}$ & $\begin{array}{l}4.8 \\
4.9\end{array}$ & $\begin{array}{l}34 \\
33\end{array}$ & $\begin{array}{l}3.4 \\
3.5\end{array}$ & $\begin{array}{l}24 \\
24\end{array}$ \\
\hline Mar & $\begin{array}{l}\text { Apr-Jul } \\
\text { Apr-Sep }\end{array}$ & $\begin{array}{l}4.3 \\
4.5\end{array}$ & $\begin{array}{l}31 \\
30\end{array}$ & $\begin{array}{l}3.2 \\
3.3\end{array}$ & $\begin{array}{l}23 \\
22\end{array}$ \\
\hline Apr & $\begin{array}{l}\text { Apr-Jul } \\
\text { Apr-Sep }\end{array}$ & $\begin{array}{l}4.1 \\
4.2\end{array}$ & $\begin{array}{l}29 \\
28\end{array}$ & $\begin{array}{l}2.8 \\
3.0\end{array}$ & $\begin{array}{l}20 \\
20\end{array}$ \\
\hline May & $\begin{array}{l}\text { May-Jul } \\
\text { May-Sep }\end{array}$ & $\begin{array}{l}3.2 \\
3.4\end{array}$ & $\begin{array}{l}28 \\
28\end{array}$ & $\begin{array}{l}2.3 \\
2.4\end{array}$ & $\begin{array}{l}20 \\
20\end{array}$ \\
\hline Jun & $\begin{array}{l}\text { Jun-Jul } \\
\text { Jun-Sep }\end{array}$ & $\begin{array}{l}1.6 \\
1.9\end{array}$ & $\begin{array}{l}35 \\
35\end{array}$ & $\begin{array}{l}1.0 \\
1.1\end{array}$ & $\begin{array}{l}22 \\
20\end{array}$ \\
\hline
\end{tabular}

Notes: (1) $\mathrm{KAF}=$ thousands of acre-feet.

(2) Streamflow averages used are for the period 1961-1990.

TABLE XXII

MONTHLY FRACTIONS FOR DISAGGREGATING SEASONAL VOLUMES INTO MONTHLY FLOWS, LOWER WILLOW CREEK

\begin{tabular}{c|c|c|c|c|c|c}
\hline \multirow{2}{*}{ Period } & \multicolumn{6}{|c}{ Month } \\
\cline { 2 - 7 } & Apr & May & Jun & Jul & Aug & Sep \\
\hline Apr-Sep & 0.197 & 0.451 & 0.224 & 0.058 & 0.033 & 0.037 \\
May-Sep & & 0.562 & 0.274 & 0.073 & 0.043 & 0.048 \\
Jun-Sep & & & 0.622 & 0.167 & 0.099 & 0.112 \\
\hline
\end{tabular}


TABLE XXIII

MEAN ABSOLUTE ERRORS FOR MONTHLY MODEL ESP AND DISAGGREGATED REGRESSION FORECASTS, LOWER WILLOH CREEK, 1969-1989 -- MONTHLY FLOHS

\begin{tabular}{|c|c|c|c|c|c|}
\hline \multirow[t]{2}{*}{$\begin{array}{l}\text { Forecast } \\
\text { Month }\end{array}$} & \multirow[t]{2}{*}{$\begin{array}{c}\text { Forecast } \\
\text { Period }\end{array}$} & \multicolumn{2}{|c|}{$\begin{array}{l}\text { Monthly } \\
\text { Model }\end{array}$} & \multicolumn{2}{|c|}{$\begin{array}{l}\text { Regression } \\
\text { (disagg.) }\end{array}$} \\
\hline & & $\mathrm{KAF}$ & $\begin{array}{l}8 \text { of } \\
\text { avg. }\end{array}$ & $\mathrm{KAF}$ & $\begin{array}{l}8 \text { of } \\
\text { avg. }\end{array}$ \\
\hline Jan & $\begin{array}{l}\text { Apr } \\
\text { May } \\
\text { Jun } \\
\text { Jul } \\
\text { Aug } \\
\text { Sep }\end{array}$ & $\begin{array}{l}1.10 \\
3.14 \\
2.59 \\
0.64 \\
0.31 \\
0.23\end{array}$ & $\begin{array}{l}42 \\
47 \\
68 \\
76 \\
74 \\
50\end{array}$ & $\begin{array}{l}0.99 \\
2.02 \\
2.11 \\
0.53 \\
0.16 \\
0.17\end{array}$ & $\begin{array}{l}38 \\
30 \\
56 \\
63 \\
38 \\
37\end{array}$ \\
\hline $\mathrm{Feb}$ & $\begin{array}{l}\text { Apr } \\
\text { May } \\
\text { Jun } \\
\text { Jul } \\
\text { Aug } \\
\text { Sep }\end{array}$ & $\begin{array}{l}1.00 \\
2.65 \\
2.32 \\
0.60 \\
0.31 \\
0.23\end{array}$ & $\begin{array}{l}39 \\
39 \\
61 \\
71 \\
74 \\
50\end{array}$ & $\begin{array}{l}1.05 \\
1.92 \\
1.92 \\
0.50 \\
0.19 \\
0.20\end{array}$ & $\begin{array}{l}41 \\
28 \\
51 \\
60 \\
45 \\
43\end{array}$ \\
\hline Mar & $\begin{array}{l}\text { Apr } \\
\text { May } \\
\text { Jun } \\
\text { Jul } \\
\text { Aug } \\
\text { Sep }\end{array}$ & $\begin{array}{l}1.02 \\
2.38 \\
2.27 \\
0.61 \\
0.31 \\
0.23\end{array}$ & $\begin{array}{l}39 \\
35 \\
60 \\
73 \\
74 \\
50\end{array}$ & $\begin{array}{l}1.14 \\
1.72 \\
1.91 \\
0.50 \\
0.20 \\
0.20\end{array}$ & $\begin{array}{l}44 \\
26 \\
50 \\
60 \\
48 \\
43\end{array}$ \\
\hline Apr & $\begin{array}{l}\text { Apr } \\
\text { May } \\
\text { Jun } \\
\text { Ju1 } \\
\text { Aug } \\
\text { Sep }\end{array}$ & $\begin{array}{l}1.01 \\
2.23 \\
2.22 \\
0.61 \\
0.31 \\
0.23\end{array}$ & $\begin{array}{l}39 \\
33 \\
59 \\
73 \\
74 \\
50\end{array}$ & $\begin{array}{l}1.28 \\
1.65 \\
1.68 \\
0.46 \\
0.21 \\
0.22\end{array}$ & $\begin{array}{l}49 \\
24 \\
44 \\
55 \\
50 \\
48\end{array}$ \\
\hline May & $\begin{array}{l}\text { May } \\
\text { Jun } \\
\text { JuI } \\
\text { Aug } \\
\text { Sep }\end{array}$ & $\begin{array}{l}1.90 \\
1.76 \\
0.53 \\
0.30 \\
0.22\end{array}$ & $\begin{array}{l}28 \\
46 \\
63 \\
71 \\
48\end{array}$ & $\begin{array}{l}1.43 \\
1.52 \\
0.45 \\
0.21 \\
0.25\end{array}$ & $\begin{array}{l}21 \\
40 \\
54 \\
50 \\
54\end{array}$ \\
\hline Jun & $\begin{array}{l}\text { Jun } \\
\text { Jul } \\
\text { Aug } \\
\text { Sep }\end{array}$ & $\begin{array}{l}1.38 \\
0.46 \\
0.29 \\
0.22\end{array}$ & $\begin{array}{l}36 \\
55 \\
69 \\
48\end{array}$ & $\begin{array}{l}1.04 \\
0.38 \\
0.25 \\
0.30\end{array}$ & $\begin{array}{l}27 \\
45 \\
60 \\
65\end{array}$ \\
\hline
\end{tabular}

Notes: (1) $\mathrm{KAF}=$ thousands of acre-feet.

(2) Streamflow averages used are for the period 1961-1990. 
TABLE XXIV

MEAN ABSOLUTE ERRORS FOR MONTHLY MODEL AIJ REGRESSION, LOWER HILLOH CREER, 1981-1989 TEST PERIOD

\begin{tabular}{|c|c|c|c|c|c|}
\hline \multirow[t]{2}{*}{$\begin{array}{l}\text { Forecast } \\
\text { Month }\end{array}$} & \multirow[t]{2}{*}{$\begin{array}{c}\text { Forecast } \\
\text { Period }\end{array}$} & \multicolumn{2}{|c|}{$\begin{array}{c}\text { Monthly } \\
\text { Model }\end{array}$} & \multicolumn{2}{|c|}{ Regression } \\
\hline & & $\mathrm{KAF}$ & s of & $\mathrm{KAF}$ & $\begin{array}{l}\xi \text { of } \\
\text { avg. }\end{array}$ \\
\hline Jan & $\begin{array}{l}\text { Apr-Jul } \\
\text { Apr-Sep }\end{array}$ & $\begin{array}{l}5.4 \\
5.6\end{array}$ & $\begin{array}{l}39 \\
38\end{array}$ & $\begin{array}{l}3.9 \\
3.9\end{array}$ & $\begin{array}{l}28 \\
26\end{array}$ \\
\hline Apr & $\begin{array}{l}\text { Apr-Jul } \\
\text { Apr-Sep }\end{array}$ & $\begin{array}{l}3.0 \\
3.1\end{array}$ & $\begin{array}{l}21 \\
21\end{array}$ & $\begin{array}{l}2.5 \\
2.6\end{array}$ & $\begin{array}{l}18 \\
18\end{array}$ \\
\hline
\end{tabular}

Notes: (1) $\mathrm{KAF}=$ thousands of acre-feet.

(2) Streamflow averages used are for the period 1961-1990. 
CHAPTER VI

SUMMARY AND CONCLUSIONS

\section{SUMMARY}

The motivation for this study has been to improve accuracy in current regression-based seasonal streamflow volume forecasts and to begin to understand the abilities and potential use of more physicallybased models. Improved accuracy in seasonal volume forecasts can provide immediate benefits under current water management decision making procedures. The use of models with a greater physical basis, including monthly models and conceptual watershed models, has potential both for greater seasonal volume forecast accuracy and for providing more detailed hydrologic information than just the seasonal volume. It is imperative, however, that the true abilities of these models be clearly understood before large amounts of resources are expended on implementing them. Heretofore, it has largely been assumed, but not tested, that these models, particularly conceptual watershed models, have superior forecasting abilities. The results of this study indicate that this assumption may not always be true and that further efforts in model development and testing are warranted.

This study has provided enhancements to and a critical examination of three modeling approaches for water supply forecasting. The first approach, linear regression as traditionally used, was improved by the 
use of more appropriate statistical techniques. For the second approach, a monthly streamflow simulation model was developed along with supporting mean areal precipitation and temperature procedures. Results from current practice with the third approach, the use of conceptual watershed models and the Extended Streamflow Prediction procedure, were used to compare with the other two approaches. The conclusions from these efforts in model development and intercomparison are given below, followed by related discussion.

\section{CONCLUSIONS}

From the results of this study, the following conclusions can be made:

1) Significant improvements in forecast accuracy over past practice with regression can be obtained by (a) using only data known at forecast time (no future data), (b) principal components regression, (c) cross-validation, and (d) systematic searching for optimal or near-optimal combinations of variables.

2) In the three test basins used in this study, regression provided better forecast accuracy than the monthly model or the conceptual models most of the time, for both seasonal volumes and monthiy flows.

3) The monthly model performed better than the conceptual watershed models (SSARR and NWSRFS) most of the time, for both seasonal volumes and monthly flows. 
4) All of the conceptual watershed modeling results used in this study were produced with the models calibrated by trial-and-error. Had these models been calibrated optimally with an automatic scheme, it might have been possible for them to equal or exceed the monthly model and regression in forecast accuracy. Hithout automatic calibration, however, one cannot generally expect to achieve this.

5) In basins of complex orography, currently existing data networks may be inadequate to describe the precipitation field, thus making it impossible to compute meaningful mean areal precipitation values for model input. This is less problematic for temperature, whose field is much less variable than precipitation. In such basins (e.g., the Big Lost River in Idaho), modeling will not be possible until a denser data network is available.

CONTRIBUTIONS OF THIS STUDY TO THE PRACTICE OF HATER SUPPLY FORECASTING

This study has provided advancements to the practice of water supply forecasting in four ways:

1) Regression techniques have been greatly improved. Advanced statistical methods have been assembled into a comprehensive approach to replace outmoded, nonoptimal procedures. This enhances current forecasting practice in all basins, and this benefit will continue in basins where regression will be used into the forseeable future. 
2) Using optimal interpolation techniques, a procedure for estimating mean areal precipitation and temperature (MAP and MAT) has been developed. Orographic effects are considered, and spatial correlation is explicitly modeled. The procedure can operate on either monthly or daily data. This procedure is more objective and statistically sound than traditional techniques and should be able to provicie the best estimates of MAP and MAT with a given data network.

3) A monthly streamflow simulation model has been developed to provide a forecasting tool intermediate in complexity between regression and daily conceptual watershed models. This type of model has heretofore not been used in water supply forecasting. This study has shown that such a model has potential for being a useful forecasting technique.

4) An initial investigation was conducted to attempt to define the conditions under which monthly or daily modeling will provide greater forecast accuracy. Heretofore, it has been assumed, but never tested, that more complex models will forecast better. The results from this study indicate that this assumption may not necessarily be true. Additional investigation into this issue is warranted before committing large amounts of resources into modeling. 
DISCUSSION

The inability of the two simulation approaches to surpass regression in forecast accuracy for seasonal and monthly streamflows raises a number of issues about modeling, both in this context and in general.

First, the calibrations of the conceptual models used in this study undoubtedly could have been better. It is clear that trial-and-error parameter adjustment is inadequate to obtain optimal values, making automated search procedures a necessity. Although automated calibration procedures have been used for a number of years, only recently have algorithms been devised that attempt to ensure that a global, rather than local, optimum has been found (Hang 1991; Duan et al. 1992). In developing such an algorithm, Duan et al. (1992) comment that calibrating a watershed model is a difficult and computationally demanding problem. Continued efforts in devising and implementing automatic calibration procedures are a first requisite to ensuring optimal forecast accuracy from these models.

A second issue is that model conceptualizations may need revision. As the functions used are only approximations of the physical processes, it is possible that other functional forms could better describe watershed behavior, particularly when aggregated in space le.g., elevation zones or the entire watershed) and time (e.g., day or month). That is, the most appropriate functional forms to represent the integral of continuous point watershed processes are perhaps yet to be developed. Calibrating a model is analogous to nonlinear regression (Troutman 1982, 
1983, 1985); not only does one need a good search algorithm (as discussed above), but also the function must be capable of representing the behavior of the system to an acceptable level of approximation.

Another aspect of model conceptualization is the identifiability of unique parameter values. Difficulties can arise due either to irregularities in the model response surface or to parameter interactions, where parameters can compensate for each other's effects (Gupta and Sorooshian 1983; Sorooshian and Gupta 1983; Beck 1987; Kleissen et al. 1990; Duan et al. 1992). If unique parameter values cannot be identified, the appropriateness and viability of the model is called into question. Model conceptualizations may need to be revised to make it possible to identify unique parameter values.

A third issue is that significant increases in forecast accuracy may not be possible to achieve with the simplifications and spatial lumping of conventional conceptual watershed models. It may be that spatially distributed models with greater physical basis are required (e.g., PRMS [Leavesley et al. 1983] and SHE [Abbott et al. 1986a,b]). If this is the case, the use of models in water supply forecasting will require much greater effort than that required to implement the models tested here and will require more precipitation and temperature observations than are currently available.

A fourth issue is that significant errors in model output may be due to uncertainty in determining mean areal precipitation, mean areal temperature, and potential evapotranspiration. More measurement sites, more variables measured, and better methods to describe orographic 
effects may be required to obtain estimates of system inputs of sufficient accuracy to allow acceptably accurate system simulations. Finally, simple models may perform as vell as complex ones for temporally-aggregated output. Conceptual models are calibrated and operated using daily data. When the daily flows generated by these models are aggregated into monthly or seasonal pexiods, it is not necessarily true that the resulting aggregated flows are simulated any better than those obtained from simpler models, which calculate aggregated flows directly. As long as daily flows are not needed for decision making, it may be that simple models are adequate or even superior.

With all of these open issues, one cannot say unequivocally at this time whether complex hydrologic models are better than simple ones for monthly and seasonal streamflow forecasting. Further research is required to elucidate these issues. Until that time, it can only be concluded that conceptual models, as they now exist and are applied, have not yet been shown to produce improved monthly and seasonal streamflow forecasts.

\section{RECOMMENDATIONS FOR FUTURE HORK}

Needs for further investigation in the arena of water supply forecasting fall into two broad categories:

1) Refine watershed simulation models with respect to calibration procedures, model conceptualization, and spatial averaging of input data. Determine under what conditions complex models are 
preferable to simple ones. Perform comparative tests on other river basins, particularly ones of diverse hydrologic regimes.

2) Examine the need for hydrologic forecasts in the context of the water management decision making at each individual forecast point. Attempt to define the mix of forecast accuracy and temporal aggregation of streamflow that would optimize water management decisions. Describe any trade-offs that may occur between using simple vs. complex models. Doing this may require the use of system optimization techniques, such as linear or dynamic programming. 


\section{REFERENCES}

Abbott, M. B., J. C. Bathurst, J. A. Cunge, P. E. O'Connell, and J. Rasmussen (1986a). "An introduction to the European Hydrological System -- Systeme Hydrologique Europeen, 'SHE', 1. History and philosophy of a physically-based, distributed modeling system," Journal of Hydrology, 87, 45-59.

Abbott, M. B., J. C. Bathurst, J. A. Cunge, P. E. O'Connell, and J. Rasmussen (1986b). "An introduction to the European Hydrological System -- Système Hydrologique Européen, 'SHE', 2. Structure of a physically-based, distributed modeling system," Journal of Bydrology, 87, 61-77.

Alley, H. H. (1984). "On the treatment of evapotranspiration, soil moisture accounting, and aquifer recharge in monthly water balance models," Hater Resources Research, 20(8), 1137-1149.

Alley, H. M. (1985). "Hater balance models in one-month-ahead streamflow forecasting," Hater Resources Research, 21(4), 597-606.

Anderson, E. A. (1968). "Development and testing of snow pack energy balance equations," Water Resources Research, 4(1), 19-37.

Anderson, E. A. (1973). "National Heather Service River Forecast System -- snor accumulation and ablation model," NOAA Technical Memorandum NHS-HYDRO-17.

Barton, M., and M. Burke (1977). "SNoTEL: An operational data acquisition system using meteor burst technology," Proceedings of the Nestern Snow Conference, 82-87.

Bastin, G., B. Lorent, C. Duqué, and M. Gevers (1984). "Optimal estimation of the average areal rainfall and optimal selection of rain gauge locations," Hater Resources Research, 20(4), 463-470.

Bastin, G., and M. Gevers (1985). "Identification and optimal estimation of random fields from scattered point-wise data," Automatica, 21(2), 139-155.

Beck, H. B. (1987). "Hater quality modeling: a review of the analysis of uncertainty," Hater Resources Research, 23(8), 1393-1442.

Beven, K. (1989). "Changing ideas in hydrology -- the case of physically-based models," Journal of Hydrology, 105, 157-172. 
Bras, R. L., and I. Rodriguez-Iturbe (1985). Random Functions and Bydrology, Addison-Hesley, Reading, MA.

Burnash, R. J. C., R. L. Ferral, and R. A. McGuire (1973). "A generalized streamflow simulation system -- conceptual modeling for digital computers," Joint Federal-state River Forecast Center (Sacramento, CA) and State of California Department of Hater Resources.

Christophersen, N., and C. Neal (1990). "Linking hydrological, geochemical, and soil chemical processes on the catchment scale: an interplay between modeling and field work," Hater Resources Research, 26(12), 3077-3086.

Christophersen, N., H. M. Seip, and R. F. Hright (1982). "A model for streamwater chemistry at Birkenes, Norway," Hater Resources Research, 18(4), 977-996.

Chua, S. - H., and R. L. Bras (1982). "Optimal estimators of mean areal precipitation in regions of orographic influence," Journal of Bydrology, 57, 23-48.

Clarke, R. T. (1973). "A review of some mathematical models used in hydrology, with observations on their calibration and use," Journal of Hydrology, 19, 1-20.

Cooley, K. R. (1986a). "Evaluation of the NWSRFS model on a Montana watershed," Proceedings of the Nestern Snow Conference, 112-121.

Cooley, K. R. (1986b). "Using real-time (SNOTEL) data in the NHSRFS model," proceedings of Cold Regions Hydrology Symposium, American Water Resources Association, 439-448.

Crasford, N. H., and R. K. Linsley (1966). "Digital simulation in hydrology: Stanford Hatershed model IV," Technical Report No. 39, Department of Civil Engineering, Stanford University.

Creutin, J. D., and C. Obled (1982). "Objective analyses and mapping techniques for rainfall fields: an objective comparison," Hater Resources Research, 18(2), 413-431.

Crook, A. G. (1984). "The SNOTEL data acquisition system: a tool in runoff forecasting," in J. J. Cassidy and D. P. Lettenmaier (eds.), A Critical Assessment of Forecasting in Western Water Resources Management, proceedings of American Water Resources Association symposium, Seattle, HA, 25-30.

Day, G. N. (1985) . "Extended streamflow forecasting using NWSRFS," Journal of Nater Resources Planning and Management, 111(2), 157170. 
Delfiner, P., and J. P. Delhomme (1975). "Optimum interpolation by kriging," in J. C. Davis and M. J. HeCullagh (eds.), Display and Analysis of Spatial Data, John Viley, London, 96-114.

Dingman, S. L., D. M. Seely-Reynolds, and R. C. Reynolds III (1988). "Application of kriging to estimating mean annual precipitation in a region of orographic influence," Hater Resources Bulletin, 24(2), 329-339.

Dooge, J. C. I. (1959). "A general theory of the unit hydrograph," Journal of Geophysical Research, 64(2), 241-256.

Dooge, J. C. I. (1973). "Linear theory of hydrologic systems," Technical Bulletin No. 1468, Agricultural Research Service, U. S. Department of Agriculture.

Druce, D. J. (1984). "Seasonal inflow forecasts by a conceptual hydrologic model for Mica Dam, British Columbia," in J. J. Cassidy and D. P. Lettenmaier (eds.), A Critical Assessment of Forecasting in Western Water Resources Management, proceedings of American Water Resources Association symposium, Seattle, WA, 85-91.

Dunne, T., and L. B. Leopold (1978). Water in Environmental Planning, H. H. Freeman, San Francisco.

Duan, Q., S. Sorooshian, and V. Gupta (1992). "Effective and efficient global optimization for conceptual rainfall-runoff models," Water Resources Research, 28(4), 1015-1031.

Freeze, R. A. (1980). "A stochastic-conceptual analysis of rainfallrunoff processes on a hillslope," Hater Resources Research, 16(2), 391-408.

Gleick, P. H. (1986). "Methods for evaluating the regional hydrologic impacts of global climatic changes," Journal of Bydrology, 88, 97116.

Gleick, P. H. (1987). "The development and testing of a water balance model for climate impact assessment: modeling the Sacramento basin," Hater Resources Research, 23(6), 1049-1061.

Gordon, H. R., and R. C. Lamb (1980). "Importance of water supply forecasts in power planning, Proceedings of the Nestern Snow Conference, 83-87.

Gupta, V. R., and S. Sorooshian (1983). "Uniqueness and observability of conceptual rainfall-runoff model parameters: the percolation process examined," Water Resources Research, 19(1), 269-276.

Gupta, V. K., and S. Sorooshian (1985). "The automatic calibration of conceptual catchment models using derivative-based optimization algorithms," Nater Resources Research, 21(4), 473-485. 
Haan, C. T. (1972). "A water yield model for small watersheds," Hater Resources Research, 8(1), 58-69.

Haan, C. T. (1977). Statistical Methods in Bydrology, Iowa State University Press, Ames, IA.

Haan, C. T., and D. M. Allen (1972). "Comparison of multiple regression and principal component regression for predicting water yields in Kentucky," Hater Resources Research, 8(6), 1593-1596.

Hanson, C. L. (1982). "Distribution and stochastic generation of annual and monthly precipitation on a mountainous watershed in southwest Idaho," Nater Resources Bulletin, 18(5), 875-883.

Hendrickson, J. D., S. Sorooshian, and L. E. Brazil (1988). "Comparison of Newton-type and direct search algorithms for calibration of conceptual rainfall-runoff models," Hater Resources Research, $24(5), 691-700$.

High Country News (1987). Hestern Hater Made Simple, Island Press, Hashington, DC.

Huggins, L. F., and J. R. Burney (1982). "Surface runoff, storage, and routing," in C. T. Haan, H. P. Johnson, and D. L. Brakensiek (eds.). Hydrologic Modeling of Small Hatersheds, Monograph No. 5 , American Society of Agricultural Engineers, St. Joseph, MI, 169225.

Ibbitt, R. P., and T. O'Donnell (1971). "Fitting methods for conceptual catchment models," Journal of the Hydraulics Division, American Society of Civil Engineers, 97(HY9), 1331-1342.

Jensen, M. E. (ed.) (1973). Consumptive use of water and irrigation water requirements, Irrigation and Drainage Division, American Society of Civil Engineers.

Johnston, P. R., and D. H. Pilgrim (1976). "Parameter optimization for watershed models," Water Resources Research, 12(3), 477-486.

Journel, A. G. (1989). "Fundamentals of geostatistics in five lessons," Short Course in Geology: Volume 8, American Geophysical Union, Washington, DC.

Karlinger, K. R., and J. A. Skrivan (1981). "Kriging analysis of mean annual precipitation, Powder River basin, Montana and Hyoming," Water Resources Investigations Report 81-050, U. S. Geological Survey.

Kleinbaum, D. G., L. L. Kupper, and K. E. Muller (1988). Applied Regression Analysis and other Multivariable Methods, 2nd ea.., PWSKENT Publishing Company, Boston. 
Kleissen, F. M., M. B. Beck, and H. S. Wheater (1990). "The identifiability of conceptual hydrochemical models," Hater Resources Research, 26(12), 2979-2992.

Klemes, V. (1978). "Physically based stochastic hydrologic analysis," in Ven Te Chow (ed.), Advances in Hydroscience, Academic Press, New York, 11, 285-356.

Klemes, V. (1983). "Conceptualization and scale in hydrology," Journal of Bydrology, 65, 1-23.

Xlemes, V. (1986). "Dilettantism in hydrology: transition or destiny?," Hater Resources Research, 22(9), 1775-188S.

Klemes, V. (1988). "A hydrological perspective," Journal of Hydrology, $100,3-28$.

Koch, R. H. (1990). "Influences of climate variability on streamflow variability: implications in streamflow prediction and forecasting," final report for grant award 14-08-0001-G1316, U. S. Geological Survey.

Koch, R. H., R. L. Allen, and N. D. Mtundu (1987). "Evaluation of simple, dynamic soil moisture model," Journal of Irrigation and Drainage Engineering, $113(3), 288-302$.

Koch, R. H., and D. C. Garen (1992). "stochastically generated climate input for water supply forecasting with a conceptual watershed model," Proceedings of the Nestern Snow Conference.

Krzysztofowicz, R. (1986a). "Expected utility, benefit, and loss criteria for seasonal water supply planning," Water Resources Research, 22(3), 303-312.

Krzysztofowicz, R. (1986b). "Optimal water supply planning based on seasonal runoff forecasts," Hater Resources Research, 22(3), 313321.

Krzysztofowicz, R., and S. Reese (1989). "A Bayesian analysis of seasonal runoff forecasts," report to Soil Conservation Service, University of Virginia.

Kuehl, D. H. (1979). "Volume forecasts using the SSARR model in a zone mode," Proceedings of the Hestern Snow Conference, 38-47.

Leavesley, G. H., R. H. Lichty, B. M. Troutman, and L. G. Saindon (1983). "Precipitation-runoff modeling system -- users manual," Hater Resources Investigations Report 83-4238, U. S. Geological Survey. 
Lebel, T., G. Bastin, C. Obled, and J. D. Creutin (1987). "On the accuracy of areal rainfall estimation: a case study," Hater Resources Research, 23(11), 2123-2134.

Lebel, T., and J. P. Laborde (1988). "A geostatistical approach for areal rainfall statistics assessment," Stochastic Hydrology and Hydraulics, 2, 245-261.

Lins, H. F. (1985). "Interannual streamflow variability in the United States based on principal components," Hater Resources Research, $21(5), 691-701$.

Linsley, R. K., M. A. Kohler, and J. L. H. Paulhus (1975). Hydrology for Engineers, 2nd ed., HcGraw-Hill, New York.

Loague, R. M., and R. A. Freeze (1985). "A comparison of rainfallrunoff modeling techniques on small upland catchments," Hater Resources Research, 21(2), 229-248.

Long, R. B. (1990). "A trade-off analysis of alternative water uses," Hater Resources Bulletin, 26(1), 157-166.

Marsden, M. A., and R. T. Davis (1968). "Regression on principal components as a tool in water supply forecasting," proceedings of the Hestern Snow Conference, 33-40.

Mather, J. R. (1981). "Using computed stream flow in watershed analysis," Hater Resources Bulletin, 17(3), 474-482.

McCuen, R. H. (1985). Statistical Methods for Engineers, Prentice-Hall, Englewood Cliffs, NJ.

McCuen, R. H., W. J. Rawls, and B. L. Hhaley (1979). "Comparative evaluation of statistical methods for water supply forecasting," Hater Resources Bulletin, 15(4), 935-947.

McCuen, R. H., and H. M. Snyder (1986). Hydrologic Modeling: Statistical Methods and Applications, Prentice-Hall, Englewood Cliffs, NJ.

McDonnell, J. J., and J. M. Buttle (1987). "On improving temperatureindex snowmelt simulations in small watersheds," Hydrological Science and Technology, American Institute of Hydrolcgy, 3(1), 5359.

Minikou, M., Y. Kouvopoulos, G. Cavadias, and N. Vayianos (1991). "Regional hydrological effects of climate change," Journal of Hydrology, 123, 119-146.

Mishalani, N. R., and R. N. Palmer (1988). "Forecast uncertainty in water supply reservoir operation," Hater Resources Bulletin, 24(6), 1237-1245. 
Hoore, R. J., and R. T. Clarke (1981). "A distribution function approach to rainfall runoff modeling," Hater Resources Research, $17(5), 1367-1382$.

Naef, F. (1981). "Can we model the rainfall-runoff process today?," Hydrological Sciences Bulletin, 26(3), 281-289.

Nelder, J. A., and R. Mead (1965). "A simplex method for function minimization," The Computer Journal, 7(4), 308-313.

Northwest Power Planning Council (1991a). "Amendments to the Columbia River Basin fish and wildlife program (phase one)," document no. 91-27, Portland, OR.

Northwest Power Planning Council (1991b). "Amendments to the Columbia River Basin fish and wildlife program (phase two)," document no. 91-31, Portland, OR.

Palmer, T. (1991). The Snake River, Island Press, Hashington, DC.

Palmer, H. C. (1965). "Meteorological drought," Research Paper No. 45, U. S. Heather Bureau.

Pearson, T. (1974). "Simulating runoff to the Hungry Horse reservoir of western Montana," Proceedings of the Hestern Snow Conference, 96102 .

Pei, D., S. J. Burges, and J. R. Stedinger (1987). "Runoff volume forecasts conditioned on a total seasonal runoff forecast," Hater Resources Research, 23(1), 9-14.

Pickup, G. (1977). "Testing the efficiencies of algorithms and strategies for automatic calibration of rainfall-runoff models," Bydrological Sciences Bulletin, 22(2), 257-274.

Press, H. H., B. P. Flannery, S. A. Teukolsky, and W. T. Vetterling (1988). Numerical Recipes in C, Cambridge University Press, Cambridge, England.

Rallison, R. E. (1981). "Automated system for collecting snow and related hydrological data in mountains of the western United States," Hydrological Sciences Bulletin, 26(1), 83-89.

Reese, S., and K. Krzysztofowicz (1989). "Stochastic disaggregation of seasonal runoff into monthly runoffs," report to Soil Conservation Service, University of Virginia.

Rosenbrock, H. H. (1960). "An automatic method for finding the greatest or least value of a function," The Computer Journal, 3(3), 175-184. 
Salas, J. D., G. Q. Tabios III, and J. T. B. Obeysekera (1986). "Seasonal model for watershed simulation," computer program documentation, Department of Civil Engineering, Colorado state University, Fort Collins, $c 0$.

Saxton, R. E., and J. L. McGuinness (1982). "Evapotranspiration," in C. T. Haan, H. P. Johnson, and D. L. Brakensiek (eds.), Hydrologic Modeling of Small Watersheds, Monograph No. 5, American Society of Agricultural Engineers, St. Joseph, MI, 229-273.

Schermerhorn, V., and M. Barton (1968). "A method for integrating snow survey and precipitation data," Proceedings of the Hestern Snow Conference, 27-32.

Shelton, M. L. (1985). "Modeling hydroclimatic processes in large watersheds," Annals of the Association of American Geographers, $75(2), 185-202$.

Smith, R. E., and R. H. B. Hebbert (1979). "A monte carlo analysis of the hydrologic effects of spatial variability of infiltration," Water Resources Research, 15(2), 419-429.

Soil Conservation Service (1972). "Hydrology," National Engineering Handbook, Section 4.

Soil Conservation Service (1972). "Snow survey and water supply forecasting," National Engineering Handbook, Section 22 .

Sorooshian, S. (1981). "Parameter estimation of rainfall-runoff models with heteroscedastic streamflow errors -- the noninformative data case," Journal of Bydrology, 52, 127-138.

Sorooshian, S., and J. A. Dracup (1980). "Stochastic parameter estimation procedures for hydrologic rainfall-runoff models: correlated and heteroscedastic error cases," Hater Resources Research, 16(2), 430-442.

Sorooshian, S., and V. K. Gupta (1983). "Rutomatic calibration of conceptual rainfall-runoff models: the question of parameter observability and uniqueness," Hater Resources Research, 19(1), 260-268.

Sorooshian, S., V. K. Gupta, and J. L. Fulton (1982). "Parameter estimation of conceptual rainfall-runoff models assuming autocorrelated streamflow data errors -- a case study," in V. P. Singh (ed.), Statistical Analysis of Rainfall and Runoff, Water Resources Publications, Littleton, Co, 491-504. 
Sorooshian, S., V. K. Gupta, and J. L. Fulton (1983). "Evaluation of maximum likelihood parameter estimation techniques for conceptual rainfall-runoff models: influence of calibration data variability and length on model credibility," Hater Resources Research, 19(1), 251-259.

Speers, D. D., and J. D. Versteeg (1982). "Runoff forecasting for reservoir operations -- the past and the future," Proceedings of the Hestern Snow Conference, 149-156.

Stedinger, J. R., J. Grygier, and H. Yin (1988). "Seasonal streamflow forecasts based upon regression," Computerized Decision Support Systems for Hater Managers, proceedings of American Society of Civil Engineers 3rd Hater Resources Operations and Management Horkshop, Colorado State University, 266-279.

Tabios, G. Q., III, and J. D. Salas (1985). "A comparative analysis of techniques for spatial interpolation of precipitation," Hater Resources Bulletin, 21(3), 365-380.

Thomas, H. A. (1981). "Improved methods for National Hater Assessment," report, contract HR15249270, U. S. Hater Resources Council, Hashington, DC.

Thomas, H. A., C. M. Marin, M. J. Brown, and M. B. Fiering (1983). "Methodology for water resource assessment," report to U. S. Geological Survey, Report NTIS 84-124163, National Technical Information Service, Springfield, VA.

Thornthwaite, C. H., and J. R. Mather (1955). "The water balance," Publications in Climatology, Laboratory of Climatology, Drexel Institute of Technology, $8(1), 1-86$.

Thornthwaite, C. W., and J. R. Mather (1957). "Instructions and tables for computing potential evapotranspiration and the water balance," Publications in Climatology, Laboratory of Climatology, Drexel Institute of Technology, 10(3), 185-311.

Troutman, B. H. (1982). "An analysis of input errors in precipitationrunoff models using regression with errors in the independent variables," Water Resources Research, 18(4), 947-964.

Troutman, B. M. (1983). "Runoff prediction errors and bias in parameter estimation induced by spatial variability of precipitation," Nater Resources Research, 19(3), 791-810.

Troutman, B. M. (1985). "Errors and parameter estimation in precipitation-runoff modeling -- 1. Theory," Nater Resources Research, 21(8), 1195-1213. 
Tredt, T. M., J. C. Schaake, Jr., and E. L. Peck (1977). "National Weather Service extended streamflow prediction," Proceedings of the Nestern snow Conference, 52-57.

U. S. Army Corps of Engineers (1987). "Streamflow synthesis and reservoir regulation (SSARR) model -- user manual," North Pacific Division, Portland, OR.

van Hylckama, T. E. A. (1958). "Modifications of the water balance approach for basins within the Delaware valley," Publications in Climatology, Laboratory of Climatology, Drexel Institute of Technology, $11(3)$.

Hang, Q. J. (1991). "The genetic algorithm and its application to calibrating conceptual rainfall-runoff models," Nater Resources Research, 27(9), 2467-2471.

Hater Management Subcommittee of the Columbia Basin Interagency Committee (1964). "Derivation of procedure for forecasting inflow to Hungry Horse Reservoir, Montana."

Hilcox, B. P., W. J. Rawls, D. L. Brakensiek, and J. R. Wight (1990). "Predicting runoff from rangeland catchments: a comparison of two models," Hater Resources Research, 26(10), 2401-2410.

Hinters, F. M., Jr., M. Kolnau, and K. Chang (1989). "Mapping precipitation in Idaho: a study of data estimation and interpolation procedures," Research Technical Completion Report 14-08-0001-G1559-32, Idaho Water Resources Research Institute, University of Idaho.

Hortman, R. T. (1989). "Statistical forecast model for Libby basin, Montana," Proceedings of the Nestern Snow Conference, 100-107.

Hu, C. F. J. (1986). "Jackknife, bootstrap and other resampling methods in regression analysis," The Annals of statistics, 14(4), 12611295.

Zuzel, J. F., and L. M. Cox (1978). "A review of operational water supply forecasting techniques in areas of seasonal snowcover," Proceedings of the Western Snow Conference, 69-77. 
APPENDIX A

PRINCIPAL COMPONENTS REGRESSION CALCULATIONS 
Calculation of principal components begins with the correlation matrix of the independent variables. An eigenvalue/eigenvector analysis of this matrix is then performed, resulting in an $\mathrm{m} X \mathrm{~m}$ matrix $\mathrm{E}$, where $m=$ number of variables. Each column of $\mathbf{E}$ is an eigenvector, and these eigenvectors are arranged in order of decreasing eigenvalue. Principal components are obtained by

$$
\mathbf{P}=\mathbf{D}_{\mathbf{B}} \mathbf{E}
$$

where $P=n X m$ matrix of principal components, $D_{s}=n X m$ matrix of standardized original data (with the mean subtracted and the result divided by the standard deviation) for the independent regression variables, and $n=$ number of observations. Each principal component is thus a linear combination of all the original variables. The first component accounts for the most variance in the original data, the second component accounts for the second most variance, and so on, until the last component only explains a very small amount of the variance. After the regression analysis is performed using the components as independent variables, the regression coefficients must be translated back into terms of the original variables. This is done in two steps. First, the components regression coefficients are converted into terms of standardized original variables by

$$
\mathbf{R}_{\mathbf{s}}=\mathbf{E} \cdot \mathbf{R}_{\mathbf{p}}
$$

where $R_{s}=m X 1$ vector of regression coefficients for the standardized variables, $\mathbf{E}^{\prime}=\mathrm{m} X \mathrm{p}$ matrix of eigenvectors corresponding to each component included in the regression, $R_{p}=p X 1$ vector of regression 
coefficients for the components, and $\mathrm{p}=$ number of components included in the regression. The coefficients are then converted from standardized to unstandardized original variables by dividing each element of the $R_{B}$ vector by the standard deviation of the corresponding original variable. The intercept of the equation in terms of unstandardized original variables $I_{0}$ is obtained by

$$
I_{0}=I_{p}-M^{T} R_{0}
$$

where $I_{P}=$ intercept of components equation, $M=m X 1$ vector of means of original variables, and $R_{0}=m X 1$ vector of regression coefficients for unstandardized original variables. 
APPENDIX B

\section{KRIGING CALCULATIONS}


The first step in kriging is to estimate the variogram. This is the function that describes the spatial correlation structure of the data. The variogram is the variance of the differences between data values separated by a distance $\mathrm{h}$ and is calculated as follows:

$$
\hat{2 T}(h)=\frac{1}{n} \sum_{1=1}^{n}\left[Y_{1}(x)-Y_{1}(x+h)\right]^{2}
$$

where $2 T(h)$ is the sample estimate of the variogram, $h$ is the distance between data sites, $\mathrm{x}$ is a vector in a two-coordinate system describing the spatial location of a data site, $Y(x)$ is the data value at point $x$, and $\mathrm{n}$ is the number of site pairs separated by the distance $\mathrm{h}$. When dealing with precipitation and temperature measurements, $\mathrm{n}$ is usually one; $\mathrm{n}$ is greater than one only if measurements are available on a regular grid, which may exist in other contexts. One can, however, group data pairs into distance categories to help smooth out the estimated variogram: then $n$ would be the number of pairs in each distance category.

The function $T(h)$ is called the semivariogram. The values of this function are what are actually used in the kriging calculations. The typical shape and features of a semivariogram are shown in Figure 21. The semivariogram is usually modeled by one of several analytic functions:

$\begin{array}{lll}\text { Linear: } & T(h)=T_{n}+b h \\ \text { Power: } & T(h)=T_{n}+b h c \\ \text { Logarithmic: } & T(h)=T_{n}+3 b \ln (h)\end{array}$




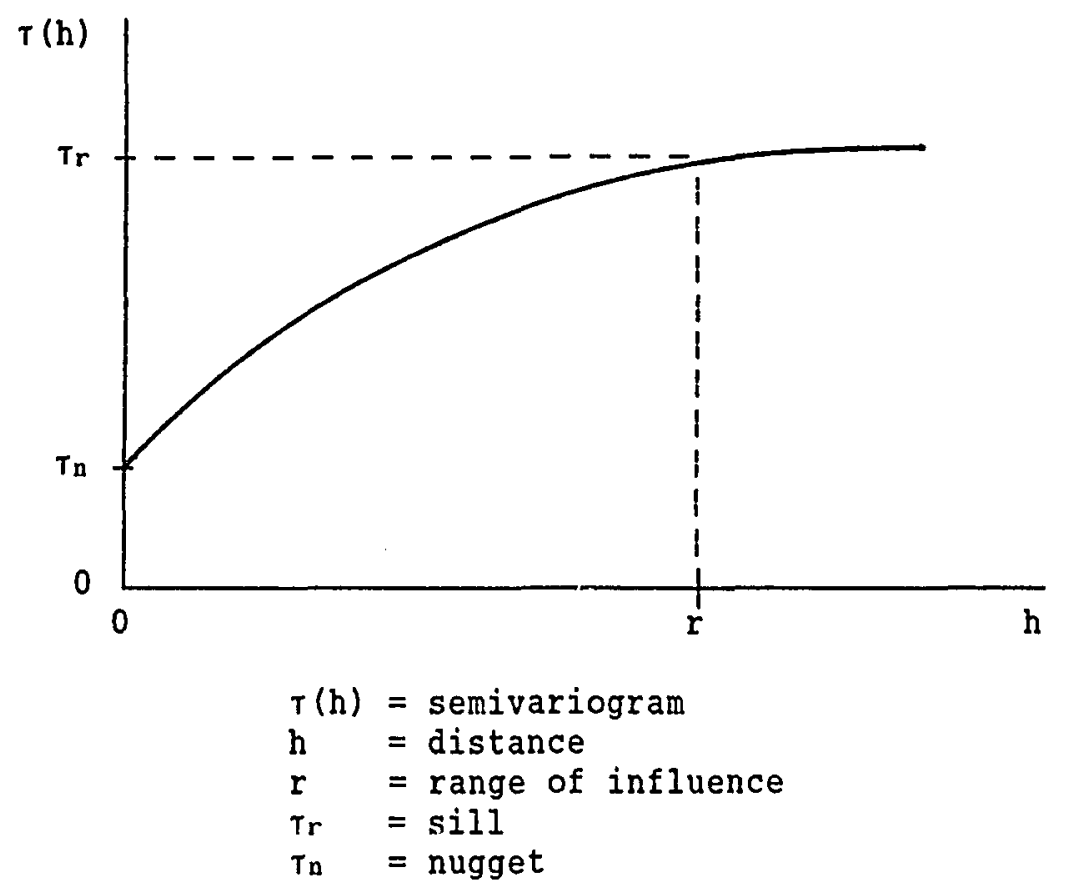

Figure 21. Typical shape of a semivariogram and its characteristic values.

Exponential: $\quad T(h)=\tau_{n}+\left(\tau_{r}-\tau_{n}\right)\left(1-e^{-(h / r)}\right)$

Spherical: $\quad \tau(h)=\left[\begin{array}{ll}T_{r} & \text { for } h>r \\ T_{n}+\left(\tau_{r}-T_{n}\right)\left[\frac{3 h}{2 r}-\frac{h^{3}}{2 r^{3}}\right] & \text { for } h s r\end{array}\right.$

The estimate of a data value at an unmeasured point $\mathrm{Y}$ is a weighted sum of the available measurements:

$$
\dot{Y}=\sum_{i=1}^{\mathbb{D}} W_{1} Y_{i}
$$


where $w_{1}$ is the weight for measurement $Y_{1}, m$ is the number of measurements, and

$$
\sum_{1=1}^{m} H_{1}=1
$$

Kriging is the algorithm for determining the weights $w_{1}$ such that the estimate $Y$ has minimum variance. This is a Lagrangian optimization problem, which requires the solution of a system of linear equations. This system is:

$$
\Gamma_{W}=\Gamma_{\mathrm{Y}}
$$

where:

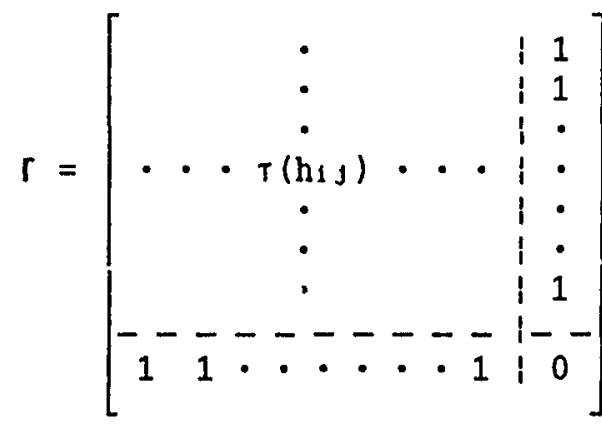

$$
w=\left[\begin{array}{l}
W_{1} \\
W_{2} \\
\vdots \\
\dot{-} \\
W_{m} \\
\alpha
\end{array}\right]
$$




$$
r_{Y}=\left[\begin{array}{c}
T\left(h_{Y 1}\right) \\
T\left(h_{Y_{2}}\right) \\
\dot{y} \\
\dot{y} \\
T\left(h_{Y m}\right) \\
1
\end{array}\right]
$$

Also, $h_{1 j}=$ distance between measurement sites $i$ and $j, h y \jmath=$ distance between the point being estimated and measurement site $j$, and $a$ is the Lagrange parameter. The column of 1's in the right-hand column of the $r$ matrix causes the Lagrange parameter $a$ to be added to each equation in the system. The row of 1 's at the bottom of the $r$ matrix and the 1 at the bottom of the $\Gamma_{y}$ vector provides the equation that causes the sum of the reights w1 to equal unity. The solution $w$ to this system gives the weights to be used on the measurements to estimate the data value at point Y. 